\title{
FLUORINE-18 CAPTURE BY SUBSTITUTED BODIPY DERIVATIVES
}

\author{
A Dissertation \\ presented to
}

the Faculty of the Graduate School

at the University of Missouri-Columbia

In Partial Fulfillment

of the Requirements for the Degree

Doctor of Philosophy

by

PATRICK L CAVINS

Dr. Timothy E. Glass, Dissertation Supervisor

MAY 2015 
The undersigned, appointed by the dean of the Graduate School, have examined the dissertation entitled

\section{FLUORINE-18 CAPTURE BY SUBSTITUTED BODIPY DERIVATIVES}

presented by Patrick L. Cavins,

a candidate for the degree of doctor of philosophy

and hereby certify that, in their opinion, it is worthy of acceptance.

Professor Timothy E. Glass

Professor Susan Lever

Professor Kent S. Gates

Professor Thomas Quinn 


\section{ACKNOWLEDGEMENTS}

It is impossible to imagine that this adventure, formally known as working towards a $\mathrm{PhD}$, would be remotely possible to achieve with out all the love, help, and advice I have received throughout my life.

First and foremost, it begins with my family. My parents have truly been a rock and pillar for me throughout my life. I can think of no two people who have helped me along this journey more than them. Words seem to imperfect and to imprecise to express the gratitude and love I feel towards them.

As we move through life, we often don't recognize and appreciate the little nudges we receive from the people who surround us until much later in life. My path in life dramatically shifted in the sixth grade, where I met one Mrs. Debbie Allen. She was my sixth grade teacher, and was a force for positive change in my life. I think it is safe to say I wouldn't be who I am today without her guidance. Later, in high school, Mrs. Christine Bear helped me discover who I was, and pushed me to think outside the box. She encouraged me attend to Knox College. My time at Knox College was truly a transformational time in my life and it was there where I first began to engage in research under the direction of the Dr. Larry Welch, and he has proven to be an excellent friend, mentor, and purveyor of bad bongos. It was also at Knox College where I met my current research advisor, Dr. Glass. He has provided with best training possible to improve and 
develop my scientific skills. l've always admired his passion towards not only chemistry but all of science. It is because of his mentorship that I have learned the skill set associated with my work, and learned how to develop into a true scientific researcher.

To my friends, all I can say is that I would have failed many times over with out your support. I would like to especially thank to Tim \& Natasha Harmon whom I have known nearly my entire life and who have been a constant source of friendship. Furthermore Josh and Sarah Alber-West (and now little Lauralynn) are two people with out whom I would have been lost many times. I would also like to thank the past and present members of the Glass group who made the daily work of research a joy.

Homo sum, humani nihil me alienum puto 


\section{Table of Contents}

ACKNOWLEDGEMENTS

LIST OF FIGURES

LIST OF TABLES

viii

ABSTRACT

I. INTRODUCTION 1

II. COMMON FLUOROPHORES 3

$\begin{array}{lr}\text { PET ISOTOPES } & 6\end{array}$

II. PRODUCTION OF RADIONUCLIDES 9

III. COMMON PET ISOTOPES AND THEIR PROPERTIES $\quad 11$

SYNTHESIS AND DEVELOPMENT OF THE BODIPY CORE

$\begin{array}{ll}\text { I. INTRODUCTION } & 15\end{array}$

CHAPTER II - PRACTICAL APPLICATIONS

Pet Radiotracer Chemistry \& Dual Mode Molecular IMAging 20

$\begin{array}{ll}\text { I. INTRODUCTION } & 20\end{array}$

II. MOLECULAR IMAGING TECHNIQUES 21

III. DUAL MODALITY (PET/FLUORESCENCE) IMAGING 25

IV. EXAMPLES OF DUAL MODALITY (PET/FLUORESCENCE) PROBES 27

CHAPTER III - SUBSTITUTED BODIPYS

Radiotracer Chemistry and Peptide Radiolabeling Synthons 31 
I. RADIOTRACER CHEMISTRY 31

II. RAdiotracer KINETICS AND $\left[{ }^{18}\right.$ F]FBA 34

III. CONVENTIONAL LABELING METHODS WITH FLUORINE-18 35

IV. NONCOVENTIONAL RADIOLABELING METHODS AND FLUORINE-18 38

v. BORON BASED DUAL MODALITY (PET/FLUORESCENCE) PROBES

$\begin{array}{ll}\text { VI. SPECIFIC AIMS AND GOALS } & 48\end{array}$

VII. SUBSTITUTED BODIPYS: C,O-BODIPY (PHENYL, HYDROXDE) AND N-BODIPY (F, DMAP) 50

\begin{tabular}{lr} 
CHAPTER IV & 58 \\
\hline
\end{tabular}

PHOTOREACTIVE BODIPYS FOR CAPTURE OF $\left[{ }^{18} \mathrm{~F}\right]$ FLUORIDE

$\begin{array}{ll}\text { I. INTRODUCTION } & 58\end{array}$

II. APPLICATIONS OF PHOTOCHEMISTRY AND PHOTOBIOLOGY 59

III. DESIGN CONSIDERATIONS FOR $\left[{ }^{18} \mathrm{~F}\right]$ FLUORIDE INCORPORATION ON THE BODIPY CORE. 61

$\begin{array}{ll}\text { V. RESULTS AND CONCLUSTIONS } & 73\end{array}$

\begin{tabular}{ll} 
APPENDIX & 75 \\
\hline
\end{tabular}

\begin{tabular}{lr} 
BIBLIOGRAPHY & 108 \\
\hline
\end{tabular}

\begin{tabular}{ll} 
VITA & 116 \\
\hline
\end{tabular} 


\section{LIST OF FIGURES}

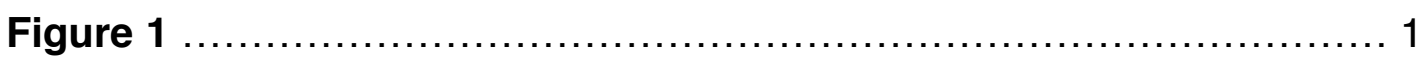

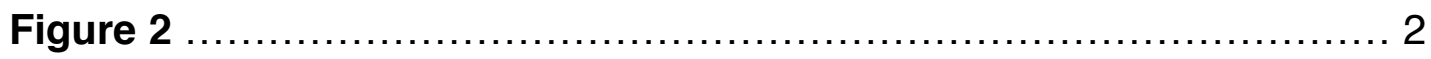

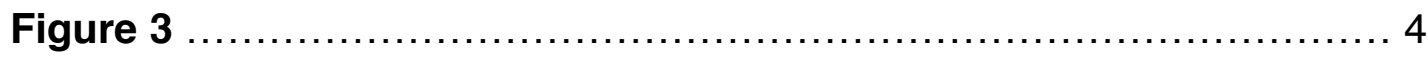

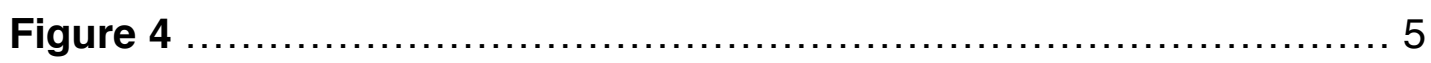

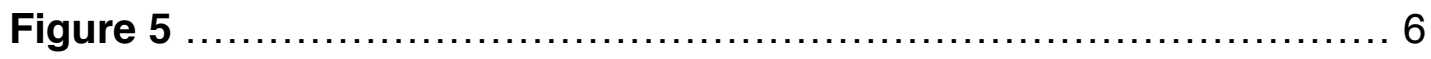

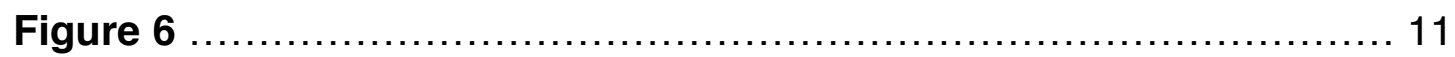

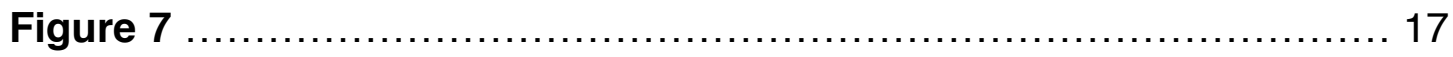

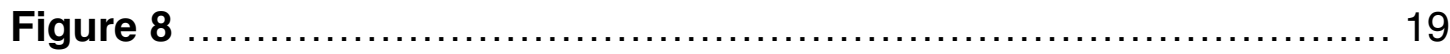

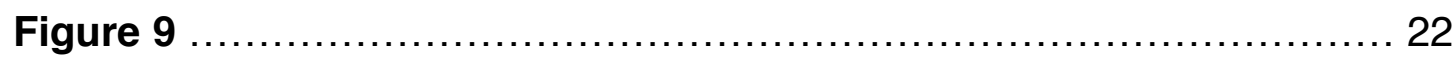

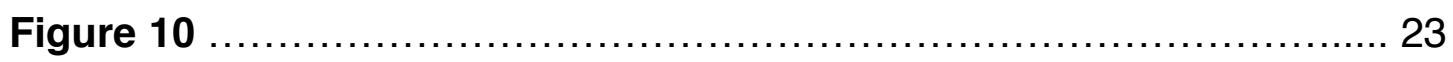

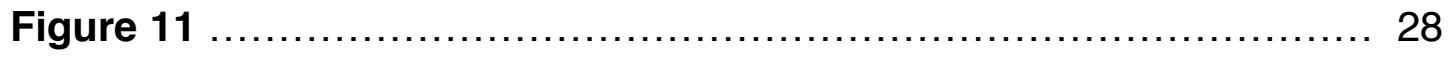

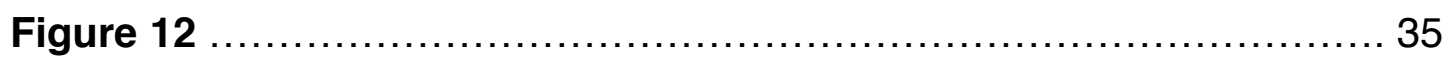

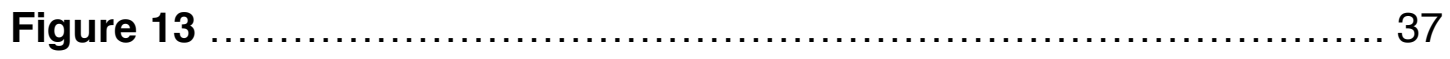

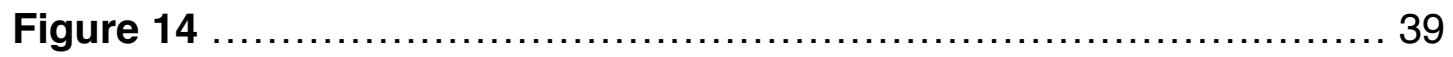

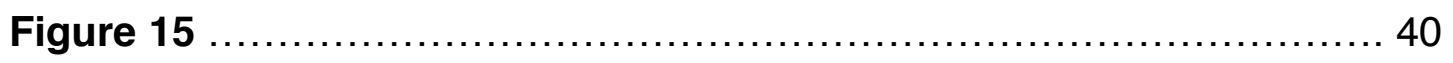

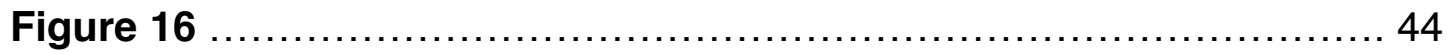

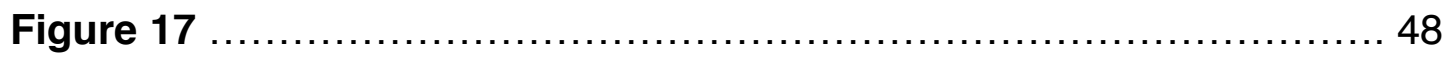

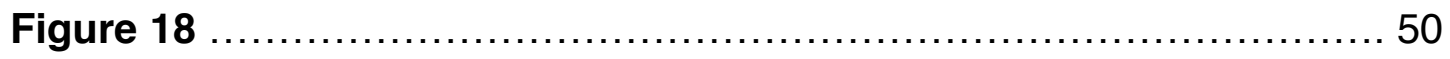

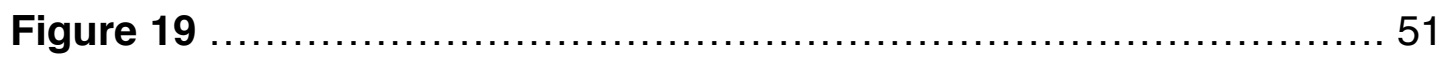

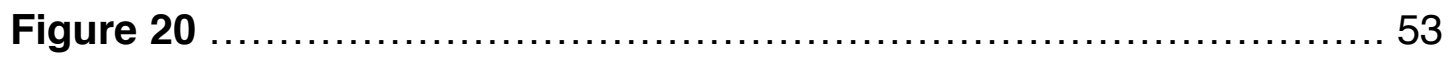

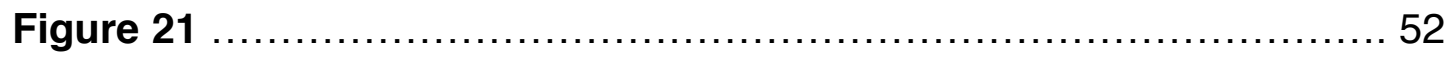

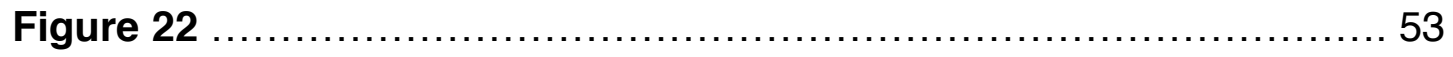


Figure 23

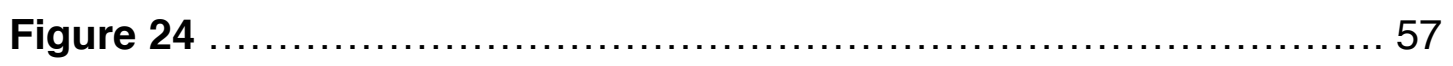

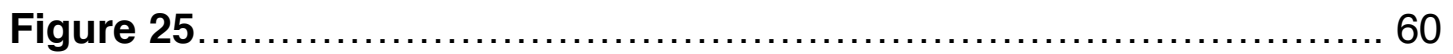

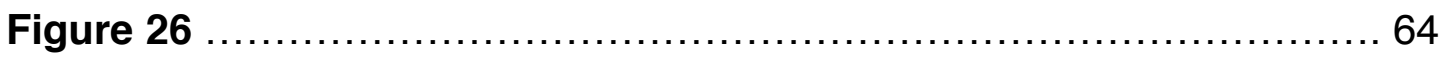

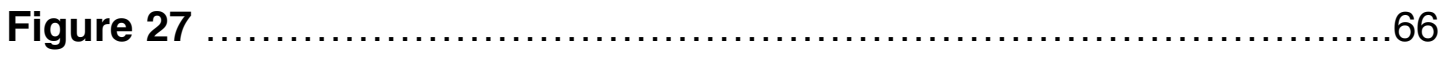

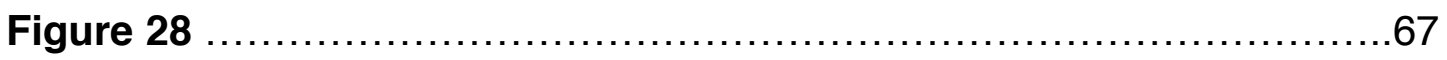

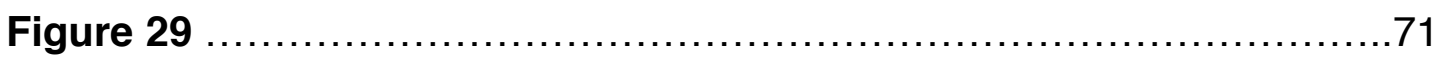

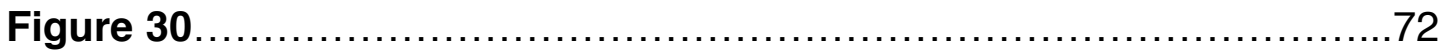

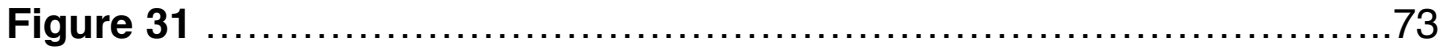

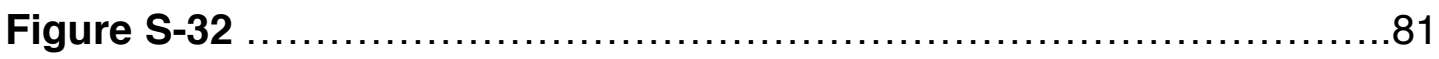

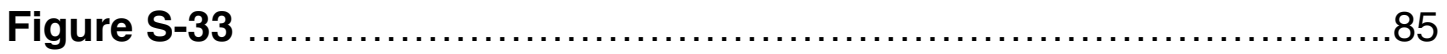

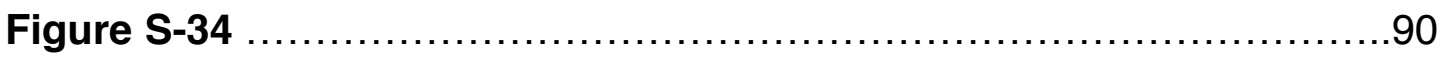

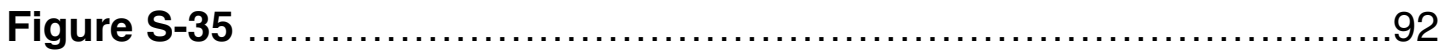

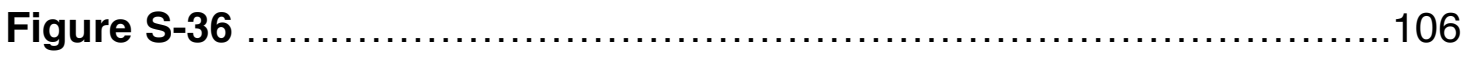

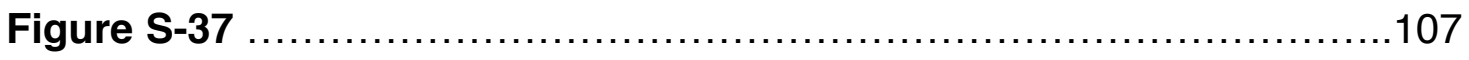




\section{LIST OF TABLES}

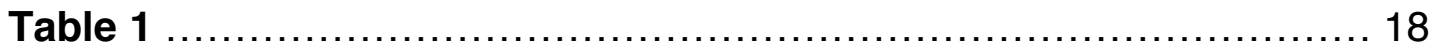

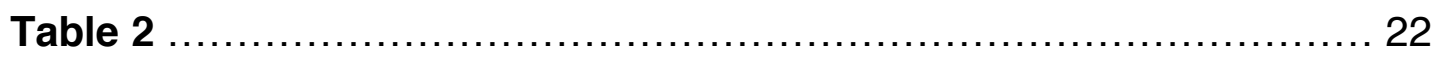

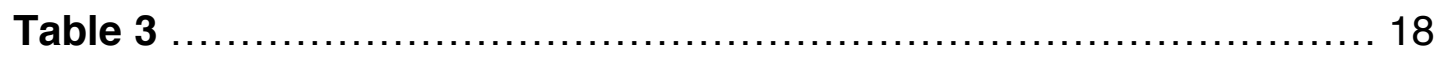

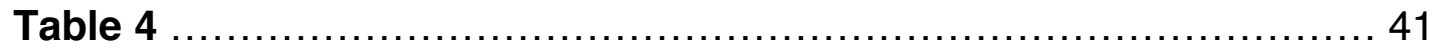

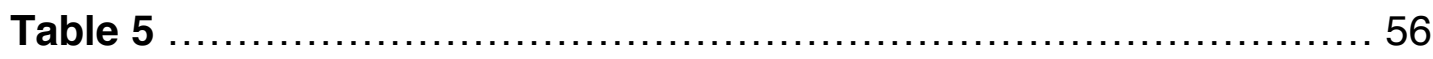

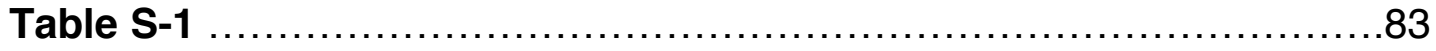




\section{ABSTRACT}

The BODIPY fluorophore is a robust and biologically stable fluorophore. The internal $\mathrm{BF}_{2}$-moeity and the excellent photophysical properties of BODIPY scaffold make it an excellent candidate to be developed as a dual modality (PET/

Fluorescence) probe. Fluorescence and PET imaging are two powerful tools currently in use by the scientific community. Dual modality imaging agents take advantage of the high spatial resolution associated with fluorescence, and the lack of signal attenuation associated with PET. Currently, $\left[{ }^{18} \mathrm{~F}\right]$ fluorine peptide radiolabeling protocols, including those used with BODIPY, are limited due to the typically harsh reaction conditions or the use of highly reactive intermediates. Herein, we report on the development of novel, stable mono- and di-substituted BODIPYS and their use for $\left[{ }^{18} \mathrm{~F}\right]$ fluoride capture. We have successfully labeled two BODIPY derivatives in high radiochemical yield and purity. Furthermore, we are working towards photoinduced methods for $\left[{ }^{18} \mathrm{~F}\right]$ fluorine incorporation. Our goal is to use these $\left[{ }^{18} \mathrm{~F}\right]-\mathrm{BODIPYs}$ in peptide constructs as a means to increase the scope and viability of the BODIPY framework as a dual modality-imaging agent for peptides. 


\section{CHAPTER I - First Principles}

Fluorescence and Absorbance

\section{i. INTRODUCTION}

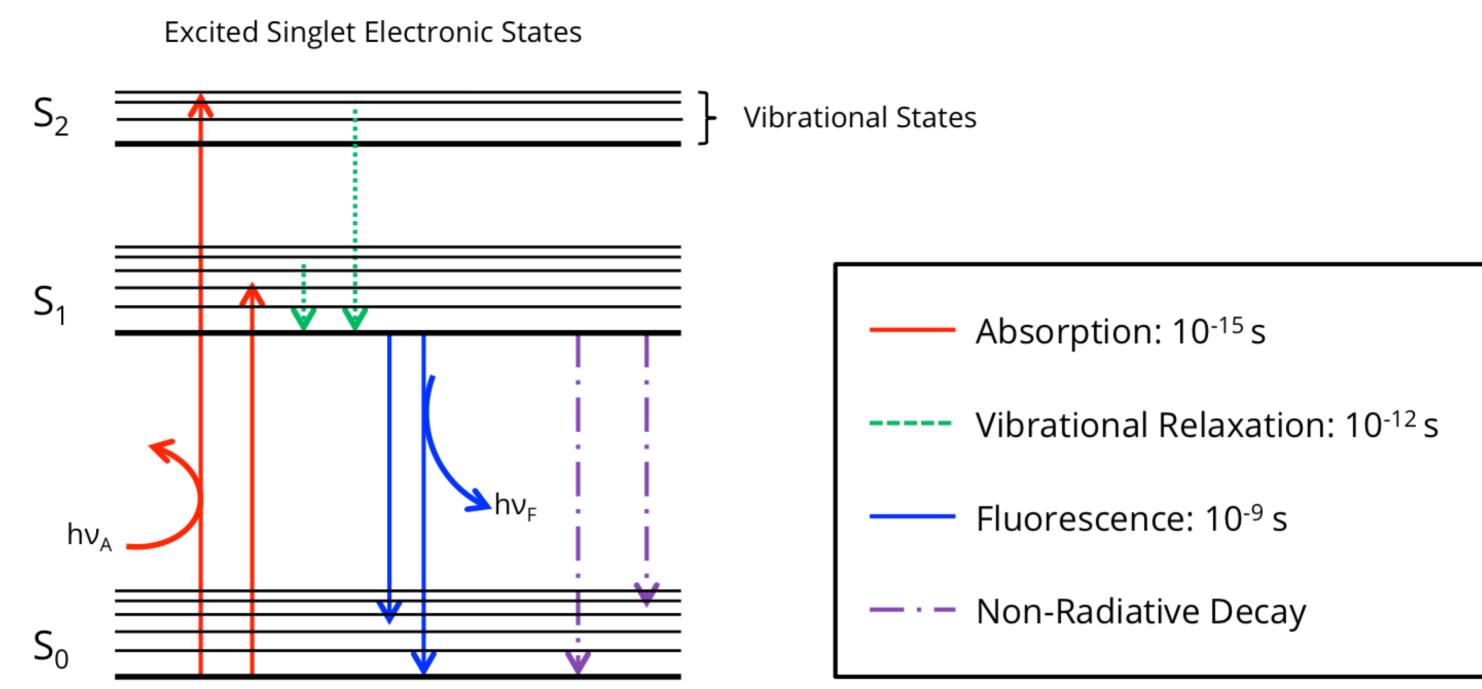

Ground State

Figure 1: Jablonski diagram describing the molecular events which lead to fluorescence.

Fluorescence and absorption are related physical processes describing the way chemical compounds interact with photons (light) and their chemical environment. Absorption is a process by which photons interact with the surrounding environment. Fluorescence is a similar process by which the surrounding matter relieves itself of the energy it has absorbed. The process by which compounds interact with a photon is commonly described using a Jablonski diagram (Figure 1). A common Jablonski diagram is broken down into two different sections. The bottom most section is the ground state $\left(\mathrm{S}_{0}\right)$ and the 
upper sections are the excited singlet electronic states $\left(S_{1}\right)$. In these different electronic states are several vibrational energy levels ${ }^{1-3}$. As light hits a chemical compound it may or may not be absorbed depending on whether it is of a

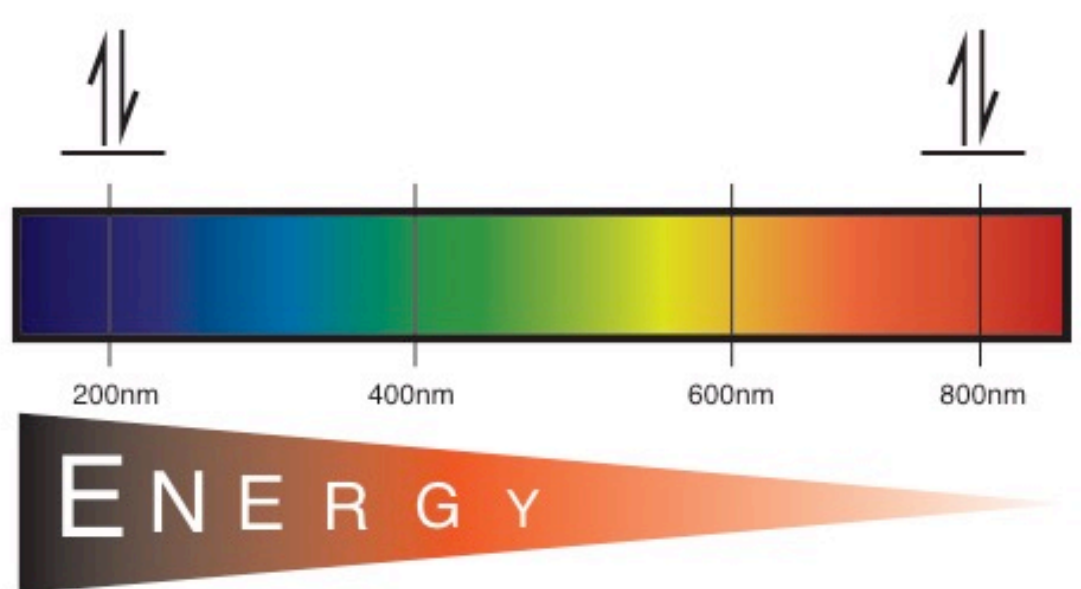

Figure 2: Scheme demonstrating the change in HOMO/LUMO gap energy as you move across UV/Vis Spectrum

suitable wavelength. Then If it is absorbed an electron is promoted from the ground state $\left(\mathrm{S}_{0}\right)$ into an excited electronic state $\left(\mathrm{S}_{1}\right)$. The ground state is also referred to as the high occupied molecular orbital (HOMO) and the first excited electron state is lowest unoccupied molecular orbital (LUMO). Once in the excited electronic state, the electron can undergo internal conversion (i.e. relaxation between the excited singlet electronic states) or undergo a rapid vibrational relaxation to lowest state (Figure 1). 
In terms of energy and the likelihood of an electron being promoted from the HOMO into the LUMO for a given molecule, we know that that molecules with a large HOMO/LUMO energy gap require large amounts of energy to cause an electron to be promoted into the excited state (LUMO) relative to those molecules that have a smaller HOMO/LUMO energy gap (Figure 2).

Additionally, it is important to understand that the HOMO/LUMO energy is not static, and that changes within the HOMO/LUMO energy gap are quite common. These changes can be caused by differences in the molecular environment of the fluorophore, the interaction of a fluorophore with other chromophores in a given system. Also covalent and/or noncovalent interactions can affect the HOMO/LUMO energy gap ${ }^{3}$.

\section{ii. COMMON FLUOROPHORES}

A helpful guide to classifying fluorophores is based on whether they are intrinsic or extrinsic fluorophores. Intrinsic fluorophores are naturally occurring chemical compounds, and extrinsic fluorophores are synthetic in origin. This classification is additionally important because it helps highlight one of the many considerations which must be taken into account when choosing a fluorophore. Primarily, intrinsic fluorophores can pose a significant background problem due to the fluorescence they produce. Intrinsic fluorophores include aromatic amino acids, some proteins such flavins and NADPH, and other compounds such a chlorophyll. Due to the simple nature of many intrinsic fluorophores they absorb light at wavelengths less than $300 \mathrm{~nm}$, but surprisingly their maximum fluorescence can be as high as $540 \mathrm{~nm}$. This has led to the development of a 
number of different fluorescent compounds which absorb and fluorescence and wavelengths greater than $380 \mathrm{~nm}$ (Figure 3$)^{2}$. A second characteristic to take notice of, due to its importance later, is the strokes shift of a fluorophore. The

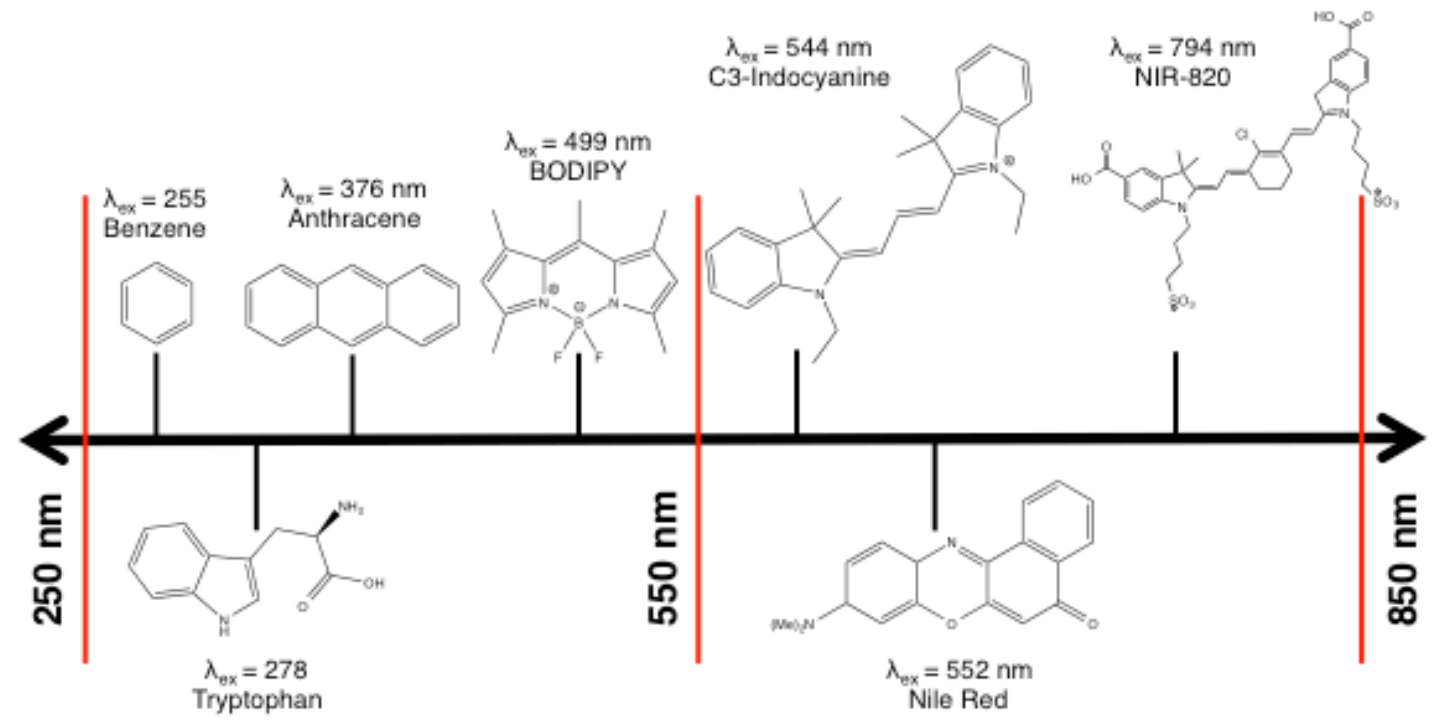

Figure 3: Scheme showing some common extrinsic fluorophores and their associated absorption max $\left(\lambda_{\theta x}\right)$

stokes shifts is the difference (in wavelength) between absorbance and

florescence maxima Furthermore, sometimes the absorbance and the fluorescence of two compounds may potentially overlap (Figure 4$)^{2}$. 


\section{Stokes Shift}

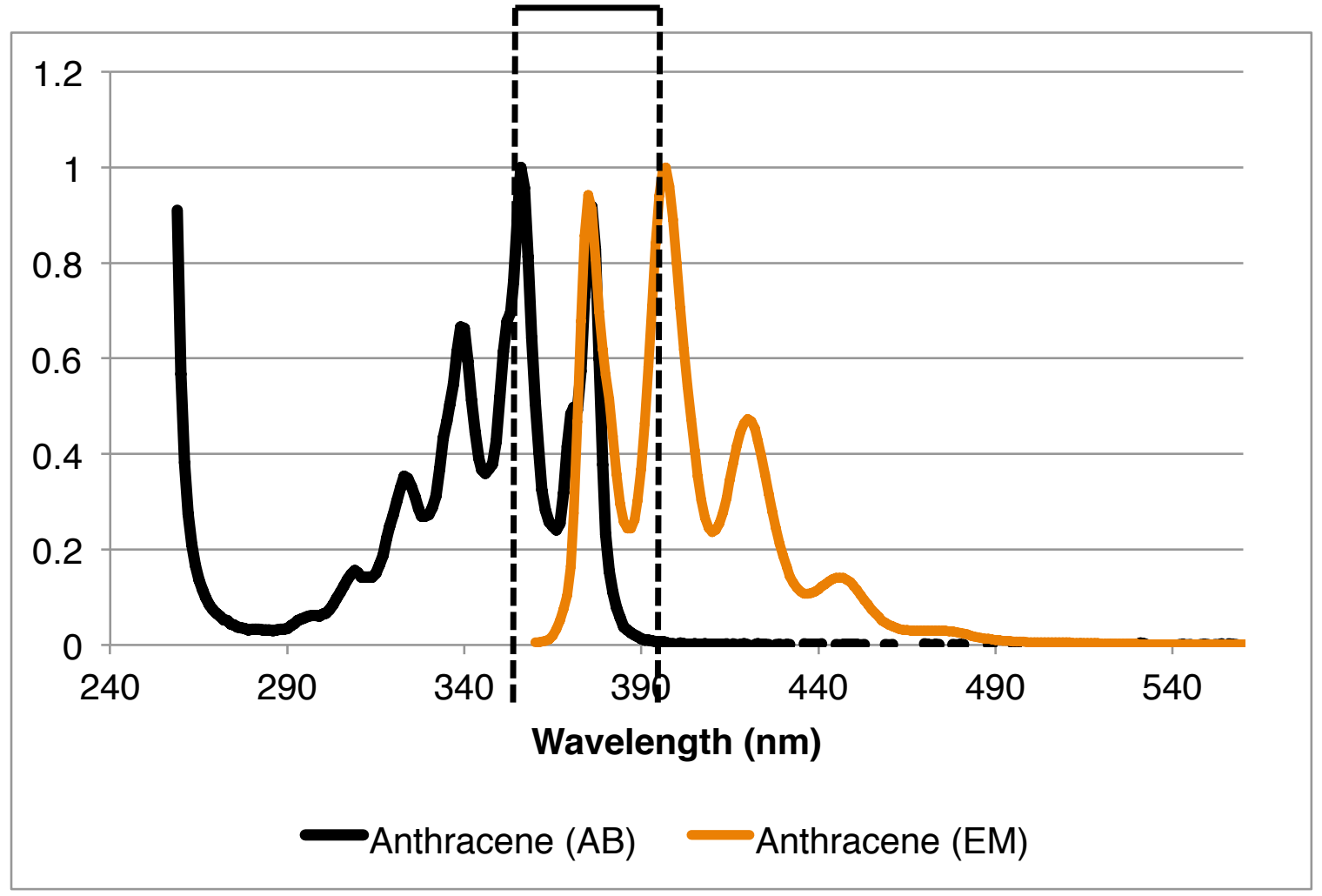

Figure 4: Sample absorbance and fluorescence spectra of anthracene in hexanes. 


\section{PET ISOTOPES}

\section{i. INTRODUCTION}

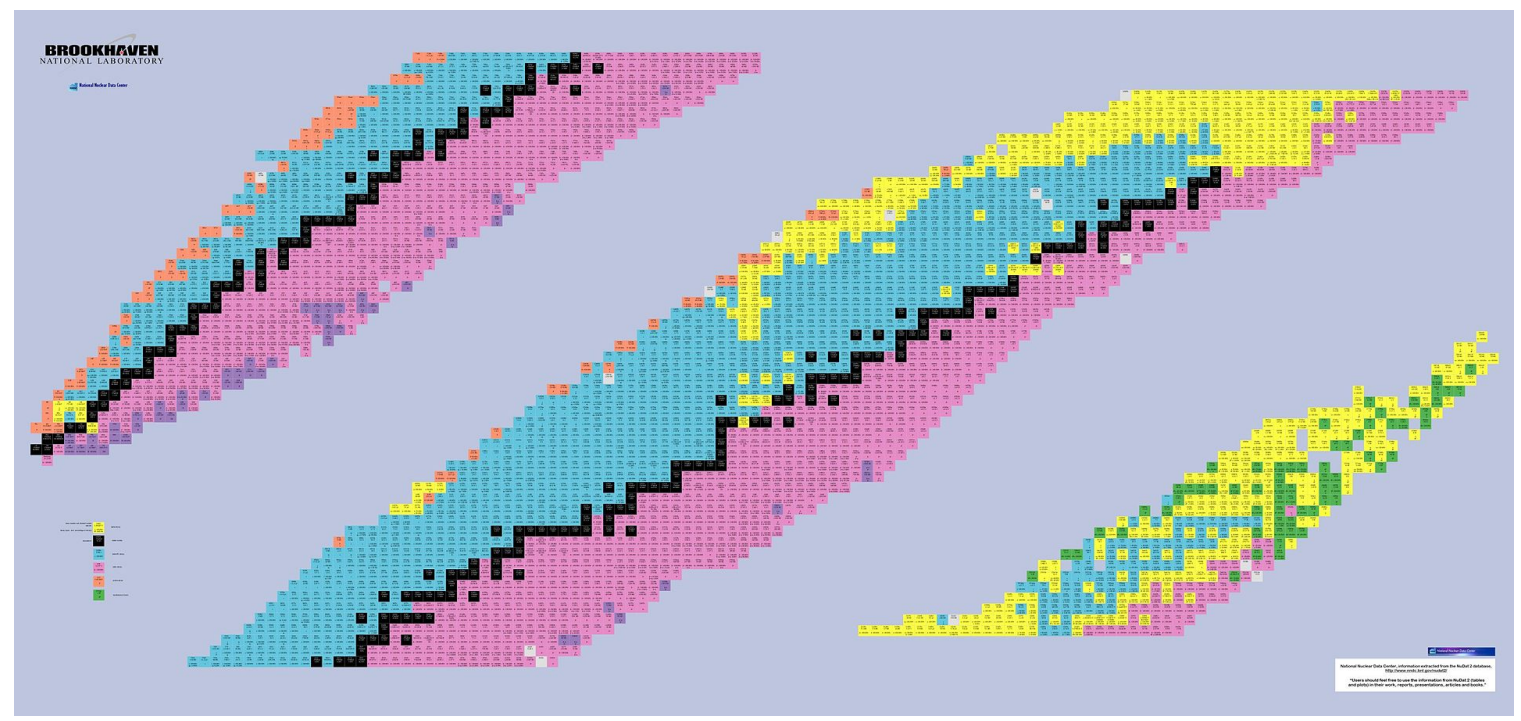

Figure 5: A chart or table of nuclides which identifies the elements and the type(s) of decay they undergo. The Y-Axis (from bottom to top) represents increasing number of neutrons and the $\mathrm{X}$-axis (from left to right)represents the increasing atomic number $(Z)$.

The development of targeted radiotracers is powerful tool used within many different disciplines of biology, medicine, and environmental sciences. There are many different types of radiotracers available to scientists today and they play integral roles in research. Positron Emission Tomography (PET) is a powerful imaging tool used by the nuclear medicine community on a daily basis. Critical to the use of PET is the ability produce and incorporate PET isotopes into chemical scaffolds effectively ${ }^{4}$.

On the most fundamental level, radiotracers are defined by the type of decay process which they undergo. A decay process for a given radionuclide is characterized by a change in $A, Z$, and/or $X$, and these changes are illustrated in 
a decay scheme (short form). The product of decay process is often referred to as the daughter ion $(D)^{5}$. For example, shown below, Polonium-210 is a radionuclide which undergoes alpha decay among other decay method. The parent isotope $(\mathrm{X})$ is shown on the left, and the daughter ion and the relevant decay products are shown on the right. Just like the periodic table is used by chemists to classify and organize elements, the chart of nuclides serves a similar role for nuclear chemists (Figure 5 ).

$$
\begin{gathered}
{ }_{84}^{210} \mathrm{Po} \rightarrow \alpha\left({ }_{2}^{4} \mathrm{He}^{+2}\right)+{ }_{82}^{206} \mathrm{~Pb} \\
{ }_{X}^{A} \mathrm{X} \rightarrow \alpha\left({ }_{2}^{4} \mathrm{He} e^{+2}\right)+{ }_{Z-2}^{A-4} D
\end{gathered}
$$

There are several common types of radioactive decay processes. The broadest breakdown is based on whether the decay process stems from the nucleus alone or from an interaction of the nucleus with shell electrons ${ }^{5,6}$.

By far the most common type of decay modes are those stemming solely from the nucleus. We can then further classify the nuclide by the type of particle which they emit. The most common type of emitted particles are alpha (a), beta $(\beta)$, and gamma $(\mathrm{Y})$ (Table 1). Furthermore, decay modes are not discreet. Some nuclei, especially those of high Z, go through many different decay modes before reaching a stable isotope. Additionally, many decay processes result in a nucleus which has been left in an excited state. This energy is commonly given off as one or more photons ( $\mathrm{Y}$ rays). Alpha decay, for example ${ }^{210} \mathrm{Po}$, is characterized by the emission of a helium nucleus $\left({ }_{2}^{4} \mathrm{He}\right)$ and is most common among high atomic 
number nuclei. Next, beta decay is a decay mode associated with the emission of an electron $\left(\mathrm{e}^{-}\right.$or $\left.\mathrm{e}^{+}\right)$. Therefore beta decay is most common among nuclides where there is an columbic imbalance in the nucleus and thus it is method by which to restore stability to the nucleus. If there is an excess of positive energy in the nucleus as in the case of ${ }^{18} \mathrm{~F}$, the excess energy is discharged by relieving the proton of its positive charge, a positron $\left(\mathrm{e}^{+} / \beta^{+}\right)$, and thereby converting it into

\begin{tabular}{|c|c|c|c|}
\hline Decay Mode & Symbol & Radiation Emitted & Example \\
\hline$\alpha$-decay & $\alpha$ & Helium Nuclei ${ }_{2}^{4} \mathrm{He}$ & ${ }_{84}^{210} \mathrm{Po} \rightarrow \alpha\left({ }_{2}^{4} \mathrm{He}^{+2}\right)+{ }_{82}^{206} \mathrm{~Pb}$ \\
\hline \multirow[t]{2}{*}{$\beta$-decay } & $\beta$ & Electrons ${ }_{-1}^{0} e^{-}$ & ${ }_{6}^{14} C \rightarrow{ }_{7}^{14} N+{ }_{-1}^{0} e^{-}+\overline{v_{e}}$ \\
\hline & $\beta^{+}$ & Positrons ${ }_{1}^{0} e^{+}$ & ${ }_{6}^{11} C \rightarrow{ }_{5}^{11} B+{ }_{1}^{0} e^{+}+v_{e}$ \\
\hline$\gamma$-decay & $\gamma$ & Photons (hv) & Emission of Excitation Energy \\
\hline Electron Capture & $\mathrm{EC}(\varepsilon)$ & X-Rays of Daughter Nuclide & ${ }_{27}^{57} \mathrm{Co}+{ }_{-1}^{0} e^{-} \rightarrow{ }_{27}^{57} \mathrm{~m} F e+v_{e}$ \\
\hline $\mathrm{F}$ & IC & Conversion Electrons (X Rays) & ${ }_{27}^{57 \mathrm{~m}} \mathrm{Fe} \rightarrow{ }_{27}^{57} \mathrm{Fe}+\gamma$ \\
\hline
\end{tabular}

Table 1: A summary of the major types of radioactive decay modes a neutron. We refer to this type of decay processes as positron decay $\left(\beta^{+}\right)$. Also these isotopes are commonly referred to as PET isotopes. Related to positron decay is beta minus decay $\left(\beta^{-}\right)$whereby a nucleus with too many neutrons converts one neutron into a proton and therefor emits an electron $\left(\mathrm{e}^{-}\right)$and electron antineutrino $(\bar{v})$. There are two types of decay processes associated with interaction of the nucleus with its shell electrons. We refer to these two types of processes as electron capture (EC) and internal conversion (IC) (Table 1). Electron capture is a process whereby the nucleus absorbs a bound shell (kernel) electron. This generally occurs in cases of proton rich nuclei and thus the 
capture of an electron converts the proton into a neutron. This causes the production of electron neutrino $\left(v_{e}\right)$, and generally many other types of electromagnetic radiation (auger electrons, X-Rays, and gamma rays). Internal conversion is process whereby excess nuclear energy is donated to a kernel electron. This kernel electron is then ejected becoming what is know as a conversion electron.

\section{ii. PRODUCTION OF RADIONUCLIDES}

There are three ways radionuclides are produced. The first and by far the most common is by using a nuclear reactor. Copper-64 which can produced using a reactor although it is more commonly made using a accelerator ${ }^{7,8}$. Second, some nuclides are produced via a generator. Notable among them is ${ }^{99 \mathrm{~m}} \mathrm{Tc}$. However, we are going to focus on radionuclide production via accelerators, in this case a cyclotron, because they are the most common way PET isotopes are produced ${ }^{6}$. In the case of accelerator based production methods, a charged particle (commonly protons, deuterons, or a particles) are accelerated to specific energy (i.e. speed) at which point they released from the ring and then are allowed then allowed to bombard a target. We describe these types of reactions using the form

$$
A(p, n) D
$$

where A represents the target (i.e what will by bombarded by the accelerator's beam), $p$ denotes the type of particle used to bombard the target with (in this case protons), $\mathrm{n}$ represent a product of the nuclear reaction (here it is a neutron), and $D$ is the daughter isotope produced by the nuclear reaction. Just like with a 
chemical reaction where it is useful to describe the rate of a reaction (i.e. kinetics), the same is true with nuclear reactions. The broadest and most simple term used to describe the rate of radionuclide production is the term activation cross section or sometimes just cross section. Just like in kinetics the cross section essentially represents the probability that given nuclear reaction will occur. The relative scale of a given cross section represents the 'sum' effect of the attractive and repulsive interactions (columbic interactions) between the incoming particle and the target. The activity of a given radionuclide produced inside accelerator is dependent on three factors. The first factor is the energy of the incoming beam towards the target. The second factor is the number of target nuclei available to interact with the incoming beam, and the third factor is the probability that incoming beam will interact with the target nucleus ${ }^{9}$. For the PET radiopharmaceutical community, an understanding of the rate of production is important because one must understand that maximum amount of activity which can produced via a given method. The incoming particle beam provides an infinite source of constant energy which can be put towards the production of a radionuclide, and therefore the radionuclide's production is constant. By this measure the daughter activity starts from zero and increases at a constant rate until a saturation point is reached. At the saturation point, the rate of disintegration essentially equals the rate of production. It is as this point where the maximum theoretical specific activity (i.e. the saturation specific activity) is reached (Figure 6). Maximum theoretical specific activity is the most important 


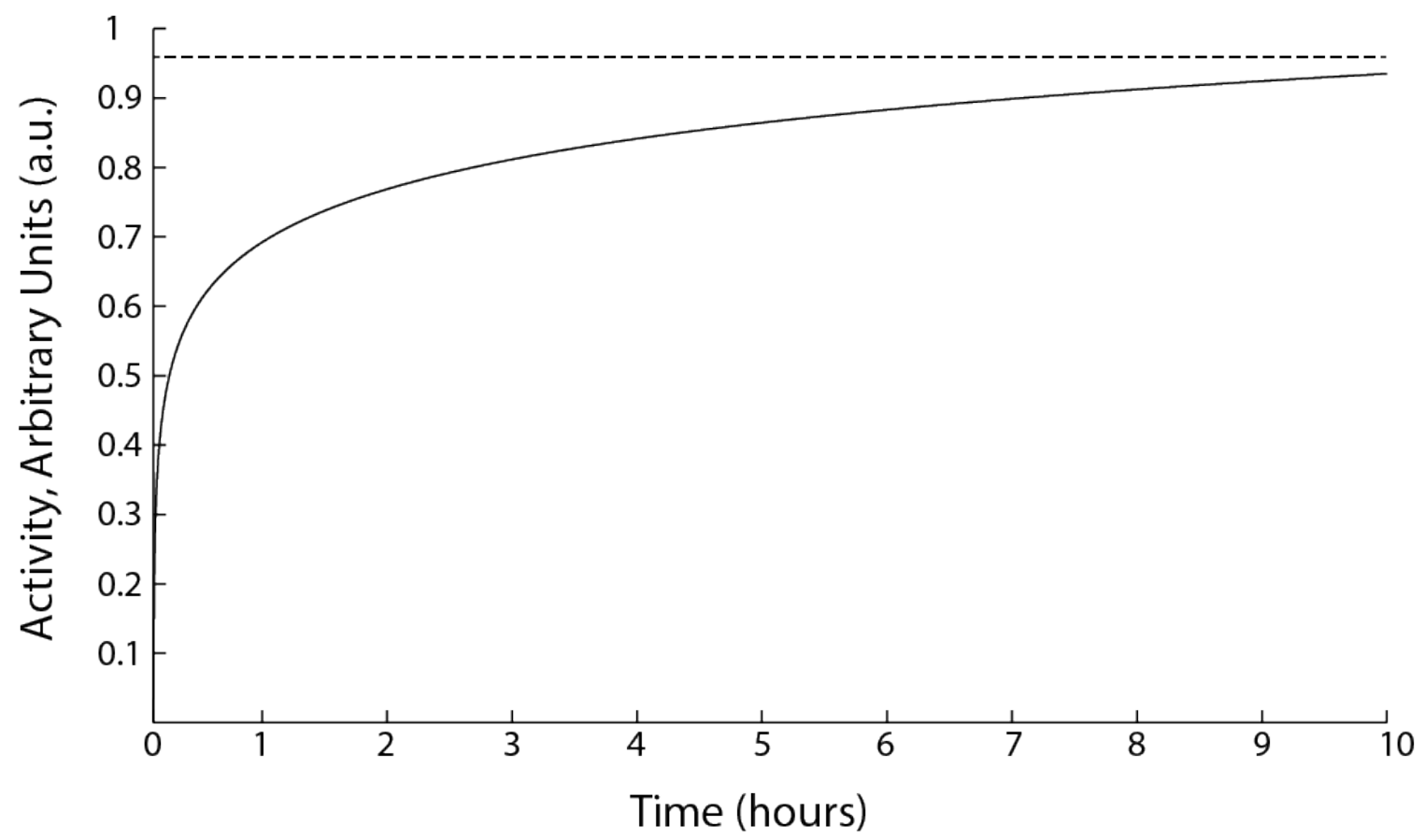

Figure 6: The dash lined represents the infinite source of energy provided by the cyclotron's beam. The solid line represents the production of given radionuclide over time.

production related quantity for a PET radiochemist. Some texts refer to this as the carrier free specific activity (CFSA). The term specific activity (SA), to be discussed in more detail later, is used to describe the ratio of a quantity of activity to a quantity of mass. The Systeme Internationle (SI) unit for activity is Becquerel $(\mathrm{Bq})$, and it is used regularly outside the US. In the US, the unit most commonly used is a Curie ( $\mathrm{Ci})$. A single curie is equal to 37 billion $\mathrm{Bq}$.

\section{iii. COMMON PET ISOTOPES AND THEIR PROPERTIES}

Since the development of fluordeoxyglucose (FDG) in the late 1970 s by Wolf and Fowler, the development of PET based radiotracers has exploded in the scientific literature ${ }^{10}$. This activity has led to an increasing number of PET 


\begin{tabular}{|c|c|c|c|c|c|c|}
\hline Radionuclide & Half-Life & $\begin{array}{c}\text { Decay } \\
\text { Mode(s) }\end{array}$ & $\begin{array}{l}\text { Max. Energy } \\
(\mathrm{MeV})\end{array}$ & $\begin{array}{c}\text { Distance } \\
\text { Traveled in } \mathrm{H}_{2} \mathrm{O}\end{array}$ & $\begin{array}{l}\text { Production } \\
\text { Method(s) }\end{array}$ & $\begin{array}{c}\text { Nuclear } \\
\text { Reaction(s) }\end{array}$ \\
\hline${ }^{11} \mathrm{C}$ & $20 \mathrm{~min}$ & $\beta^{+}(99.8 \%)$ & 0.96 & $5.0 \mathrm{~mm}$ & Accelerator & ${ }^{14} \mathrm{~N}(p, a)^{11} \mathrm{C}$ \\
\hline${ }^{13} \mathrm{~N}$ & $10 \mathrm{~min}$ & $\beta^{+}(100 \%)$ & 1.19 & $5.4 \mathrm{~mm}$ & Accelerator & ${ }^{16} \mathrm{O}(\mathrm{p}, \mathrm{a})^{13} \mathrm{~N}$ \\
\hline${ }^{15} \mathrm{O}$ & $2 \min$ & $\beta^{+}(99.9 \%)$ & 1.72 & $8.2 \mathrm{~mm}$ & Accelerator & $\left.{ }^{14} \mathrm{~N}(p, n)\right)^{15} \mathrm{O}$ \\
\hline${ }^{18} \mathrm{~F}$ & $110 \mathrm{~min}$ & $\begin{array}{c}\beta^{+}(97 \%) \\
\varepsilon(3 \%)\end{array}$ & 0.63 & $0.51 \mathrm{~mm}$ & Accelerator & ${ }^{18} \mathrm{O}(\mathrm{p}, \mathrm{n}){ }^{18} \mathrm{~F}$ \\
\hline${ }^{64} \mathrm{Cu}$ & $12.7 \mathrm{hrs}$ & $\begin{array}{c}\beta^{-}(38.5 \%) \\
\beta^{+}(17.6 \%) \\
\varepsilon(43.9 \%)\end{array}$ & 0.66 & $0.57 \mathrm{~mm}$ & $\begin{array}{c}\text { Accelerator } \\
\text { Reactor }\end{array}$ & ${ }^{64} \mathrm{Ni}(p, n){ }^{64} \mathrm{Cu}$ \\
\hline 124 & 4.18 days & $\begin{array}{l}\beta^{+}(26 \%) \\
\varepsilon(74 \%)\end{array}$ & 0.97 & $5.1 \mathrm{~mm}$ & Accelerator & ${ }^{124} \mathrm{Te}(\mathrm{d}, 2 \mathrm{n})^{124}$ \\
\hline${ }^{86} Y$ & $14.7 \mathrm{hr}$ & $\begin{array}{l}\beta^{+}(33 \%) \\
\varepsilon(66 \%)\end{array}$ & 1.22 & $3.9 \mathrm{~mm}$ & Accelerator & ${ }^{86} \operatorname{Sr}(p, n)^{86} Y$ \\
\hline${ }^{89} \mathrm{Zr}$ & 3.3 days & $\begin{array}{l}\beta^{+}(23 \%) \\
\varepsilon(73 \%)\end{array}$ & 0.90 & $1.9 \mathrm{~mm}$ & Accelerator & ${ }^{89} Y(p, n)^{89} Z r$ \\
\hline
\end{tabular}

Table 2: Table of Common PET isotopes and some relevant characteristics isotopes being developed and therefore readily available for chemists to use and develop (Table 2). As with any type of application, the correct approach is critical. There are several different factors one must consider when choosing a PET isotope to develop into a PET radiotracer. The most important factor being biological half-life of the molecular receptor you are trying to target with your radiopharmaceutical ${ }^{4,9,11,12}$. This leads to useful breakdown of PET isotopes of those with half-lives greater than twelve hours and those with half-lives less than twelve hours (Table 2). Isotopes with half-lives less than twelve hours are excellent candidates for biological targets which have short in vivo half-lifes or which clear quickly from the biological system. Whereas some biological targets, like antibodies, have long biological half-lives and therefore take extended periods of time to accumulate sufficiently in the target tissue. 
One of the most commonly used short lived PET isotopes is $\left[{ }^{11} \mathrm{C}\right]$ carbon. Since, carbon is present in the majority of biologically active molecules there has always been a great deal of interest in developing $\left[{ }^{11} \mathrm{C}\right]$ carbon based radiotracers. $\left[{ }^{11} \mathrm{C}\right]$ carbon labeled compounds will behave identical to their cold counterparts. Additionally, a number of different [11C]carbon synthons are readily available, and therefore an ever increasing number of biomolecules have been successfully labeled ${ }^{13}$. Like $\left[{ }^{11} \mathrm{C}\right]$ carbon, the presence of the stable isotope $\left[{ }^{14} \mathrm{~N}\right]$ nitrogen in many biological molecules makes the use and development of $\left[{ }^{13} \mathrm{~N}\right]$ nitrogen into radiotracers potentially very useful. However, $\left[{ }^{13} \mathrm{~N}\right]$ nitrogen has very short half-life $\left(T_{1 / 2}\right)$ of just under 10 minutes and produces a high energy positron. The high energy positron leads to poor spatial resolution in-vivo. These two factors have led to the limited development of $\left[{ }^{13} \mathrm{~N}\right]$ nitrogen based radiotracers. One advantage that $\left[{ }^{13} \mathrm{~N}\right]$ nitrogen does have over other tracers is the ability to produce it, via the cyclotron, in different chemical forms ${ }^{14,15}$. $\left[{ }^{15} \mathrm{O}\right]$ oxygen is another potentially powerful PET isotope because of its biogenicity with biomolecules. However, the two minute half-life has meant that $\left[{ }^{15} \mathrm{O}\right]$ oxygen has not be widely developed as a PET isotope. However, when possible $\left[{ }^{15} \mathrm{O}\right] \mathrm{H}_{2} \mathrm{O}$ has been used as a very effective measure cerebral blood flow, and Berridge has developed $\left[{ }^{15} \mathrm{O}\right]$ butanol for that purpose and also a myocardial perfusion agent ${ }^{16,17}$. Similar to naturally occurring oxygen is $\left[{ }^{18} \mathrm{~F}\right] \mathrm{fluoride}$. This radioisotope is the most common isotope used in PET, and is commonly referred to as the "radionuclide of choice"12. Furthermore, the field of 
$\left[{ }^{18} \mathrm{~F}\right]$ fluorine radiochemistry has exploded in recent years, and therefore greatly expanded the number potential substrates which can be labeled with fluorine-18. 


\section{SYNTHESIS AND DEVELOPMENT OF THE BODIPY CORE}

\section{i. INTRODUCTION}

4,4-difluoro-diaza-s-indacenes (BODIPY) are a class of fluorophores first synthesized by Kreuzer in the late 1960's ${ }^{18}$. Unfortunately, this class of fluorophores was under developed well into the 1980s, and therefore rarely used by many synthetic chemists ${ }^{19}$. Recently, developing BODIPY based fluorophores has garnered increased interest in the scientific literature ${ }^{20}$. The abbreviation BODIPY comes from the similarity between the BODIPY scaffold and the carbocycle $s$-indacene. Compared to other common fluorophores shown above BODIPYs have superior quantum yields, and are insensitive to different solvents. Furthermore, their fluorescent properties are not generally modulated by $\mathrm{pH}$ and they function well at physiologically relevant conditions. Interestingly, the BODIPY scaffold is reminiscent of the cyanine series of dyes if you exclude the $\mathrm{BF}_{2}$ motif. Thus, sometimes the BODIPY scaffold is referred to as a rigidified cyanine dye, and it is this rigidity which leads to its excellent photophysical properties. However, many BODIPYs are not water soluble, and emit at wavelengths less than $600 \mathrm{~nm}$. They also can exhibit a small stokes shifts which can be problematic in biological systems and for the development of fluorescent sensors. Papers are being published weekly addressing some of these less than favorable characteristics ${ }^{20}$.

\section{ii. SYNTHETIC APPROACHES}


Three different methods have been developed in the literature to synthesize the BODIPY core (Figure 7). Generally speaking, the methods which have been developed to date are quite similar to those used originally for the synthesis of porphyrins. The first method involves the condensation of a pyrrole (a weak nucleophile) with acyl chlorides (strong electrophiles). The reaction provides the methene linker between the pyrrole subunit. Next, this unstable dipyrromethene intermediate is then treated with a non-nucleophilic base (generally triethylamine) and then mixed with $\mathrm{BF}_{3}-\mathrm{Et}_{2} \mathrm{O}$ (Figure 7) ${ }^{21}$. A second but related synthetic pathway involved the use of the aldehydes, generally aromatic. The aldehyde and the pyrrole are mixed in the presence of a strong acid like TFA, and then an oxidant like 2,3-dichloro-5,6-dicyano-1,4-benzoquinone (DDQ) is then added to the reaction ${ }^{20}$. Next, it is again treated with a base and complexed with boron as described above. Finally, Recently, Burgess and Dehaen have described a third method of synthesizing BODIPYs using $\mathrm{POCl}_{3}$ in conjunction with aldehyde containing pyrroles to give the dipyrromethene core which is then reacted with base and then later complexed with a boron source ${ }^{22}$. All of these methods tend to produce symmetrical BODIPY cores with differences at the meso position (Figure 7). One common synthetic problem relates to pyrrole polymerization. Therefore substituted pyrroles are commonly used, and this results in meso substituents which are orthogonal to the BODIPY core. The orthogonal relationship between meso substituent and the BODIPY core means that the core's photophysical properties are largely unchanged when compared to simple 
BODIPYs. However, this disconnect has help led to the development of many chemical sensors as discussed below.

A

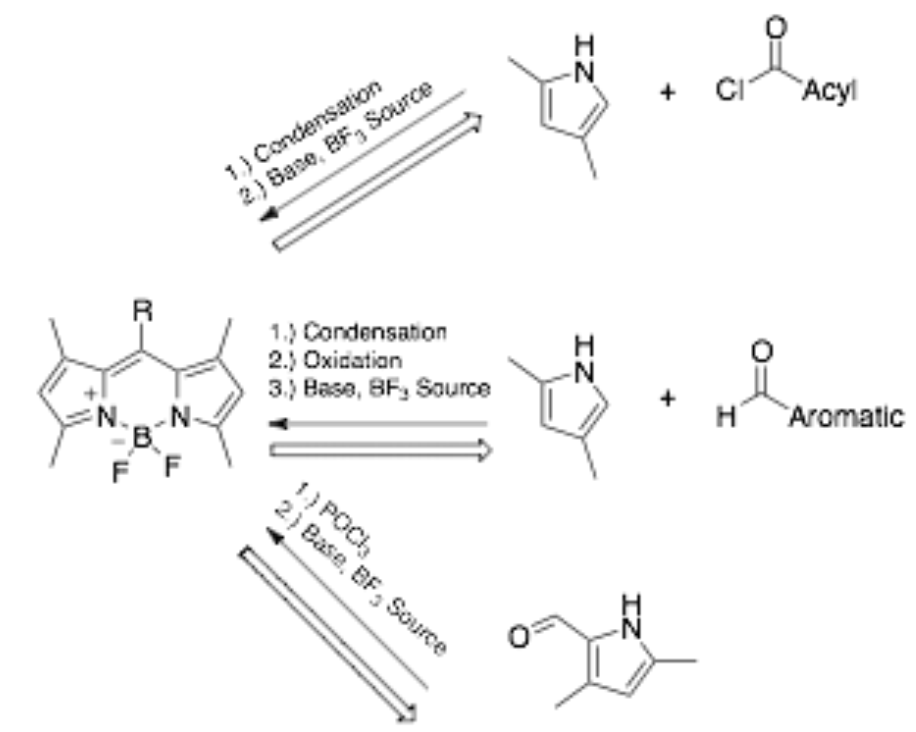

B
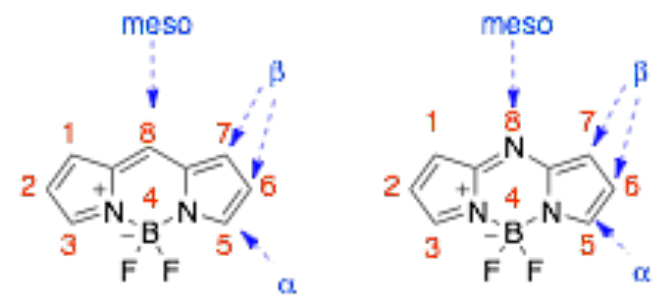

Figure 7: (A) Three most common synthetic routes to making BODIPY dyes (B) IUPAC number scheme for BODIPY and azaBODIPY dyes

Synthetic routes to access asymmetric BODIPYs can be different from from those used to synthesize symmetric BODIPYs discussed above. Burgess ${ }^{22}$ was the first to use $\mathrm{POCl}_{3}$ as a means synthesize symmetric BODIPY dyes, but others ${ }^{23,24}$ have since used the same method to develop asymmetric BODIPY dyes. Additionally, asymmetric BODIPYs can be made via the condensation of a 
pyrrole that is substituted with a carbonyl group and a pyrrole which lacks a substituent at the 2-position. This method has been developed largely to prepare BODIPY dyes for use as bioconjugates. Furthermore, the development of nonfluorinated BODIPY analogues has led to the development of additional nomenclature use to describe the substituents on the boron (specifically the 4,4' position (Figure 8)). For example, carbon substituents are to referred as $C$ BODIPY, oxygen substituent can be denoted with the letter $O$, and nitrogen with the letter $\mathrm{N}^{19}$. The synthesis of this type of substituted BODIPY has grown in popularity over the past ten years, and therefore several different methods have accompanied this rise in popularity. The earliest examples of substituted $C$ BODIPY dyes can be found in a patent written by Murase in 2002, in which he described the synthesis of alkyl and aryl substitution at the boron center ${ }^{25}$. This was followed by a series of papers published by Ziessel which described substitutions on the boron center of the BODIPY scaffold to produce both monoand/or di-substituted $C$-BODIPYs bearing alkyn| $\left.\right|^{26,27}$, and ary| ${ }^{28}$ substituents. Ziessel et al achieved these substitutions by using either organlithium reagents or Grignard reagents in stoichiometric amounts. One unusual method to produce disubstituted $C, O$-BODIPY's bearing an aryl substituent was published by Gabbaï et al. He demonstrated that my using modified boron source $\left(\mathrm{BPhCl}_{2}\right)$ you can cleanly obtain the $C, O$-BODIPY by eluting the $C, C$-BODIPY product over silica. Additionally he demonstrated that this product can be cleanly converted to monosubstituted C-BODIPY using $\mathrm{KHF}_{2}$ in acetonitrile ${ }^{29}$. The 
development of $O$-BODIPY dyes has been just as robust as that of $C$-BODIPY dyes. Burgess reported the first example of an O-BODIPY dye. He used sodium phenoxy to produce disubstituted $O$-BODIPYS ${ }^{30}$. A more rigorous study of dialkoxy and diaryloxy derivatives was carried out by Hibert et al in 2007. Using $\mathrm{AlCl}_{3}$ he demonstrated that a number of $O$-BODIPY dyes could be easily synthesized, and interestingly he only reported the synthesis of disubstitions at the boron core ${ }^{31}$. Furthermore it has been recently reported that by using a different lewis acid, TMS-OTf, accompanied by a non nucleophilic base and an alkyl alcohol certain alkoxy monosubstituted O-BODIPYs can be obtained ${ }^{32}$. The development of nitrogen substituted BODIPY dyes has lagged behind that of

A

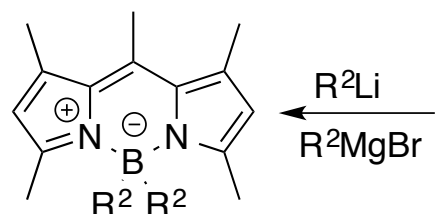

B

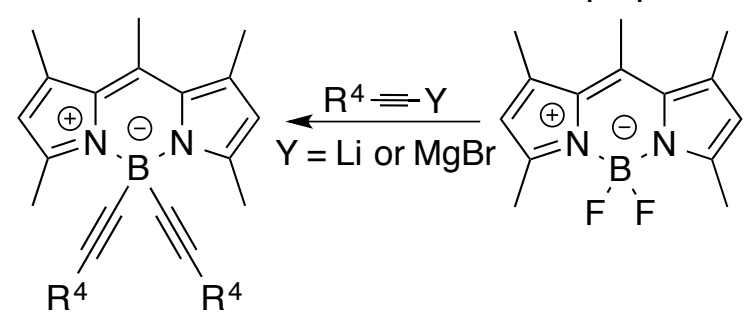

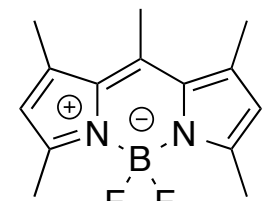

$F^{\prime}$ ' $F$

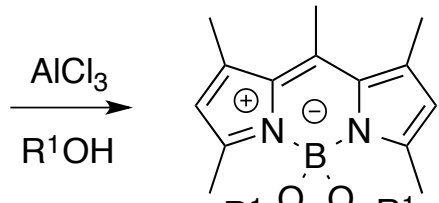

$\mathrm{R}^{1} \mathrm{O}^{\circ} \mathrm{O}-\mathrm{R}^{1}$

$\underset{\text { 2. } R^{3}-X}{\stackrel{\text { TMS-OTf }}{\longrightarrow}}$

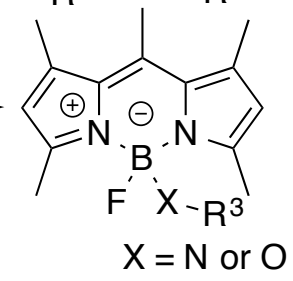

Figure 8: Summary of four common methods used to produce substituted BODIPY dyes

other heteroatom substitutions on the BODIPY core. To date, only example of an $N$-BODIPY can be found in the literature. This $N$-BODIPY dye was synthesized using TMS-OTf as a lewis acid followed by the addition of dimethylamino pyridine (DMAP) in toluene ${ }^{33}$. 


\section{CHAPTER II - Practical Applications}

\section{PET Radiotracer Chemistry \& Dual Mode Molecular Imaging}

\section{i. INTRODUCTION}

A clearer understanding of diseases and health conditions, such as drug addiction $^{34}$, detection and progression of Alzheimer's disease ${ }^{35}$, breast cancer ${ }^{36}$, tumor hypoxia ${ }^{37}$, and cardiac function ${ }^{38,39}$ are reliant on molecular imaging based techniques. The implementation of tracer- and optical-based imaging agents has proven beneficial, but no one imaging methodology is perfect. Therefore, researchers have combined multiple imaging modalities to collect more data efficiently, allowing for image reconstruction and interpretation as a whole to be more accurate.

In vivo imaging techniques provide a system for studying changes in complex biological systems. No single imaging technique is ideal for every biological system or capable of providing all the necessary information in a single test ${ }^{40}$. Therefore, a multitude of different techniques are required, which increases the time for treatment decisions to be made ${ }^{4}$. Using different techniques necessitates the collection and compilation of data from different instruments, under varying conditions, and at different times. The inconsistencies created by using this approach can lead to inaccuracies during image reconstruction. Alignment of these many images, especially in relation to each other, is non trivial ${ }^{9,41}$. 
Researchers have therefore focused on trying to decrease the amount of instrumentation required, so images can be collected and reconstructed more efficiently and accurately. To realize this goal, researchers have begun to combine multiple imaging instruments into a single multimodal apparatus. Thus, net multimodality imaging agents are being developed in tandem with the development of new instrumentation ${ }^{42}$. For the purposes of this dissertation, we are concerned with the development of new fluorine- 18 based dual modality (PET/fluorescence) imaging agents that are capable of being conjugated to clinically relevant peptides.

\section{ii. MOLECULAR IMAGING TECHNIQUES}

PET imaging is the result of a nuclear decay process whereby a proton rich nucleus converts a proton into a neutron, and the excess energy (charge) is given off in the form of a positron. The positron travels in a nonlinear path until it reaches an energetically similar electron. The positron annihilation occurs, and two antiparallel 511kEV photons are produced (Figure 9). These two photons are detected by a ring of detectors. Because these photons are produced simultaneously this process can be referred to as coincidence detection ${ }^{11}$. 
The power of PET imaging lies in its ability to provide exquisitely sensitive measurements due to low amounts of background noise. The low background is the result of a lack of intrinsic radiation occurring within a given subject. Studying

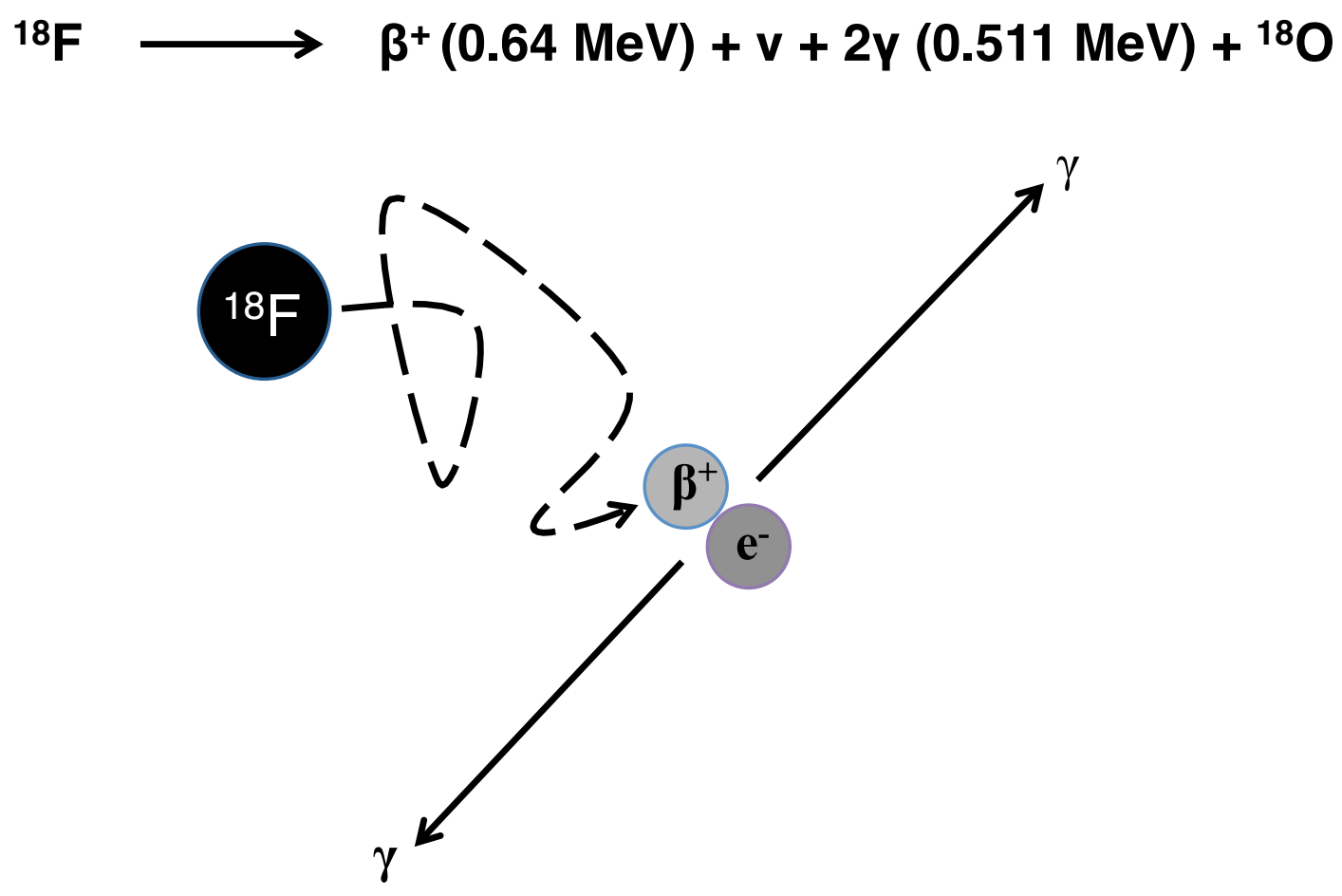

Figure 9: Schematic illustrating the positron decay for flourine-18 which results in the creation of two anti-parallel $511 \mathrm{keV}$ photons

the biological half-life or metabolism of specific bioanlytes and drugs is a common use for in-vivo PET imaging. However, this method requires that a radionuclide of an appropriate half life can be incorporated into the target. Additionally, the ability to work on the pico- to nanomolar scale means that radiochemists can monitor these biological processes at sub-pharmacologically relevant levels, which are generally in the milli- to micromolar range. However, due to differences in attenuation and anotomical location based on tissue type and positron energy (Table 1-2) the resolution can be low. 
As described previously, fluorescence is the process by which a fluorophore emits excess energy in the form of a photon. Unlike PET imaging,

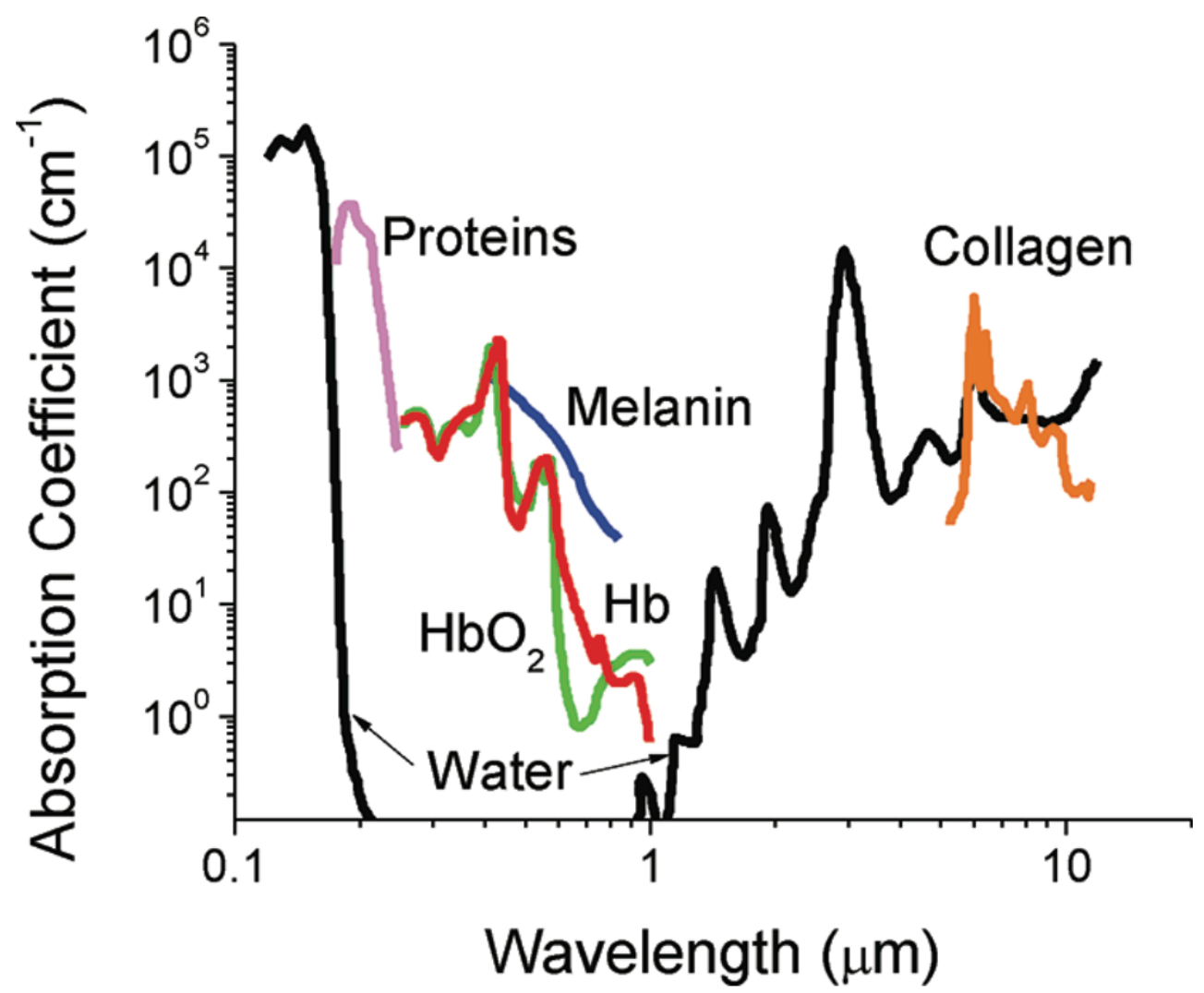

Figure 10: Intrinsic fluorescence from various tissue types and biological molecules. The range visible is approximately $200 \mathrm{~nm}$ to $10 \mu \mathrm{m}$. Adapted from Ref 16.

which is the result of the intrinsic decay of a radionuclide, fluorescence imaging requires some extrinsic source of excitation ${ }^{43}$. It is the presence of this extrinsic light source that creates the biggest problem for in-vivo small animal/clinical optical imaging. Light scattering caused by biological tissues ${ }^{44}$ and poor tissue penetration of the source photons ${ }^{39}$ are of primary concern. As a result, the accuracy and sensitivity of fluorescence imaging are highly dependent upon tissue depth ${ }^{39,45}$. A secondary concern is the autofluorescence created by 
intrinsic fluorophores (Figure 10 $)^{46}$. This can be partially mitigated by choosing a fluorophore with appropriate absorbance and emission wavelengths for a given system $^{47}$. Bioluminescent-based approaches can decrease autofluorescence problems created by source photons ${ }^{48}$. Neither choosing the correct fluorophore or a bioluminescent approach can compensate completely for scattered light caused by biological tissues ${ }^{44}$. Finally, the lack of standard optical imaging systems and the small number of targeted optical probes approved by the FDA have further slowed the adaptation of optical/fluorescence imaging based strategies $^{49}$.

Generally speaking, an image resulting from fluorescence is the result of capturing photons given off by a fluorophore, and then reconstructed to provide a graphical image. Optical imaging, in vitro, has demonstrated its ability to establish unparalleled sensitivity, specificity, and resolution. In some respects, PET imaging can categorized as a static imaging method while fluorescence imaging could be used to provide more dynamic information. Due to the nature of radioactive decay, degradation of the PET imaging probe itself is the only means by which the signal can be manipulated. This, however, can be quiet useful if you are, for example, trying to understand the drug occupancy in a specific receptor. As mentioned previously, fluorophores are quite sensitive to changes in their chemical environments. This could allow for fluorescence imaging to provide a more nuanced picture of cellular/tissue environment relative to PET imaging. 
However, translation of these characteristics into high quality in vivo images has proven difficult ${ }^{44,49}$.

\section{iii. DUAL MODALITY (PET/FLUORESCENCE) IMAGING}

As previously mentioned, PET and fluorescence imaging each have individual limitations. By combining these techniques, researchers can find new

\begin{tabular}{|ccccc|} 
Modality & $\begin{array}{c}\text { Depth } \\
\text { Limited? }\end{array}$ & $\begin{array}{c}\text { Dynamic } \\
\text { Cellular } \\
\text { Information }\end{array}$ & Resolution & Tomography? \\
\hline PET & No & No & $1-5 \mathrm{~mm}$ & Yes \\
\hline $\begin{array}{c}\text { Optical/ } \\
\text { Fluorescence }\end{array}$ & Yes & Yes & $\begin{array}{c}0.3 \mu \mathrm{m}-10 \\
\mathrm{~mm}\end{array}$ & Yes/No \\
\hline
\end{tabular}

TABLE 3: Overview of Optical and PET Imaging Methods

synergistic uses for imaging agents, and obtain more reliable data overall. First, it is well understood that both imaging modalities can have problems with signal attenuation in certain contexts. In PET imaging based techniques this is especially acute when the biological abnormality in question is near the surface or the sample in question is especially thin. In those cases, the positron may escape the tissue or sample of interest before annihilation, resulting in decreased spatial resolution overall. Conversely, optical imaging excels at collecting highresolution images at shallow tissue depths or with thin samples. Thus, the combination of PET and fluorescence imaging is quite complimentary, and allow researchers the unique ability to corroborate the data collected with one modality by examining the other. Advantageously, the opposite is true when wanting to 
examine biological abnormalities residing at deeper tissue depths. In these cases the PET image can provide a whole-body image of, for example, tumor distribution. Then the fluorescent imaging modality can be use to guide the surgical removal of a given tumor(Table 3$)^{42}$.

A second concern of many investigators is introducing an exogenous effect into a given biological system. In others words, will the techniques or chemical components used to probe the biological system cause the system to behave in a non-endogenous manner. Here in lies one of the greatest strengths of PET imaging which is the ability to administer sub pharmacologically relevant amounts of tracer into a given system. This insures no perturbation of the given biological system in question ${ }^{45}$. In this way, PET imaging can serve as an excellent source of cross-validation for fluorescent imaging where the required amount of compound is much higher and therefore the chance of perturbation is much higher. This also serves as a way by which dual modality imaging approaches can create broader impact in the scientific community. One of the barriers to wider adoption of PET imaging is the high cost involved in setting up a PET radiotracer facility, and the cost of fluorescence imaging is much lower. Thus probes which are cross validated by PET/fluorescence imaging can be more widely adopted by the greater scientific community.

As mentioned previously, PET imaging is an excellent mechanism by which quantitative pharmacokinetic data can be collected. The combination of PET with fluorescence imaging grants the ability to carry out long term studies 
using only a single dose of tracer. A fundamental difference between optical imaging and nuclear imaging is that the emission of radioisotopes is a single event that is governed by the half-life of the radionuclide. This half-life can range from a few seconds to several years. Radionuclides with short half-lives, such as

${ }^{18} \mathrm{~F}$ and ${ }^{11} \mathrm{C}$, are useful for rapid signal acquisition and minimize patient exposure to prolonged radioactivity.

While the signal for PET imaging is collected with out any additional perturbation of the system in study, fluorescence imaging techniques require a source of light to excite the fluorophore of interest so that its fluorescence can be detected. A common misconception is that the high photon flux light sources which are commonly used in fluorescence microscopy are also used for in vivo fluorescence imaging when in fact lower flux light sources are more common. This gives the additional benefit of minimizing photobleaching which allows for optical signals to be detected in tissues for several weeks after a single administration of the imaging agent ${ }^{9,49}$. Considering that signal regeneration is the hallmark of optical contrast mechanisms, dual imaging with ${ }^{18} \mathrm{~F}$ or ${ }^{11} \mathrm{C}$ could provide early pharmacokinetic data by PET followed by fluorescence to provide more long term qualitative data set.

\section{iv. EXAMPLES OF DUAL MODALITY (PET/FLUORESCENCE) PROBES}

There are several different designs for dual modality probes in the literature. The first approach to dual modality probes tended to favor the 
development of tripodal designs using larger radionuclides ${ }^{42}$. This design is
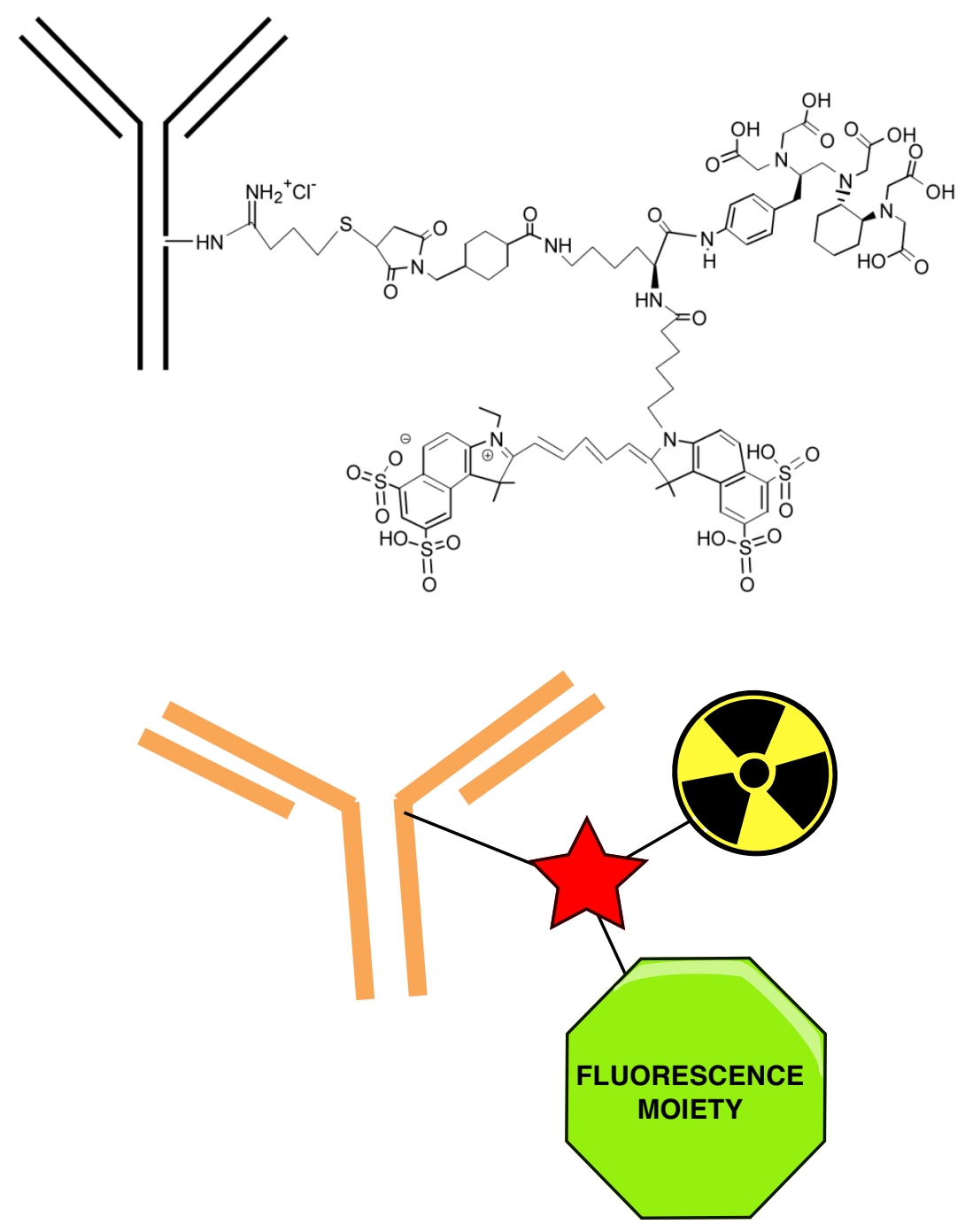

FIGURE 11: (A) a tripodal scaffold which contains a radiometal chelator, a fluorescence dye, and a targeting vector. (B) These three moieties are connected by various different linkers.

exemplified in an early dual modality publication by Brechbiel et al wherein the three different modalities are linked together by a central core molecule, in this case -lysine (Figure 11) ${ }^{50}$. Furthermore, this approach has been expanded to include a wide variety of different nanoparticles ${ }^{51}$. The use of large radioisotopes 
is well suited for this type of approach because many of them are easily chelated under mild conditions, and mild conditions are required due to the sensitive nature of many antibodies or peptides. Furthermore, many of the larger radionuclides have longer half-lives which is also amenable to use with antibodies specifically because accumulation in the target tissue is quite slow relative to other types of biological molecules. It is quite important to check that the bioactivity of the compound remains unchanged by the presence of the functionalized chelate. In the case of $\mathbf{A}^{50}$, no difference is seen the chelate bioconjugate relative to a known standard, but in some instances the functionalized chelate changes the overall activity of the biomolecule ${ }^{52}$ or changes the expected accumulation of the biomolecule ${ }^{53}$. Finally, few examples in the literature can be found of dual modality chromophores with exhibit some kind of dynamic response. Ogawa et al have reported a dual modality chemodosimeter. The goal of this work was to understand molecular targets and to quantify the delivery of antibodies. The platform used was an $\left[{ }^{111}\right.$ In]Indium radionuclide with an ICG type fluorophore. The ICG fluorophore is not fluorescent when bound to the cell receptor, however upon internalization, fluorescence is restored. The ${ }^{111}$ In functions as a means to quantify the number of antibodies delivered to the target tumo (Figure 11) (4. $^{54}$.

Overall, the majority of PET/fluorescence dual modality utilized this tripodal functionalized approach suffer from various shortcomings. Primarily, the series of indocyanine green type dyes while providing a NIR fluorophore suffer 
from poor quantum yields. Also, as mentioned previously ${ }^{64} \mathrm{Cu}$ and ${ }^{111}$ In suffer from impure isotope decay processes. Moreover, the 2.8 day half life associated with indium-111 can be undesirable in studying some biological macromolecules. More generally, the platforms used are often bulky in nature and do not lend themselves to be easily used across several studies.

Overall, the majority of PET/fluorescence dual modality utilized this tripodal functionalized approach suffer from various shortcomings. Primarily, the series of indocyanine green type dyes while providing a NIR fluorophore suffer from poor quantum yields. Also, as mentioned previously ${ }^{64} \mathrm{Cu}$ and ${ }^{111}$ In suffer from impure isotope decay processes. Moreover, the 2.8 day half life associated with indium-111 can be undesirable in studying some biological macromolecules which have short biological half-lives. More generally, the platforms used are often bulky in nature and do not lend themselves to be easily used across several studies. 


\section{CHAPTER III - SUBSTITUTED BODIPYS}

Radiotracer Chemistry and Peptide Radiolabeling Synthons

\section{i. RADIOTRACER CHEMISTRY}

\begin{tabular}{|c|c|}
\hline \multicolumn{2}{|c|}{$\begin{array}{c}\text { Relevant Bond } \\
\text { Dissociation Energies at } \\
298 \mathrm{~K}\end{array}$} \\
\hline $\mathrm{C}-\mathrm{F}$ & $115 \mathrm{kcal} \mathrm{mol}^{-1}$ \\
\hline $\mathrm{Ph}-\mathrm{F}$ & $127 \mathrm{kcal} \mathrm{mol}^{-1}$ \\
\hline $\mathrm{Si}-\mathrm{F}$ & $129 \mathrm{kcal} \mathrm{mol}^{-1}$ \\
\hline $\mathrm{B}-\mathrm{F}$ & $186 \mathrm{kcal} \mathrm{mol}^{-1}$ \\
\hline $\mathrm{Al}-\mathrm{F}$ & $156 \mathrm{kcal} \mathrm{mol}^{-1}$ \\
\hline $\mathrm{P}-\mathrm{F}$ & $105 \mathrm{kcal} \mathrm{mol}^{-1}$ \\
\hline
\end{tabular}

TABLE 4: Relevant Bond

Strengths for F-X Bonds

To aid in the development new of tracers or in new tracer labeling methods it is crucial that the existing restraints and working conditions be clearly understood and defined. One of the biggest working constraints and challenges in the field of radiochemistry is related to the minute amounts of radionuclide available for chemical reactions. These constraints are increased when working with isotopes whose half-lives are less than twelve hours. As an example, $1 \mathrm{Ci}$ of activity, a rather large amount of activity to use during the development of new tracers, represents only about 60 nanomoles of fluorine-18. In this case it makes 
even the microscale conditions that are common place among organic chemists look large. For these reasons, fundamentals differences exist in the kinetics of tracer chemistry, reaction time scales, and trace impurities in reaction materials and components ${ }^{11,55}$. For the purposes of this dissertation we will focus on the problems associated with tracer radiochemistry and fluorine- 18 .

Although many different halogens are used and are currently being developed for use in tracer chemistry, fluorine-18 unique among them. The high electronegativity of 4.0 on the pauling scale, correspondingly high electron affinity $\left(83 \pm 3 \mathrm{kcal} / \mathrm{g}\right.$ atom), and the high enthalpy of hydration $\left(504 \mathrm{~kJ} \mathrm{~mol}^{-1}\right)$ all make working with fluorine-18 challenging ${ }^{56}$. Unlike other related biologically relevant radionuclides fluorine-18 has a relatively long half life, and therefore some multistep chemistry and purification is possible. This has lead to a diverse set of incorporation methods for fluorine-18 which in turn has resulted in the formation of many different fluorine-18 bonds. The relevant bond dissociation energies are summarized in Table 4.

Integrating fluorine-18 into organic frameworks can be broken down into three broad categories: nucleophilic additions, substitution reactions, and electrophilic additions. A second common classification is based on the type of bond formed during the radiofluorination reaction. Perhaps the most common bond formed is the carbon-fluorine bond, and those bond-forming reactions are therefore often referred to as conventional labeling methods. Non-conventional labeling methods refer to the formation of heteroatom fluorine bonds. Although 
conventional labeling reactions have been used extensively in the development of tracers, it is the recent development of these nonconventional labeling methods which has lead to the surge in ${ }^{18} \mathrm{~F}$-PET radiopharmaceuticals in the literure ${ }^{57}$.

The most common method of production for fluorine-18 is via the proton neutron cross reaction using an $\left[{ }^{18} \mathrm{O}\right]$ oxygen enriched water target and a medical grade cyclotron(Table 2$)^{58}$. After eluting the target water over an ion exchange cartridge commonly using either tetrabutyl ammonia bicarbonate (TBAB) or potassium carbonate $\left(\mathrm{K}_{2} \mathrm{CO}_{3}\right)$, the fluorine-18 can be prepared in a way suitable for nucleophilic reactions. . Based on the formulation of fluorine-18 from the target the reactivity of the fluorine-18 will change drastically. The use of TBAB or potassium carbonate/K2.2.2 and the p,n reaction results in a formulation of fluorine-18 which is most commonly associated with nucleophilic fluorination reactions ${ }^{59}$.

While electrophilic fluorine $\left(F_{2}\right)$ or electrophilic sources of fluorine would be of great use to the radiotracer community until recently it has been under developed. Overall, target based approaches to produce electrophilic, $F_{2}$, fluorine-18 has been problematic because carried-added based production methods are required, and therefore lead to low specific activity starting materials. The most common way to produce $\left[{ }^{18} \mathrm{~F}\right] \mathrm{F}_{2}$ is via a ${ }^{20} \mathrm{Ne}(\mathrm{d}, \mathrm{a}){ }^{18} \mathrm{~F}$ reaction where $F_{2}$ is may also be present in the target(Table 2) ${ }^{59,60}$. Furthermore, radiolabeling with electrophilic fluorine reagents like $\left[{ }^{18} \mathrm{~F}\right] \mathrm{F}_{2}$ can result in complex 
mixtures of products which can not be resolved on the radiochemistry time scale $^{12}$. However, in the past four years the landscape regarding electrophilic fluorination reactions has shifted dramatically. This shift has been made in large part due work by Doyle ${ }^{61}$, Governour ${ }^{62,63}$, Groves $^{60}$, and Hooker ${ }^{64}$ to new develop organo- and metallo-based formulation methods leading to electrophilic sources of fluorine-18.

\section{ii. Radiotracer Kinetics and $\left[{ }^{18}\right.$ F]FBA}

As mentioned previously the amounts of the radionuclide present are exceedingly small, and therefore it affects many aspects of the associated chemistry. One of the earliest and still a common method used to image peptides was $\left[{ }^{18} \mathrm{~F}\right]$ fluorobenzaldehyde $\left(\left[{ }^{18} \mathrm{~F}\right] \mathrm{FBA}\right){ }^{65} \cdot\left[{ }^{18} \mathrm{~F}\right] \mathrm{FBA}$ is an indirect labeling approach, where the $\left[{ }^{18} \mathrm{~F}\right]$ fluoride displaces a trimethylammonium group to give the fluorinated product (Figure 12) ${ }^{66,67}$. While we talk about this reaction in bimolecular terms kinetically speaking it is a pseudo first order reaction, and this is true for all radiofluorination reactions. Functionally this means that the concentration of the ligand or the prosthetic group is always in excess relative to the amount of fluorine-18 present. This is quite different from normal fluorination type reactions where the fluoride source is in excess relative to the ligand/ prosthetic group. For this reason the translation of common cold fluorination methods to the tracer level is not common ${ }^{68}$. This method of nucleophilic aromatic type substitution reaction has been expanded to several different prosthetic groups, but due to the lipophilic nature of this prosthetic group changes 
in the in-vivo pharmacokinetics of target peptides has been reported ${ }^{65,69,70}$ (Figure 12).

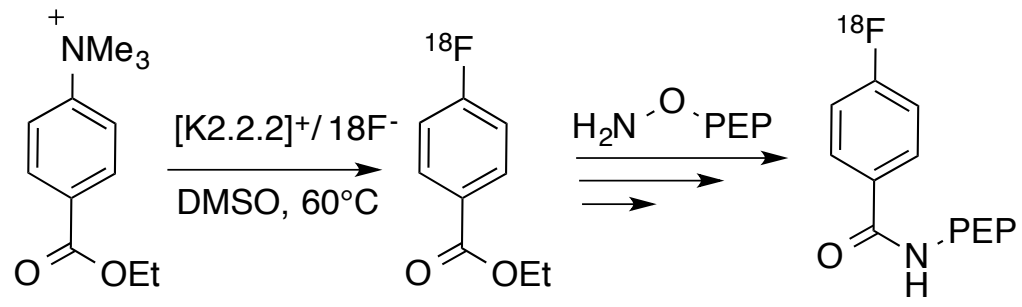

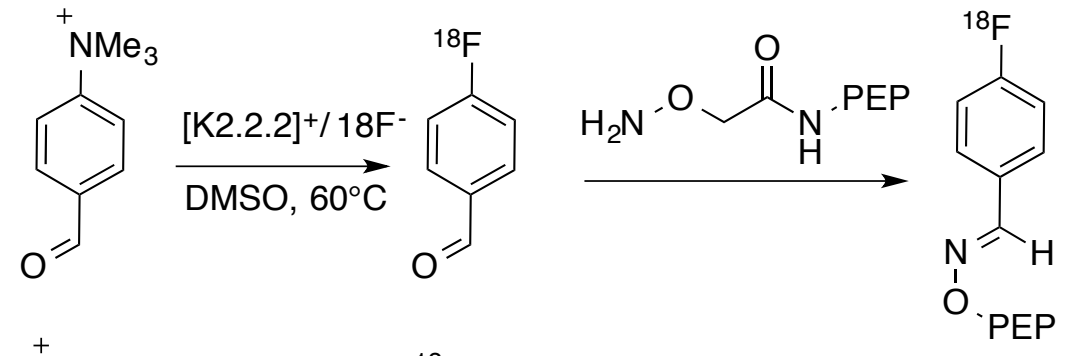

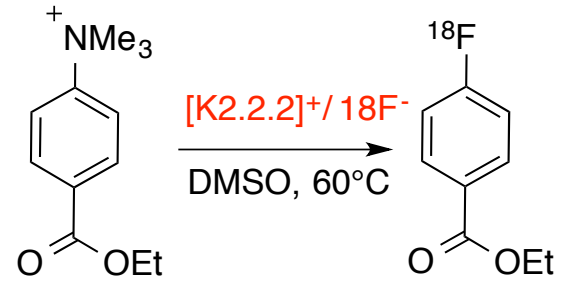<smiles>[18O][B]P</smiles>

$\mathrm{A}=\mathrm{FBA}$

$B=18 F-$

Rate $=k[A][B]$

$\mathrm{k}=\mathrm{k}^{\prime}[\mathrm{A}]$

Rate $=k^{\prime}[B]$

Figure 12: $\left.{ }^{18} \mathrm{~F}\right] \mathrm{FBA}$ is a common prosthetic group used in tracer development for peptide imaging

\section{iii. CONVENTIONAL LABELING METHODS WITH FLUORINE-}

\section{8}

To understand the development of PET based tracers used as bioconjugates it is important to clearly understand the context. Perrin et al has recently published a useful set of guidelines or goals that should be considered 
when developing and evaluating PET tracer based bioconjugates. Primarily developing methods which do not require an azeotropic drying step and methods which do not require HPLC based purifications. That being said high radiochemical yields (>25\%), good purity (>98\%), and high SA (1 Ci/ $/ \mu \mathrm{mol})$ when necessary are imperative. Furthermore, prosthetic groups should be small in nature, not affect the bioactivity of the conjugate, and stable in-vivo. Finally, conjugation to the prosthetic group should be simple and quick or be shelf stable so that radiofluorination can occur in the last $\operatorname{step}^{71}$. Much of the literature focused on peptide conjugation and fluorine-18 containing prosthetic groups have worked towards developing methods which form carbon-fluorine bonds. The earliest and the most common among these prosthetic groups has been $\left[{ }^{18} \mathrm{~F}\right]$ fluorobenzoic acid or $\left[{ }^{18} \mathrm{~F}\right]$ flurobenzaldehyde both of which are commonly abbreviated FBA (Figure 12). The success of FBA is due in large part to mild, often aqueous conditions, under which chemoselective oxime/amide formation can occur. Although formation of the amide is selective some amine containing amino acids such as lysine and arginine may be problematic for some applications. Oximine bond formation, however, has proven to be quite selective. By testing the aldehyde against several potentially reactive amino acids(Lys, Arg, His, Ser, Cys) it was shown that only cysteine (2-5\% reactivity) maybe prove problematic. However, when the hydroxyl amine derivative was in the reaction mixture, the oxime was detected as the soul product in $92-95 \%$ yields $^{66,67}$. An epoxide bearing benzaldehyde was reported by Wanger et al, these three 
membered rings are generally very reactive towards nucleophiles. Therefore attack by the nucleophilic fluorine-18 anion is straightforward, and was able to be carried out in $80-95 \%$ radiochemical yield. However attempts to carry out the same reaction with a peptide conjugated to aldehyde failed (Figure 13). Groves and Hooker recently described an organometallic based approach which utilized benzylic radiofluorination method to produce an alkyne functionalize compound

A

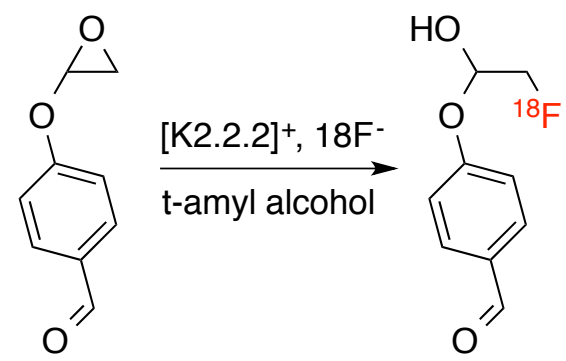

B

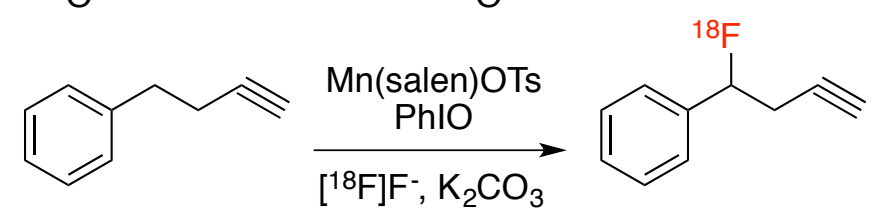

C<smiles>NC1=NN=CC2C1N=CN2C1OC2OC1C(O)C2[Se]CC[C@H](N)C(=O)[O-]</smiles>

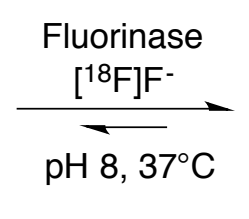<smiles>NC1=NN=CC2C1N=CN2C1C(O)OC(O)C1[I-]</smiles>

Figure 13: Common prosthetic groups which form carbonfluorine bonds and can be used for bioconjugation which can be used later for click chemistry ${ }^{60}$. The reported radiochemical conversion was $40 \% \pm 5 \%$ for the reaction (Figure 13). Recently enzymatic type approaches to incorporate fluorine-18 have been explored by Gifford ${ }^{72}$ and the first peptide based enzymatic approach was published by O'Haganl ${ }^{73}$. O'Hagan and co-workers have demonstrated the ability of an enzyme, fluorinase isolated 
from bacteria, to selectively incorporate $\left[{ }^{18} \mathrm{~F}\right]$ fluorine directly from the target solution. This eliminates the normal azeotropic dry downs required in most protocols. The $\left[{ }^{18} \mathrm{~F}\right]$ fluoride can be incorporated via a S-adenosyl-I- methionine (AdoMet) substrate containing an alkyne which can be coupled later to peptide. They have also demonstrated that a 5'- chloro-5'-deoxyadenosine substrate containing a flexible PEG linker and the RGD peptide can be used (Figure 13). This incorporation is done in under thirty minutes directly from the cyclotron target water. The reported nondecay corrected radiochemical yields are 12\%. Chemistry of this natures represents what is often referred to as the "Gold Standard" whereby [18F]fluoride is administered in the final step.

\section{iv. NONCOVENTIONAL RADIOLABELING METHODS AND FLUORINE-18}

We know that the high hydration enthalpy of fluorine generally decreases its overall nucleophilicity and therefore make the use harsh labeling conditions more necessary. As a result, the goal of creating a shelf stable bioconjugates remains largely unrealized. Recent work has focused on the use of heteroatoms as $\left[{ }^{18} \mathrm{~F}\right]$ fluorine scavengers. Aluminum is known to form strong bonds with fluorine, and furthermore the aluminum fluorine bond is known to be stable invivo (Table 3). Biological systems are also known to tolerate small amounts of AIF chelates as well. While many different chelates and approaches to conjugation have been developed for longer lived isotopes. The main set of

methods used to chelate fluorine-18 has been developed by McBride et $\mathrm{al}^{74,75}$ 
(Figure 14). These chelates are hydrophilic, and therefore are usable in biological systems. They are however quite sensitive to changes in $\mathrm{pH}$, and some loss of fluorine-18 can occur. Furthermore, high temperature $\left(105^{\circ} \mathrm{C}\right)$ may be required for effective incorporation of fluorine-18, and therefore problematic for some peptides constructs ${ }^{75}$.

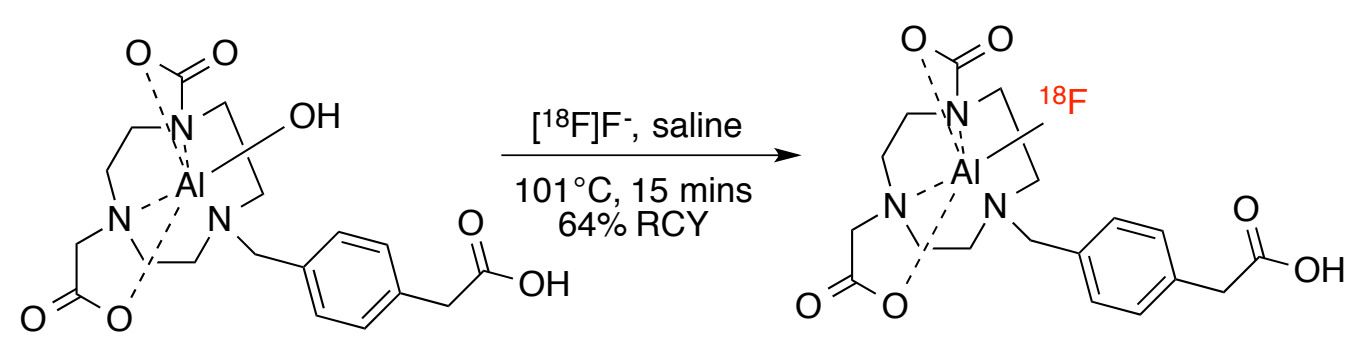

Figure 14: One example an aluminum $\left[^{18} \mathrm{~F}\right]$ fluorine chelate developed by McBride which can be conjugated to different peptides.

The strength of the fluorine silicon fluorine bond is well characterized, and therefore molecules incorporating silicon have been explored as fluoride acceptors. This is type of strategy is most commonly referred to as the SiFA approach or silicon-fluorine acceptor. These receptors function via an $\left[{ }^{18} \mathrm{~F}\right]$ fluoride isotope exchange reaction. These types of reactions are useful because the activation energy is low for the formation of a pentacoordinate siliconate $\left(E_{a}=15.7 \mathrm{kcal} / \mathrm{mol}\right)$ thereby allowing for rapid isotope exchange (Figure 15). However, these reactions suffer from being inherently "carrier added" because of the inability to separate the cold and the hot compounds. This also means that many constructs exhibit low specific activity and therefore will be a poor choice for some peptides. Originally, work focused on the synthesis of an 
FBA-Silicon derivative which was able to successfully label certain peptides with an RCY between $75-95 \%$ and RCP of $50-55 \%$ post solid phase cartridge based extraction and HPLC purification ${ }^{76}$. Initially these molecules suffered from high

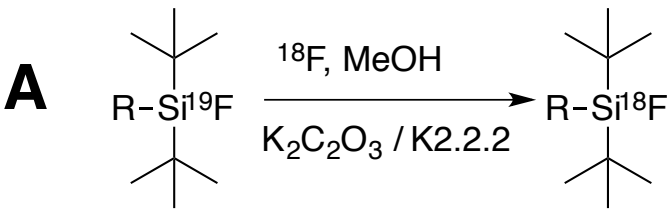
B

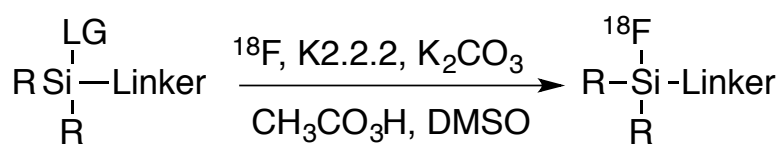
$L G=E$ thoxy, OH, $\mathrm{H}$

Figure 15: Two examples of SiFA-type prosthetic lipophilicity ${ }^{77}$. However, recently a charged silicon fluoride acceptor has been reported to address these concerns. Although the RCY was near $100 \%$ the total RCP was low at $34 \%{ }^{78}$. A substitution based silicon precursor has been recently reported as well demonstrating about $50 \%$ incorporation of $18-\mathrm{F}$ at the silicon center. However, no RCP was reported because of difficulties in separating the hot and the cold compounds ${ }^{79}$. The in vivo stability of different SiFA prosthetic groups has been investigated, and in some instances leaching of fluorine-18 has been detected ${ }^{80}$.

Boron has long been used as a traditional fluoride scavenger by many sensor chemists. Organoboron complexes, including boronic acids and boronic esters, have been used to detect fluoride in various different types of media. However, even though simple triaryl boron frameworks will form a bond with 
fluorine, this bond suffers complete hydrolysis under aqueous conditions ${ }^{81}$. For this reason, their use as scavengers for $\left[{ }^{18} \mathrm{~F}\right]$ fluoride has not been explored. Seminal work by Perrin has shown that under the right conditions boronic acids and esters can be used capture fluorine-18. Initial reports from the Perrin lab focused on carrier added conditions and the development of different boron based scaffolds to capture fluorine- 18 which where increasingly more stable to hydrolysis ${ }^{82-85}$. In recent examples, low $\mathrm{pH}$ has been required to stave off hydrolysis of fluoride during the isotope exchange reaction ${ }^{86}$. Many peptides are not stable at low $\mathrm{pH}$ even for short periods of times, and isotopic exchange conditions result in carrier added conditions. Newly reported zwitterionic boronates still work via the same isotope exchange mechanism, and are thus still essentially carrier added type approaches ${ }^{71}$. Recently a second approach based on a BODIPY framework, which contains a boron core, has begun to be explored recently. The precedent for this reaction comes from work published by Gabbaï demonstrating that a simple pentamethyl N-BODIPY(F,DMAP) could detect fluoride anions from a tetrabutylammonium source in organic media ${ }^{33}$. Due to the fluorescence properties of the BODIPY core, changes in fluorescence where able to observed. From a tracer standpoint, the ability to incorporate $\left[{ }^{18} \mathrm{~F}\right]$ fluoride into a stable framework is highly desirable. To that end Conti and Gabbai published the first BODIPY scaffold which had been successfully labeled with $\left[{ }^{18} \mathrm{~F}\right]$ fluoride (Figure 16). The synthon developed was C,O-BODIPY(Phenyl, Hydroxyl) which also contained a charged trimethylated aniline at the 8-position. Using carried 
added conditions they demonstrated that the disubstituted BODIPY core could incorporate $\left[{ }^{18} \mathrm{~F}\right]$ fluoride in $22 \%$ decay corrected radiochemistry yield, and a formulated $\mathrm{SA}$ of $25 \mathrm{mCi} / \mu \mathrm{mol}$. Using just $\left[{ }^{18} \mathrm{~F}\right]$ fluoride in the reaction mixture did not yield a labeled product due to the strength of the boron hydroxide bond ${ }^{87}$. Lowering the $\mathrm{pH}$ is known to increase the lability boron hydroxide bond ${ }^{81}$, and thus an activated $C, O-B O D I P Y(P h e n y l$, Triflate) complex was formed via addition of TMS-OTf to the starting material| ${ }^{88}$. Which also consequently lowered the overall $\mathrm{pH}$, and under those conditions the radiochemical yield (61\%) and the SA (1.4 Ci/ $/ \mu \mathrm{mol})$ increased. Later, Conti and Gabbai published a second approach to labeling the BODIPY core via isotopic exchange reaction ${ }^{51}$. As demonstrated above, the use of isotopic exchange reactions are commonly used to incorporate fluorine-18. By employing a variety of different lewis acids, Conti demonstrated that ${ }^{19} \mathrm{~F}-{ }^{18} \mathrm{~F}$ exchange was possible on the BODIPY scaffold. By employing the use of TMS-OTf on the BODIPY scaffold, a yield nearing $20 \%$ could be achieved. However by using a mild lewis acid yields, the labeled product in yields greater than $90 \%$ and with a SA approaching $1 \mathrm{Ci} / \mu \mathrm{mol}$. In a related method, Mazitschek demonstrated that TMS-OTf along with some quenching/stabilizing reagents could be used to label the BODIPY core in $60-75 \%$ radiochemical yields with a $\mathrm{SA}$ in the range of $0.91 \mathrm{Ci} / \mu \mathrm{mol}$. Mazitschek not only activated the BODIPY core with TMS-OTf like Conti and Gabbai but also employed the use of a nonnucleophilic amine base to stabilize the O-BODIPY $(\mathrm{F}, \mathrm{OTf})$ intermediate during labeling. Furthermore, they employed a tert-butanol to act as silicon sponge. It 
should be noted that Matizeschek also reported that acidic conditions were required to obtain good yields of $\left[{ }^{18} \mathrm{~F}\right] \mathrm{F}-\mathrm{BODIPY}($ Figure 16$){ }^{89}$.

Overall several trends can be found in current literature reports. First, clearly the internal $\mathrm{BF}_{2}$ moiety of the BODIPY core is quite stable, and therefore it must be activated in some way (both groups used TMS-OTf) to achieve $\left[{ }^{18} \mathrm{~F}\right]$ fluoride incorporation. One concern with these types of approaches is cross metathesis of the activated BODIPY complex back into cold starting material thereby lowering the SA. Although no data is provided, Mazitschek alludes to this problem in his report, however no mention is made of a similar issue in the publication by Conti and Gabbai. As mentioned above, TMS-OTf is used by both groups to form an activated BODIPY(F, OTf) intermediate, however to much excess of the reagent was reported by Conti and Gabbai et al to lead to the formation of $\left[{ }^{18} \mathrm{~F}\right] \mathrm{TMS}^{90}$. An additional concern is the low $\mathrm{pH}$ required by both methods, Mazitshek et al went as far to say that under insufficiently acidic conditions the reaction stalls ${ }^{91}$. Comparing the yields between the two reports, it appears that quenching/stabilizing reagents are beneficial to the overall yield ${ }^{90,91}$. Clearly these combined results demonstrate that either the boron or the fluorine of the $\mathrm{BF}_{2}$ core is perhaps more labile than previously thought. Additionally, the isotopic exchange approach and the activated intermediate approach both report similar specific activities $(\approx 1 \mathrm{Ci} / \mu \mathrm{mol})$. Although the C,O-BODIPY(Phenyl, Hydroxyl) yields where the lowest, the lack of intrinsic fluorine sources may prove beneficial overall. 

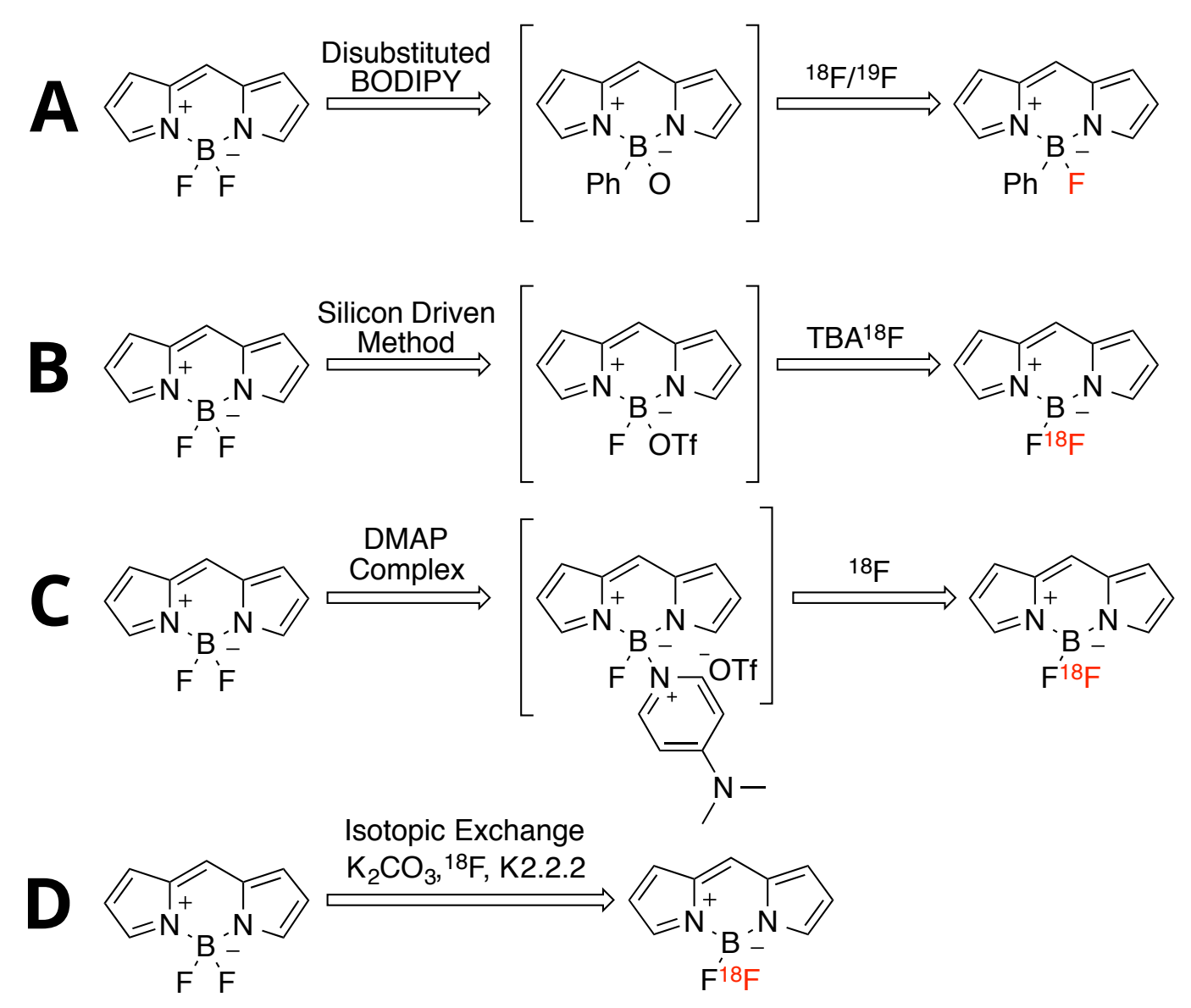

$E$<smiles>[R]c1c(F)cc(F)c([B])c1F</smiles>

Figure 16: Summary of different boron based fluorine-18 capture methods which are currently in use. 


\section{v. BORON BASED DUAL MODALITY (PET/FLUORESCENCE) PROBES}

The development of BODIPY and boron based scavengers for $\left[{ }^{18} \mathrm{~F}\right]$ fluoride has meant a concurrent development of the scaffold as dual modality imaging agent. A primary concern of many PET radiochemists who work with fluorine-18 is the possibility of leaching fluorine-18 into the bone. To date, none of the probes (boron-based) published in the literature show any significant leaching of $\left[{ }^{18} \mathrm{~F}\right]$ fluoride into the bone. In the initial report by Gabbai and Conti ${ }^{88} 95 \%$ of $\left[{ }^{18} \mathrm{~F}\right]$ fluorinated BODIPY construct remained intact after a $6 \mathrm{hr}$ incubation in PBS buffer. This result was corroborated by Mazitschek et $\mathrm{al}^{91}$. Furthermore, reports by Perrin has demonstrated that their functionalized boron center is stable under biologically relevant conditions ${ }^{71,92}$. When comparing these probes to the current literature surrounding dual modality probes we can begin to see a few trends emerge. Primary among them is the use of better fluorophores. Both the rhodamine derivative employed by Perrin and the BODIPY framework employed by others are far superior to the commonly used indocyanine green for small animals models. Furthermore, the red shift associated with rhodamine fluorescence $\left(\lambda_{\mathrm{em}}=584 \mathrm{~nm}\right)$ relative to the BODIPY core $\left(\lambda_{\mathrm{em}} \approx 500\right)$ is a distinct advantage. Secondly, the incorporation of fluorine-18 into a compact scaffold means biomolecules with a shorter half-live in-vivo can be studied more accurately. The approach to dual modality imaging used by Perrin et al is much like the tripodal design discussed earlier where a central molecule links the three 
individual moieties. In this case, a pentaerythritol was used as the central molecule. It was successfully linked to the aforementioned rhodamine dye, a zwitterionic alkylammoniomethyltrifluoroborate $\left(\mathrm{AMBF}_{3}\right)$ and then also conjugated with two RDG cyclic peptides. Under the appropriate conditions the tripodal construct was produced in high $\mathrm{SA}(3.5 \mathrm{Ci} / \mu \mathrm{mol})$ well above the $\mathrm{SA}$ required for high quality PET images. An aliquot of the construct was saved and diluted with cold standard to a SA of $0.01 \mathrm{Ci} / \mu \mathrm{mol}$ to provide the necessary amount of mass required for ex-vivo fluorescence imaging (Table 5). Interestingly, at concentrations this low (approximately $10^{-6} \mathrm{M}$ ) this dose could be essentially used for a blocking experiment as well, although not in this protocol. Using this

\begin{tabular}{|ccccc|}
\hline $\begin{array}{c}\text { Specific Actvity } \\
\left(\mathbf{C i} \mathbf{~ m o l}_{-} \mathbf{-}\right)\end{array}$ & $\begin{array}{c}\text { Injected Dose } \\
(\boldsymbol{\mu} \mathbf{C i})\end{array}$ & $\begin{array}{c}\text { Injected Mass } \\
(\mathbf{n m o l})\end{array}$ & $\begin{array}{c}\text { Mass in Tumor } \\
(\mathbf{p m o l})\end{array}$ & $\begin{array}{c}\text { Fluorescent } \\
\text { Detection }\end{array}$ \\
\hline 3.5 & 100 & 0.03 & 0.006 & $\mathrm{~N}$ \\
\hline 0.01 & 100 & 10 & 17 & $\mathrm{Y}$ \\
\hline
\end{tabular}

TABLE 5: Summary of relevant PET and fluorescence data for the tripodal $\left[{ }^{18} \mathrm{~F}\right] \mathrm{AMBF}_{3}$ bearing imaging modality adapted from reference \# method, excellent correlation was seen between the PET images and the fluorescent images. Furthermore, the approach elegantly describes and demonstrates the necessary methods required to collected relevant PET and fluorescence data. One would hope that over time with improvements in fluorophore detection methods, we will be able to negate the need to use low SA injections so that fluorescence can be effectively visualized.

While multiple different literature reports can be found utilizing aryl boron scaffolds for fluorine-18 incorporation, the reports of BODIPY based approaches 
are more limited. To date, only one dual modality BODIPY based bioconjugates has been reported and validated in the literature by Conti and Gabbai. Using the previously explained isotope exchange reaction they labeled a BODIPY scaffold containing an activated NHS ester, after successful incorporation of fluorine-18 in $79 \%$ radiochemical yield, the scaffold was then conjugated to the RGD peptide. Following formulation, the BODIPY constructed was injected into U87MG tumor bearing mice. In vivo PET imaging showed large uptake in the kidney, liver, and uptake in the tumor. This construct is largely lipophilic and thus large uptake in both the kidney and liver is to be expected. In this study, no specific activity related directly to the peptide BODIPY scaffold is provided, and therefore comparison between this work and that of Perrin is not possible. However it can be said that it must be lower relative to the work published by Perrin due to the ability discern a fluorescence signal with out a second injection of the construct. Furthermore, a comparison of the ex vivo PET and fluorescence images shows much larger fluorescence signal accumulation in the tumor relative to the PET image, and similar results can be seen in work published by Perrin (Figure 17). Overall both approaches still suffer from using essentially carrier added conditions due the presence of large amounts of cold starting material. However it must be said that based on the images provided the $\mathrm{AMBF}_{3}$ construct appear to capture fluorine- 18 . 


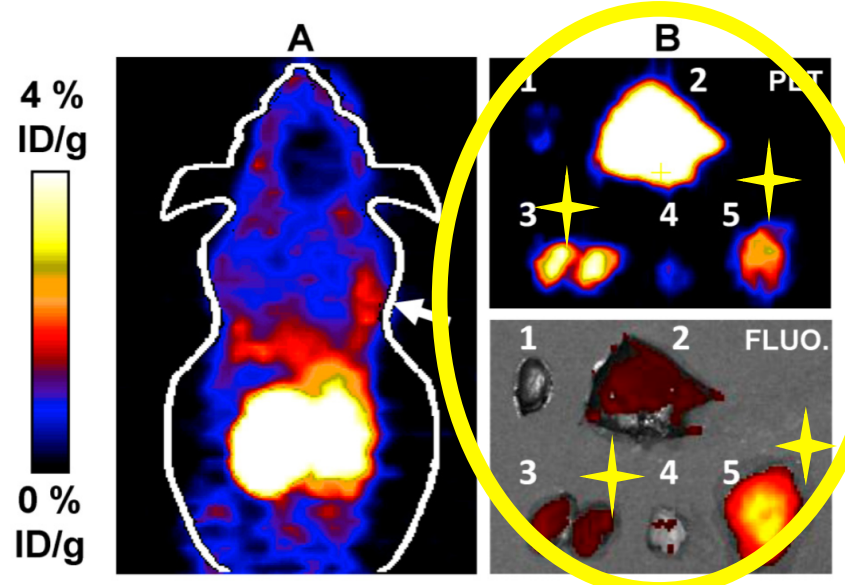

Figure. 3. Top: Scheme for the synthesis of $\left[{ }^{18} \mathrm{~F}\right] 2$ and $\left[{ }^{18} \mathrm{~F}\right] 2-\mathrm{RGD}$ and HPLC trace showing $\left[{ }^{18} \mathrm{~F}\right] 2$ in the crude reaction mixture. Bottom: microPET imaging (A, the white arrow indicates the tumor location) and Ex vivo PET/fluorescence imaging (B) of major organs and tumor $0.5 \mathrm{~h}$ after injection of [ $\left.{ }^{18} \mathrm{~F}\right] 2$-RGD into a U87MG tumor bearing nude mouse. The fluorescence images were obtained by irradiation of the organs at $\lambda=535 \mathrm{~nm}$. The fluorescence image was reconstructed hacod $\mathrm{nn}$ the emission intensity measured at $\lambda=580 \mathrm{~nm}$. I: Heart, 2: Liver, 3: Kidneys, 4:Muscle, 5: Tumor.

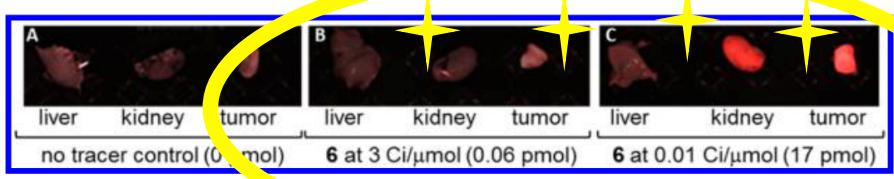

Figure 6. Ex vivo fluorescence in organs to which $\left[{ }^{18} \mathrm{~F}\right] 6 \mathrm{C} \ldots$ liver, kidney, and tumor: (A) organs from moucr ...t received no tracer (control); (B) organs from mouse injected with 6 at $3.5 \mathrm{Ci} / \mu \mathrm{mol}$; (C) organ _. tho mouse iniected writh, u.v1 $\mathrm{Ci} / \mu \mathrm{mol}$.

FIGURE 17: A direct comparison of the ex-vivo PET and fluorescence images collected from an $\left[{ }^{18}\right.$ F $\mathrm{AMBF}_{3}$ peptide construct and $\left[{ }^{18} \mathrm{~F}\right]-\mathrm{BODIPY}$ peptide constructe. Images adapted from Ref \# and \#

\section{vi. SPECIFIC AIMS AND GOALS}

Effectively monitoring and characterizing different disease states is an integral but difficult part of molecular imaging. In order to be successful and meet these demands, a diverse set of molecular imaging tools must be readily available. The development and implementation of a variety of different radiolabeled biological molecules has been an integral part of the advancement of molecular imaging ${ }^{93}$. Peptides and peptidometics serve a diverse role in biological systems, and radiochemists have developed numerous different 
methods by which they can be labeled ${ }^{36,69,94}$. Two major factors must be considered when deciding to label a construct with a radionuclide. First, the radionuclide of choice must have a half-life which is appropriate for the half-life of the biological molecule you wish to label ${ }^{92}$. Second, we want to be able to incorporate the nuclide in such a way that the biological activity of the peptide is unaffected ${ }^{50}$. Because of these two requirements no one single approach is going to work for all peptides.

While tagging peptides and other biological molecules with radionuclides has a long history only recently have people begun to focus and develop dual modality based approaches for labeling peptides. The constraints though have not changed with the addition of an additional imaging modality ${ }^{42}$. Orginal designs of dual modality probes focused on a tripodal design. Therein, each modality (targeting, fluorescence, and PET) is connected to a central core ${ }^{50}$. This approach has yielded many useful dual modality targeted approaches, but in some instances the additional modality has changed the normal biological activity of the target ${ }^{50,92,95}$.

Bearing in mind the work put forth by other researchers we hope to develop a platform which was less bulky, and one which allowed the radionuclide to be incorporated in the last step. A strong candidate based on the initial results published by Gabbai was the BODIPY scaffold ${ }^{33}$. The BODIPY framework is know to be stable under biologically relevant conditions, and internal $\mathrm{BF}_{2}$ moiety can be modified in way amenable to fluorine-18 incorporation. 


\section{vii. SUBSTITUTED BODIPYS: C,O-BODIPY (PHENYL, HYDROXDE) AND N-BODIPY (F, DMAP)}<smiles>CC1=CC(C)N=C1</smiles>

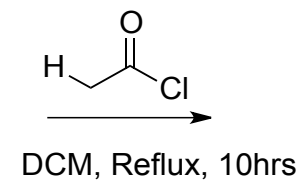<smiles>CC1=CC(C)=NC1=C(C)c1[nH]c(C)cc1C</smiles>

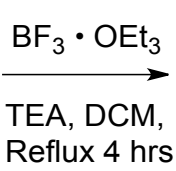

Reflux 4 hrs

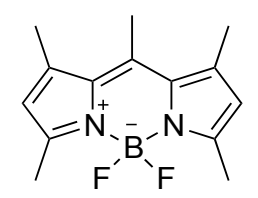

$172 \%$<smiles></smiles>

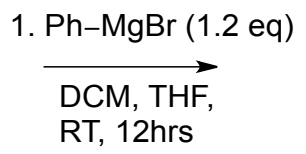

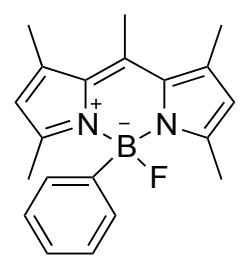

$225 \%$

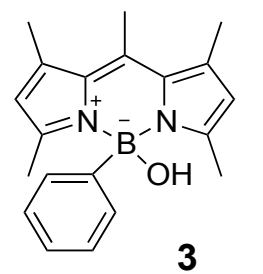

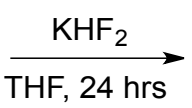

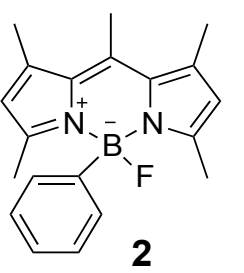

1. TMS-OTf, DCM, RT 2hrs

2. DCM: $\mathrm{H}_{2} \mathrm{O}$ Extraction

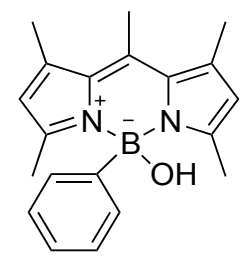

3

FIGURE 18: Synthesis of a disubstituted $C, O$-BODIPY(Phenyl, Hydroxyl) scaffold.

Pentamethyl BODIPY (1) was synthesized from 2,4-dimethylpyrrole and acetyl chloride in dichloromethane giving rise to the dipyrrin core to which BF3etherate and absolute triethylamine affording the final product in reasonable yields ${ }^{21}$. The final product 1 was then subjected to phenyl-magnesium bromide to give the monoarylated BODIPY $(\mathbf{2})^{96}$. Next, TMS triflate was used to remove the boron fluoride bond and which point a water workup afforded the C,O-BODIPY (Phenyl, Hydroxide) (3) (Figure 18) ${ }^{33}$. These two compounds where then subjected to treatment from a fluoride source $\left(\mathrm{KHF}_{2}\right)$ in excess under NMR conditions, and it was demonstrated that 3 captures fluoride quantitatively after 24 hrs via fluorine NMR (Figure 18). Although 24 hours was required for 
quantitative capture, a majority of the fluorine was captured after 20 minutes.

However, after working through several sets of HPLC conditions the mono- and di-substituted BODIPY's where unable to be separated, a requirement for radiolabeling.
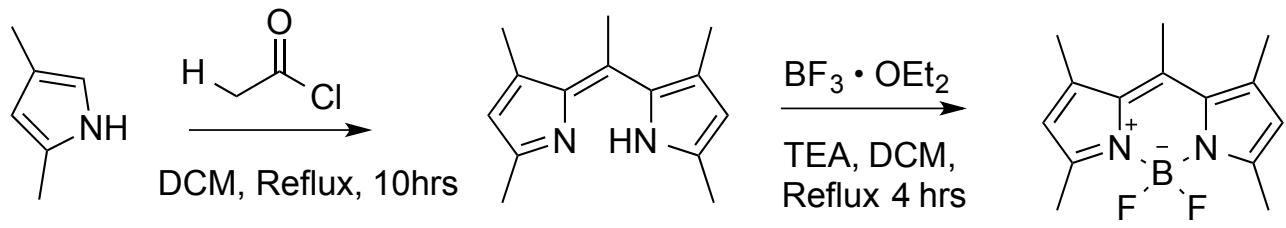

$172 \%$<smiles>Cc1cc(C)[n+]2c(C)c1-c1c(C)cc(C)n1B2F</smiles>

1. TMS-OTf, $\mathrm{CH}_{2} \mathrm{Cl}_{2}$, Rt (30 mins)

2. DMAP (1 hr)

3. $\mathrm{H}_{2} \mathrm{O}: \mathrm{DCM}$ Extraction
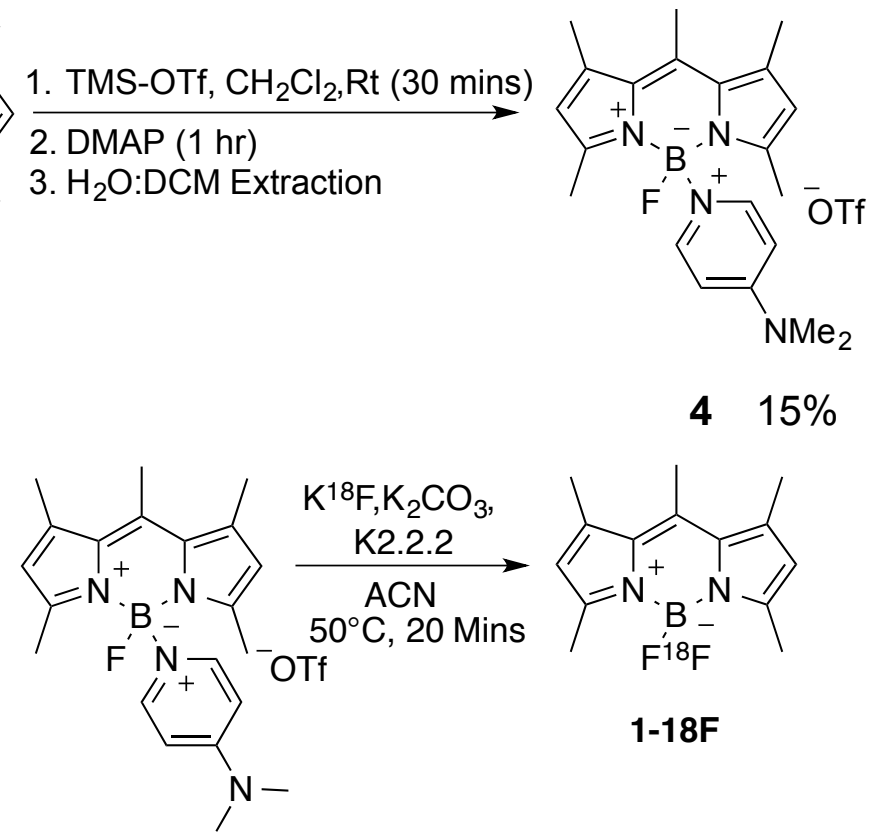

RCY: $44 \%$

RCP: $93 \%$ via Silica SepPak and then reinjection

FIGURE 19: (A) Synthesis of pentamethyl BODIP scaffoldt (1) and the $\mathrm{N}$ BODIPY(F, DMAP) prosthetic group (4). (B) Summarized radiolabeled conditions for the pentamethyl BODIPY 
Returning to the seminal work by Gabbai et al, we endeavored to synthesize the pentamethyl N-BODIPY(F, DMAP). 2,4-dimethyl pyrrole was reacted with acetyl chloride and then later mixed with TEA followed by $\mathrm{BF}_{3}-\mathrm{OEt}_{2}$. The addition of TMS-Triflate in methylene chloride followed by DMAP gave the
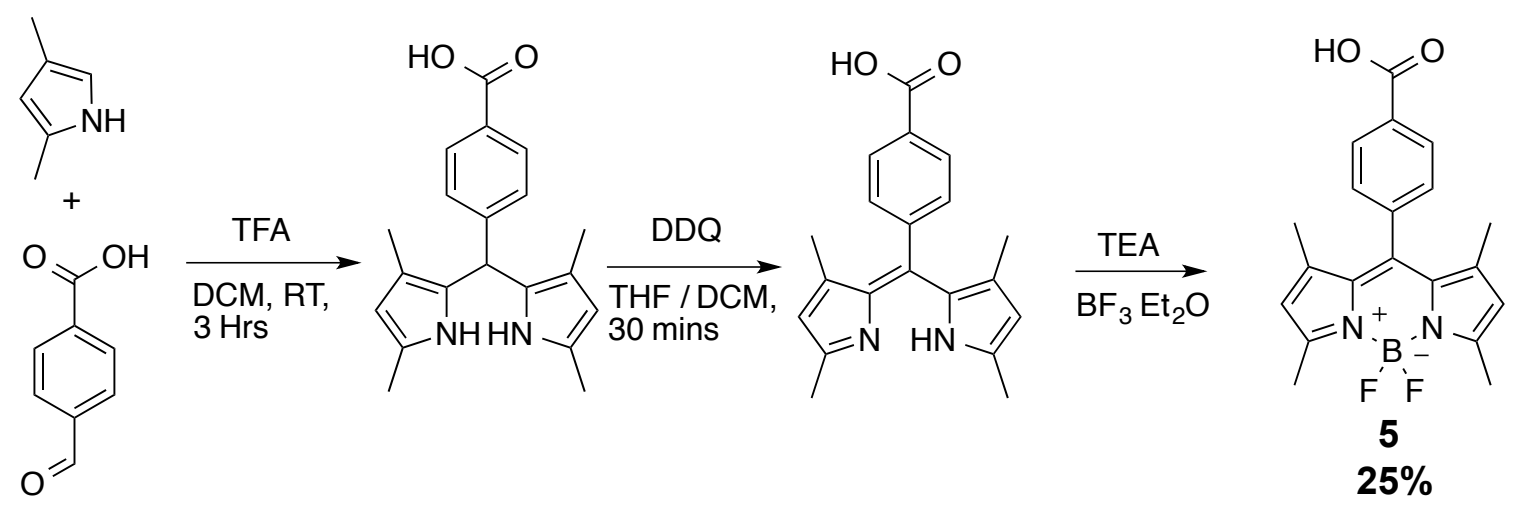

Figure 20: Synthesis of a BODIPY scaffold containing a carboxylic acid handle

DMAP substituted N-BODIPY (4) (Figure 19). A second target in the form of a carboxy derivative of the BODIPY scaffold that could be functionalized with both the DMAP substitution and the NHS ester to be used for bioconjugation. Synthesis of the BODIPY starting material (5) followed literature precedent and was similar to other previously synthesized BODIPY scaffolds (Figure 20) ${ }^{97}$. Successful synthesis of the scaffold in $25 \%$ yields suggested two synthetic pathways summarized in Figure 21. Initially the carboxy BODIPY (5) was reacted with n-hydroxy succinimide and DCC to give the NHS ester BODIPY (6) cleanly in 43\% yield, however reacting 6 with TMS-Triflate and DMAP under various conditions only gave decomposition products. Furthermore attempts to first make the DMAP substituted N-BODIPY (F, DMAP) 7 construct and then couple the NHS ester (8) where also unsuccessful (Figure 21)). However, using 


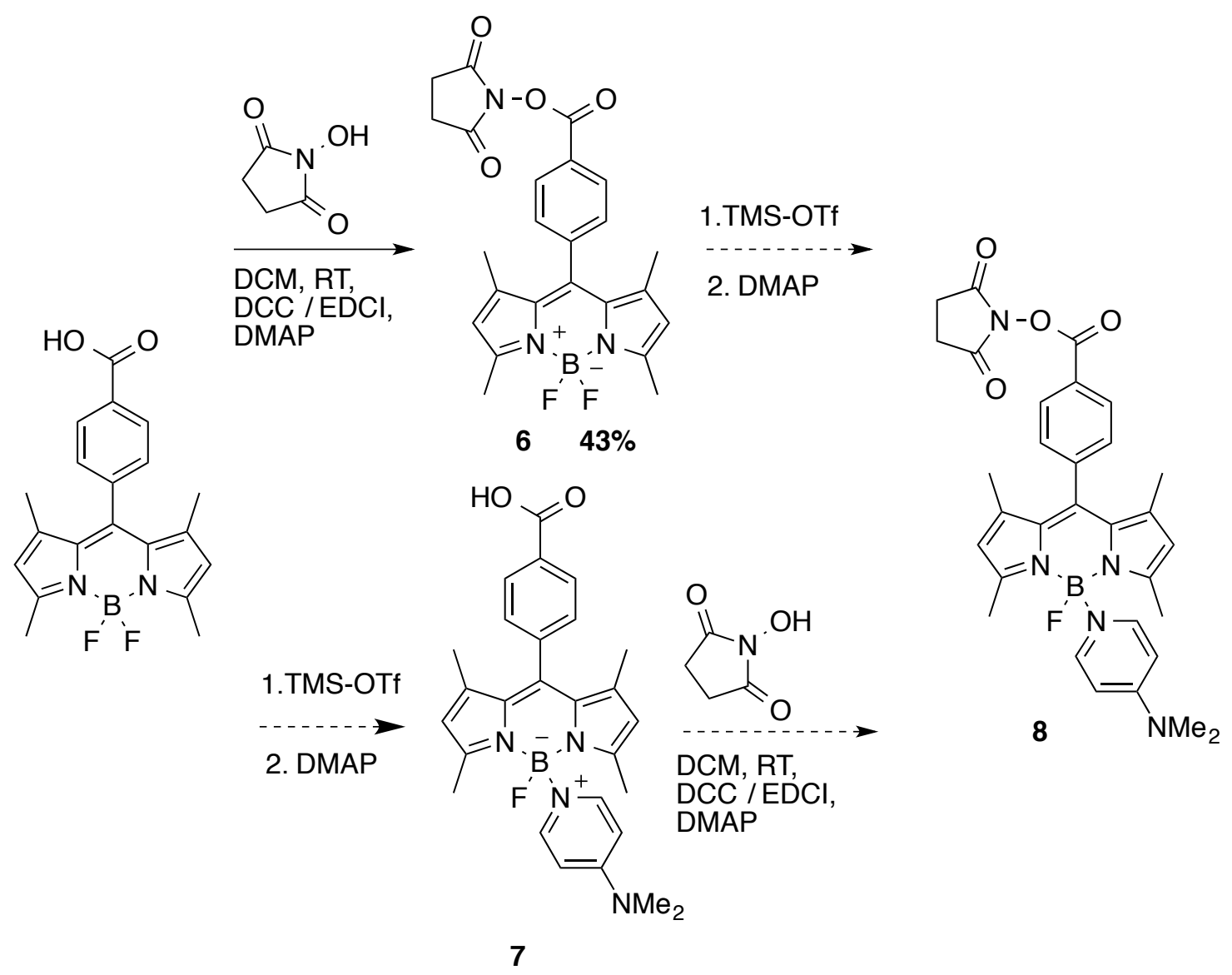

FIGURE 21: Unsuccessful attempt to synthesize a DMAP substituted and a NHS containing BODIPY scaffold for radiolabeling.

a methyl ester gave the N-BODIPY(F, DMAP) conjugate (11) in 37\% yield (Figure 23). With two prosthetic groups in hand we began to develop a radiolabeling protocol for the BODIPY scaffold.

To prepare the pentamethyl BODIPY $\left(F,{ }^{18} \mathrm{~F}\right)$ construct and the methyl benzoate BODIPY $\left(F,{ }^{18} \mathrm{~F}\right)$ adduct, the $\left[{ }^{18} \mathrm{~F}\right]$ fluorine and $\left[{ }^{18} \mathrm{O}\right] \mathrm{H}_{2} \mathrm{O}$ mixture produced via ${ }^{18} \mathrm{O}(\mathrm{p}, \mathrm{n}){ }^{18} \mathrm{~F}$ reaction was loaded onto an anion exchange resin. $\mathrm{A}$ mixture of water, $\mathrm{ACN}, \mathrm{K}_{2} \mathrm{CO}_{3}$, and $\mathrm{K}_{\text {2.2.2. }}$ was used to elute the $\left[{ }^{18} \mathrm{~F}\right]$ fluoride form the resin. Once eluted, the reaction mixture was heated to $110^{\circ} \mathrm{C}$ until dryness at which point 2 more azeotropic dry downs occurred using 1.0 mL ACN each. After 
the final dry down had completed, the mixture was then reconstituted in either 0.3 $\mathrm{mL}$ of $\mathrm{ACN}$ or $0.2 \mathrm{~mL}$ of $\mathrm{ACN}$ for use with the pentamethyl $\mathrm{N}$-BODIPY(F, DMAP) (4) construct or methyl benzoate N-BODIPY (F, DMAP) (11) construct. To develop appropriate labeling conditions and as a proof of concept, the pentamethyl construct 4 was first examined. The reconstituted mixture in $0.3 \mathrm{~mL}$ was further broken down into $0.1 \mathrm{~mL}$ aliquots so that conditions could be developed more quickly. After examining a variety of conditions (Table S-1) the best RCY (44\%) and RCP (93\%) was found by incubating the precursor in 0.1 $\mathrm{mL} \mathrm{ACN}$ with $\left[{ }^{18} \mathrm{~F}\right]$ fluoride for 20 minutes at $50^{\circ} \mathrm{C}$ (Figure 19). Furthermore, increasing the reaction times or increasing the temperature did not yield better result. Incubation with DMSO in place of ACN showed decreased yields as well (data not shown). Once the reaction was complete, it was heated to dryness at which point it was cooled to room temperature. Once at room temperature it was taken up in a minimal amount of dichloromethane (DCM) and injected onto a preconditioned (using a 2:1 mixture of DCM, hexanes) Silica Sep-Pak. The silica Sep-Pak captures unreacted $\left[{ }^{18} \mathrm{~F}\right]$ fluoride and the charged starting material 4. The overall charge neutral product (1) could be eluted cleanly with $5 \mathrm{~mL}$ of 2:1 DCM/hexanes mixture. Radio-HPLC was used prior to and after the Sep-Pak to confirm the identity of the radiolabeled product. Furthermore, RCY and RCP was calculated using radioTLC. The average synthesis time for pentamethyl $\operatorname{BODIPY}\left(F,{ }^{18} \mathrm{~F}\right) 1-{ }^{18} \mathrm{~F}$ was $1 \mathrm{hr}$. 
Due to a desire to eventually use this BODIPY construct for peptide labeling, it was necessary to translate our bench work into an Ekert \& Ziegler automated synthesis module. Initially, we employed the same method developed on the bench for the pentamethyl derivative (4) to the methyl benzoate derivative (11) inside the automated synthesis module. Several new constraints on the possible conditions which can used inside the synthesis module where however quickly apparent. Primarily, our Sep-Pak method had to be updated. Due to an inability to remove all the acetonitrile (and possible water condensate) under a reasonable amount of time separation mixtures using dichloromethane could not be used because no separation was observed. To overcome this shortcoming the Sep-Pak was preconditioned with pure ACN, and then also eluted with pure ACN as well. Using $6 \mathrm{~mL}$ of $\mathrm{ACN}$ was found to be optimal for eluting the labeled methyl benzoate construct (9-18F). However compared to the pentamethyl construct the Sep-Pak was less effective at separating the starting materials and unreacted $\left[{ }^{18} \mathrm{~F}\right]$ fluoride from the desired product. Furthermore, working on the bench with small volumes of tracer and precursor was quite easy, but due to the nature of the synthesis module larger volumes of solvent are required so that transfers can happen cleanly. The incubation of 11 with $\left[{ }^{18} \mathrm{~F}\right]$ fluoride, $\mathrm{K} 2.2 .2$, and $\mathrm{K}_{2} \mathrm{CO}_{3}$ in $\mathrm{ACN}$ at $35^{\circ} \mathrm{C}$ for 20 minutes gave a RCY of $40 \%$ with an average RCP greater than $93 \%$ (Figure S-36) . Chemical identity was determined via radioTLC and 
radioHPLC coinjection (Figure 22).

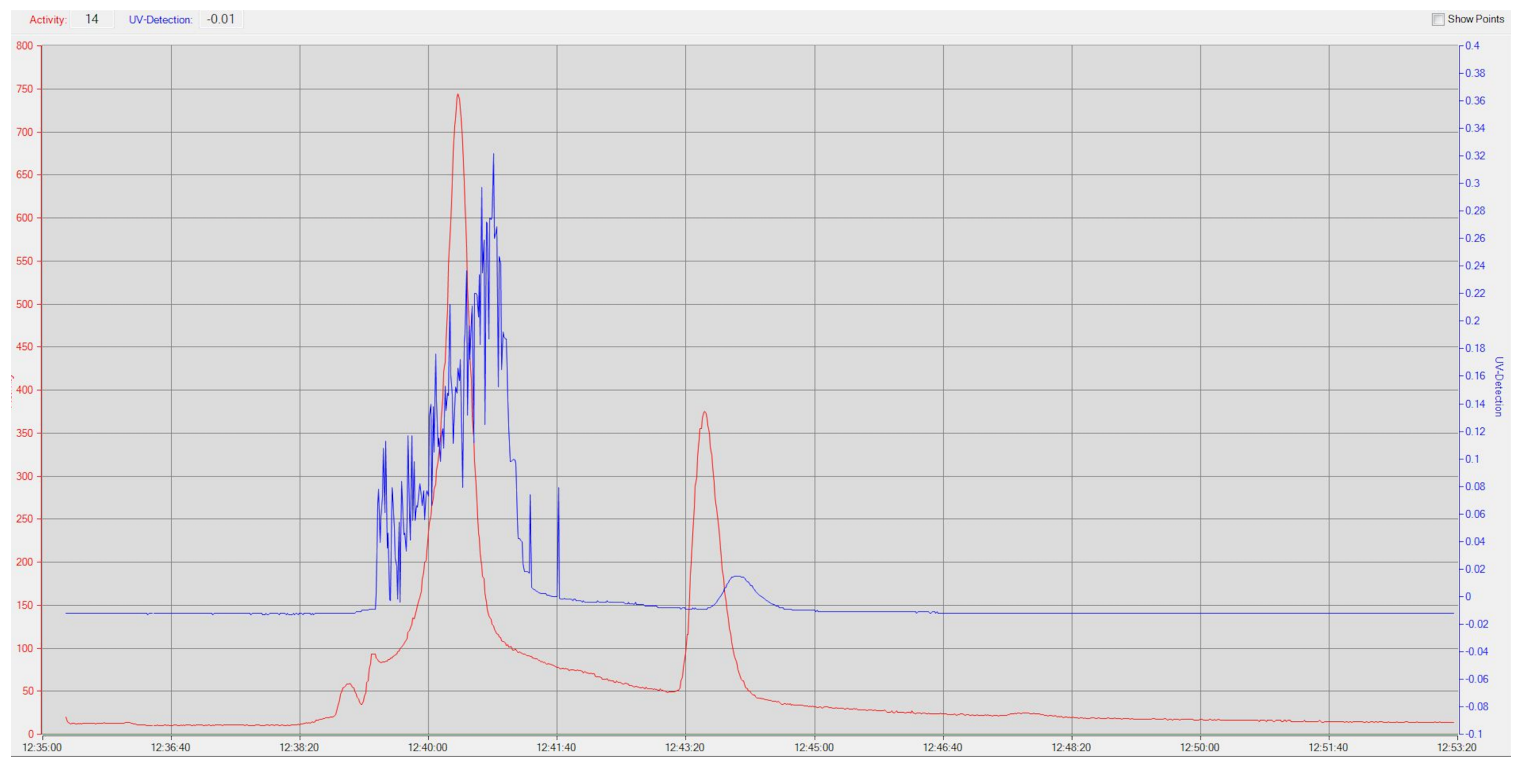

Figure 22: Coinjection of 8 Methy Ester BODIPY (F,F) cold standard with the crude reaction mixture from the radiolabeling containing the 8 Methy Ester $\operatorname{BODIPY}\left(F,{ }^{18} \mathrm{~F}\right)$ 


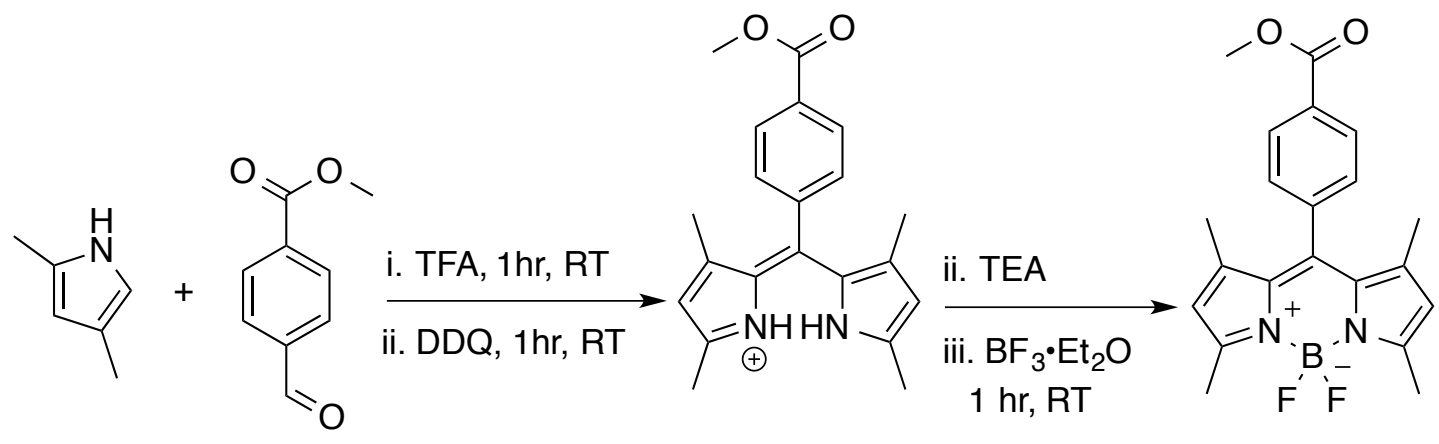

9

$41 \%$

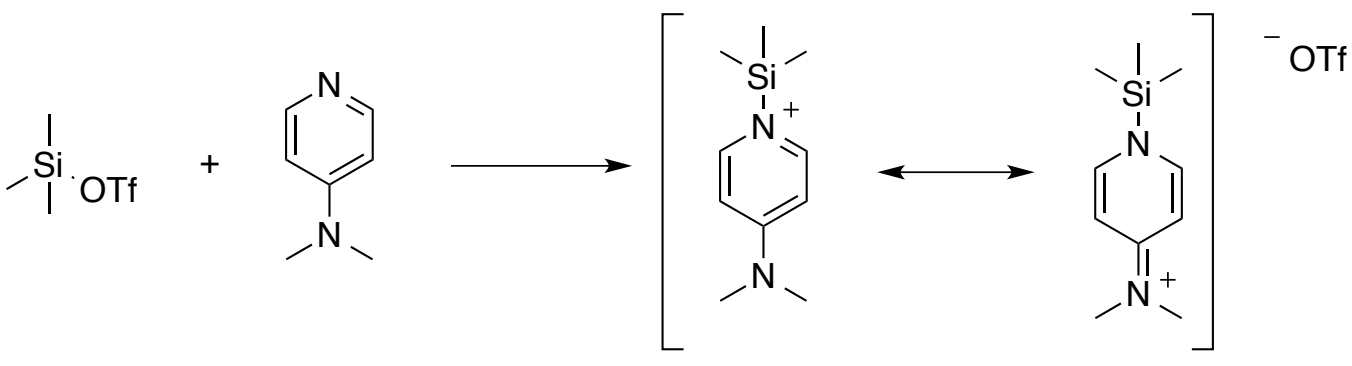

10

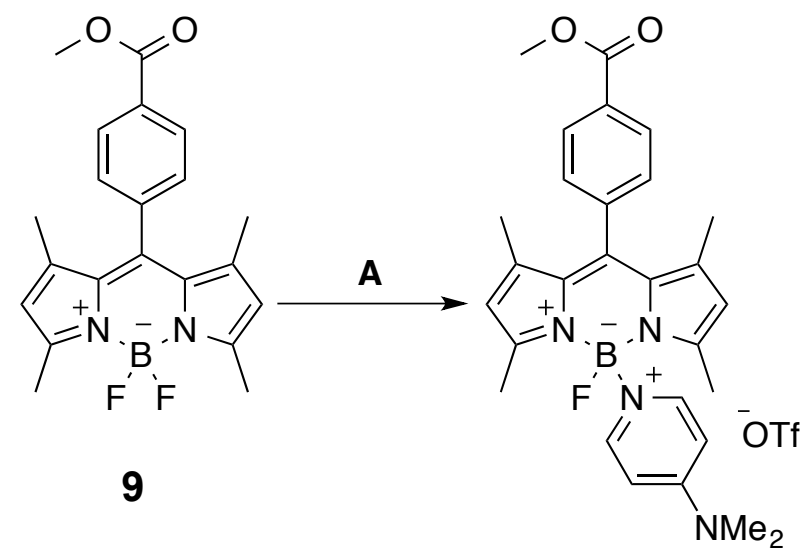

11

$37 \%$

Figure 23: Synthesis of N-BODIPY(F, DMAP) 4. Reagents and Conditions: (i) TFA, $1 \mathrm{hr}, \mathrm{RT}$ (ii) DDQ, 1hr, rt (iii) TEA and (iv) $\mathrm{BF}_{3} \mathrm{Et}_{2} \mathrm{O}$ combined for $1 \mathrm{hr}$ RT. 3 was then treated with prepared reagent $A$ to produce 4 . 


\section{CHAPTER IV}

\section{PHOTOREACTIVE BODIPYS FOR CAPTURE OF $\left[{ }^{18}\right.$ F]FLUORIDE}

\section{i. INTRODUCTION}

For fluorine-18 labeled peptides to be more broadly used in the scientific community several issues must be addressed. As previously discussed in earlier chapters, the presence of water greatly decreases the nucleophlicity of fluoride, and therefore necessitates the use of azeotropic drying steps to remove water from the reaction mixture ${ }^{69}$. This procedure is followed by a reaction, that links the $\left[{ }^{18} \mathrm{~F}\right]$ fluoride to a prosthetic group typically using harsh conditions. Finally, the prosthetic group can then be conjugated to the peptide of interest. Given the short half-life of fluorine-18 this multi-step approach is challenging ${ }^{69}$. Thus there has been renewed interest single-pot based methods for labeling peptides with fluorine-18 containing prosthetic groups. The goal for ${ }^{18} \mathrm{~F}$-tracers in this context should be to develop methods which provide tracers in high SA $\left(>1 \mathrm{Ci} \mu \mathrm{mol}^{-1}\right)$, good RCY, and high purity. Methods should also strive to eliminate time consuming azeotropic drying and HPLC purifications. Ideally, bioconjugation should be straightforward and if possible occur prior to any radiolabeling. A perfect or "Gold Standard" ${ }^{18} \mathrm{~F}$-tracer would meet all these requirements ${ }^{92}$.

A wide variety of different approaches have been developed to synthesize

and implement better ${ }^{18} \mathrm{~F}$-tracers. However the use of photochemical approaches has not yet been explored as a means to incorporate fluorine-18 into tracer 
molecules. Light induced deprotection via photolabile protecting groups (PPGs) has long been used as a means to release caged biological compounds, deprotect organic functional groups to facilitate easier synthesis schemes, induce polymerization, and activate small inorganic compounds ${ }^{98}$. PPG-based approaches have several advantages. Using the proper wavelengths PPGs are biocompatible and nondestructive toward many organic functional groups ${ }^{98}$. However, a survey of the current scientific literature finds no evidence of the use of PPGs, caged compounds, or photo-active compounds in the development of radiotracers.

\section{ii. APPLICATIONS OF PHOTOCHEMISTRY AND PHOTOBIOLOGY}

The use of light has a long and varied history in many disciplines across science. It is also one of the cleanest energy sources ${ }^{99}$. For many, their first experience with photochemistry comes in organic II learning about $2+2$ cycloadditions and Norrish reactions or in introductory biology learning about thymine dimers. In both instances light is the mechanism by which bonds can be formed, but for the purposes of this chapter we are more interested in mechanisms associated with the release of chemicals (i.e. bonds breaking). In the context of chemistry, light mediated deprotection of organic molecules was first developed in the 1960s. Later, light was also used by biologists to mediate the release of cyclic adenosine monophosphate (cAMP) and ATP. Essentially, 
the use of light (i.e. energy) as specific wavelengths allows research to control the spatial and temporal release of various compounds ${ }^{98}$.

Schofield discovered that a carboxybenzl (Cbz) group when attached to an amine containing compound could be cleaved using $254 \mathrm{~nm}$ light (Figure 24) ${ }^{100}$. This compound was developed as an orthogonal protecting group for

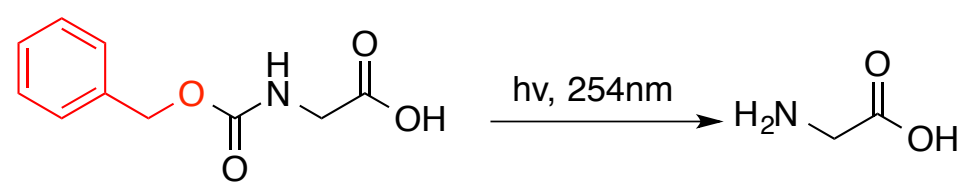

A<smiles>[R]C(=O)OCc1ccccc1[N+](=O)[O-]</smiles>

B<smiles>NC1=NC=NC2C1N=CN2C12COC1(O)OP(=O)(OCc1ccccc1[N+](=O)[O-])OC2</smiles><smiles>COP(=O)(O)OCC(O)(COP(=O)(O)CO)N1C=NC2C(N)=NCNC21</smiles>

Figure 24: Examples of (A) two commonly used PPGs and (B) the use of PPG to create a simple caged compound version of cAMP

amines. The same group was the o-nitrobenzyl based protecting group. This protecting group can be used to selectively deprotect carboxylic acid and amines in the presence of other protected functional groups (Figure 24) ${ }^{101}$. This protecting group has been used extensively in the literature, and many different 
derivatives of this basic scaffold have been investigated. Furthermore, some groups have even used this motif for the release of biologically relevant analytes. Just as PPGs have been used extensively in synthetic organic chemistry, we see similar widespread adoption in the biological community. One classic example reported by Schlaeger makes use of an o-nitrobenzyl group connected to cAMP. Upon irradiation with light the cAMP is released cleanly(Figure 24) ${ }^{102}$. The use of PPGs has also been expanded away from simple biological molecules, and have been developed as prodrugs for large biological macromolecules. For example, Lerner has described a method using 5'-(amethyl-nitro-piperonyl) oxy-carbonyl (MeNPOC) as PPG conjugated to insulin. The protected insulin prodrug show decreased activity in-vitro until irradiated with $365 \mathrm{~nm}$ light. Insulin's function is to regulate the metabolism of glucose in the body, and thus the PPG-Insulin molecule can be used to administer the correct dose (via photo deprotection) of insulin relative to changes in glucose levels. While the use of $365 \mathrm{~nm}$ light is suitable for use in in vitro applications PPGs which are activated at longer wavelengths will be required for this approach to be applied in vivo.

\section{iii. DESIGN CONSIDERATIONS FOR $\left[{ }^{18} \mathrm{~F}\right]$ FLUORIDE INCORPORATION ON THE BODIPY CORE.}

By examining the literature, we can begin to understand the different variables that must be considered in the context of PPGs ,and the relative importance of those parameters to the known the limitations of working with 
fluorine-18. The design parameters that must be considered can be broken down into two broad categories. First, chemical yields and ease of separation are essential. Ease of separation is especially important in the context of tracer development. While the nearly 2 hour half-life of fluorine- 18 does grant the user more time relative to carbon-11. The shortest purification process possible though is still highly desirable. The PPG should also not compete with the capture of $\left[{ }^{18} \mathrm{~F}\right]$ fluoride by the prosthetic group. Second, from a photochemical perspective the PPG while reactive should remain stable in the absence of light. Furthermore, the release of the PPG during irradiation from the prosthetic group should be fast, and the product of should be inert to additional photochemical related processes.

As described previously, multiple groups including work done by the Glass group have demonstrated that the BODIPY core can be used to incorporate $\left[{ }^{18} \mathrm{~F}\right] \mathrm{fluoride}$ under the appropriate conditions. However, as described by Perrin, the current methods all have potential shortcomings that will lead to a decreased adoption of the BODIPY core for tracer purposes. The biggest shortcoming is a reliance on either unstable intermediates and/or harsh reaction conditions to make the BODIPY core amenable to $\left[{ }^{18} \mathrm{~F}\right]$ fluoride incorporation. Those issues also mean that conjugation of a peptide to the BODIPY core prior to radiolabeling is not possible. Under the appropriate conditions, the deprotection of PPGs can be mild and quick. Furthermore, many of the current protecting groups do not cause side reactions and can be removed on timescales amenable to the 2 hour 
half-life of fluorine-18. As noted previously, methods of substituting at the boron of the BODIPY core are known although they are limited. Furthermore, in the patent literature Nagano et al described a method whereby a phenol derivative on the boron of a BODIPY core could be dissociated using light ${ }^{103}$. As it is a patent, other relevant data (time, wavelengths, and side products) were not disclosed.

By Examining the PPG literature one will find various mechanisms by which photocleavage occurs. However, mechanisms involving the generation of radicals are the most common. While the mechanism of this deprotection is unknown and has not been studied extensively, we can find some clues in the literature. A series of reports in the literature from groups led by Daub and Nagano have begun to probe some of the different mechanisms whereby the fluorescence properties of the BODIPY scaffold can be modulated. The BODIPY core can be divided into 3 distinct regions. The first two regions groups off the 8position of the BODIPY core, and the fluorine atoms attached to boron are orthogonal from the third region which is the BODIPY scaffold itself (Figure 7). The work done by these two groups has focused on focus on the orthogonal nature of the benzene moiety and not the nature of the boron substituents. However both regions are orthogonal to the BODIPY core so the methods by which these regions interact with light should be related. Both groups found that PeT (photoinduced electron transfer) based mechanisms are responsible for changes in fluorescences ${ }^{30,104}$. PeT is a process whereby an electron is 
transferred from a donor moiety into that of fluorophore. The name of this mechanism is based on the origin of the electron. In donor PeT (d-PeT) the excitation of an electron from the fluorophore creates an half-empty orbital in the HOMO of fluorophore that is then filled by the HOMO of a nearby donor. Acceptor-PeT (a-PET) is a related process, where excitation of the fluorophore promotes an electron into the LUMO which can transfer in the LUMO of the acceptor. Both processes can cause fluorescent quenching. Results presented by Nagano and Daub demonstrate that the PeT mechanism does occur between the benzene moiety and the BODIPY moiety ${ }^{105,106}$. Furthermore, the PeT based ON/OFF fluorescence mechanism is shown to be quite sensitive to differences in solvent polarity ${ }^{106}$.

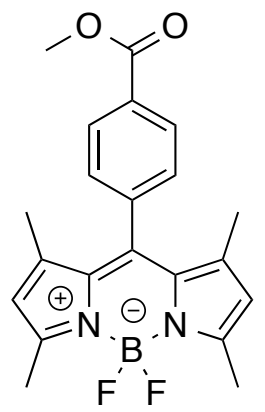

9
1. $\mathrm{AlCl}_{3}, 30$ mins, $\mathrm{RT}$

2. o-nitrobenzylalcohol 10mins, RT

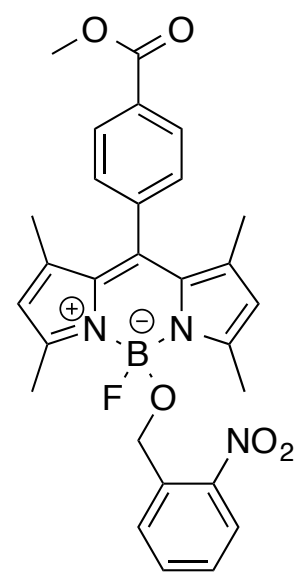

12

$17 \%$

Figure 25: Synthesis of a o-nitrobenzyl alcohol derivative of BODIPY

iv. DEVELOPING THE BODIPY CORE FOR $\left[{ }^{18} \mathrm{~F}\right]$ INCORPORATION 
As described above several reports and a patent indicated that the BODIPY core may be amenable to photolability of substituents on the boron. Using known literature methods we made two different BODPIPY scaffolds one containing a phenyl at the 8-position and second containing a phenyl methylbenzoate at the 8-position. Based on the patent published by Nagano and a second publication by Hibert, it was known that substitutions for fluorine could be made on the BODIPY core by using the lewis acid $\mathrm{AlCl}_{3}{ }^{31}$. Initially using the methyl benzoate derivative and $\mathrm{AlCl}_{3}$ we obtained the $\mathrm{O}$-BODIPY $(\mathrm{F}, \mathrm{O}-$ Nitrobenzyl) (12) in low yields (Figure 25). Once the O-BODIPY(F,o-Nitrobenzyl) was in hand several attempts where made to induce fluorine incorporation under cold conditions with excess amounts of fluorine. The o-nitrobenzyl PPG is well known to work well with wavelengths less than $320 \mathrm{~nm}$, and thus could be excited without exciting the BODIPY core itself. Using a Rayanette based light source producing 254nm light, and several different solvents it was not possible discern the formation of the BODIPY $(F, F)$ product (Figure 26). Furthermore, no major product was able to be detected from the reactions; instead the dye and the PPG decomposed under these conditions. These results indicate that the flux of photons (and perhaps the associated heat) produced by the Rayanette is too strong for this system. Next we attempted to use a milder LED based light source which produced broad spectrum $313 \mathrm{~nm}$ light under similar conditions. Upon irradiation of the scaffold using $\mathrm{KHF}_{2}$ we saw small amounts of incorporation fluoride anion, but these results where difficult to repeat due the presence of 
trace amounts of difluoro BODIPY in the starting material. We also where concerned by the use of $\mathrm{KHF}_{2}$ would create acidic conditions since a report in the

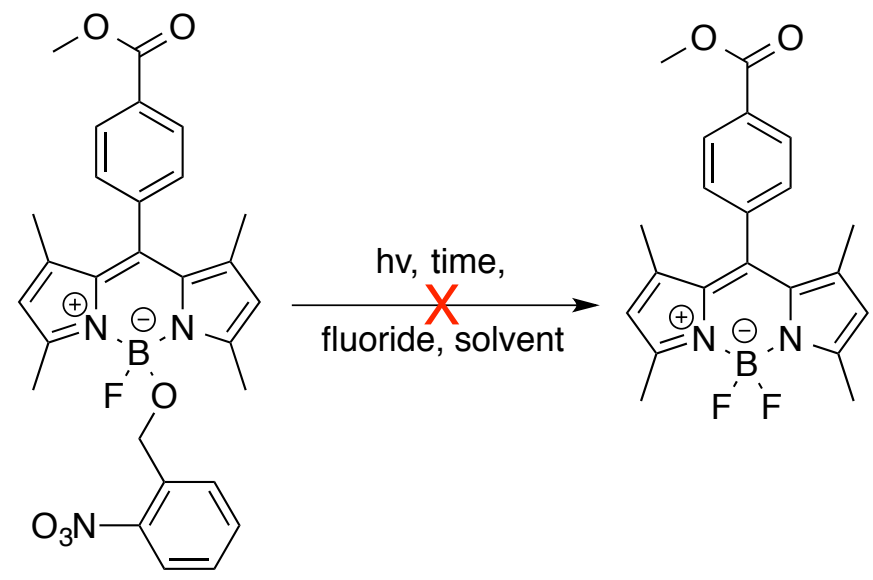

\begin{tabular}{|cccccc|}
\hline & TIME & $\lambda_{\text {EX }}$ & SOVENT & F-SOURCE & RESULT \\
\hline 1 & 10 mins & $254 \mathrm{~nm}$ & $\mathrm{ACN}$ & $\mathrm{KHF}_{2}$ & Decomposition \\
\hline 2 & $5 \mathrm{mins}$ & $254 \mathrm{~nm}$ & $\mathrm{ACN}$ & $\mathrm{KHF}_{2}$ & Decomposition \\
\hline 3 & $5 \mathrm{mins}$ & $254 \mathrm{~nm}$ & $\mathrm{MeOH}$ & $\mathrm{KHF}_{2}$ & Decomposition \\
\hline 4 & $5 \mathrm{mins}$ & $254 \mathrm{~nm}$ & $\mathrm{ACN}$ & $\mathrm{TBAF}$ & Decomposition \\
\hline 5 & $10 \mathrm{mins}$ & $310 \mathrm{~nm}$ & $\mathrm{ACN} / \mathrm{H}_{2} 0$ & $\mathrm{KHF}_{2}$ & $\begin{array}{c}\text { Small Product } \\
<5 \%\end{array}$ \\
\hline 6 & $10 \mathrm{mins}$ & $310 \mathrm{~nm}$ & $\mathrm{DCM}$ & $\mathrm{TBAF}$ & No Product \\
& & & & & \\
\hline
\end{tabular}

Figure 26: Summary of reaction conditions used to induce fluorine incorporation on the Methyl Ester BODIPY (9).

literature that demonstrated that metathesis of fluorine atoms on the BODIPY core is possible ${ }^{91}$. We also tested this compound using TBAF as an organic 
fluoride source, and we did not see product after ten minutes of irradiation using $313 \mathrm{~nm}$ light.
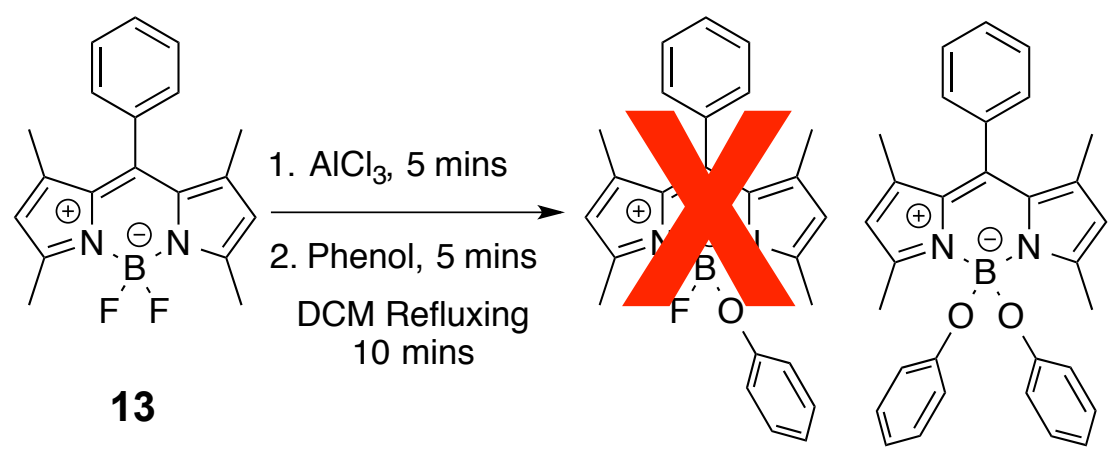

14<smiles>CC1=CC(C)=NC1=C(c1ccccc1)c1c(C)cc(C)n1CF</smiles>

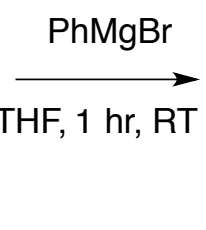

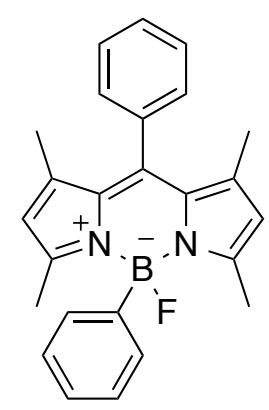

15

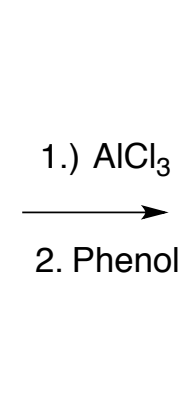

(1)

16

Variable

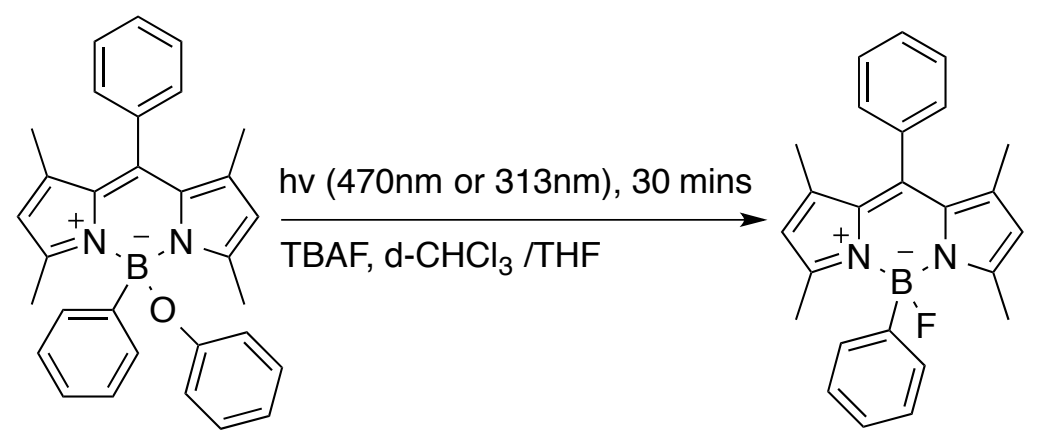

16

15

Figure 27: Synthesis of disubstituted phenol containing BODIPY derivatives.

Concurrently, we where working on developing a BODIPY scaffold which contained a phenol derivative based on the Nagano patent. We also hoped to address concerns of the presence of cold fluoride by using a disubstituted 
BODIPY core that possesses no intrinsic fluorine. Using the method first demonstrated by Hibert we attempted to make a monosubstituted $O$ BODIPY(F,Phenol) which we later hoped to covert into a C,O-BODIPY(Phenyl, Phenol). This synthetic route did not prove fruitful because the sole product of the reaction of the 8-Phenyl BODIPY with $\mathrm{AlCl}_{3}$ in the presence of equimolar amounts of phenol only yielded the disubstituted O,O-BODIPY(Phenol,Phenol) 14 (Figure 27). However, the $C, O-B O D I P Y(P h e n y l$, Phenol) derivative could be produced by first installing the phenyl group via the corresponding Grignard reaction, 15. Following subsequent purification, the dye was then subjected to treatment with $\mathrm{AlCl}_{3}$ and Phenol which yielded the disubstituted $C, O-$ BODIPY(phenyl, phenol) (16) in variable yields. After purification of the dye, we then subjected it to variety of different of photolysis conditions. Initially we subjected this dye to photolysis conditions using the $313 \mathrm{~nm}$ light as we had done previously with the O-BODIPY $(\mathrm{F}, O$-nitrobenzyl) derivative. Under these conditions we saw clear capture of fluorine in the ${ }^{19} \mathrm{~F}-\mathrm{NMR}$, but based on changes in the vinyl protons on the BODIPY core even with excess amounts of fluoride the reaction was not complete. Furthermore the ${ }^{19} \mathrm{~F}-\mathrm{NMR}$ clearly demonstrates the presence of unknown fluorine containing side products (Figure 28). Next we tested the difference in light sources also provides some interesting insights. The $313 \mathrm{~nm}$ light source will clearly excite the phenol chomophore, and the $465 \mathrm{~nm}$ light source will excite only the BODIPY core. The initial data demonstrates that exciting the BODIPY core leads to better incorporation of fluorine-19 (Figure 28). 
To further enhance the capture of fluorine another light source was constructed using $465 \mathrm{~nm}$ light as well, but which produced an increased flux (7-fold increase over the first generation). Using the same condition as before but using only half an equivalent TBAF the new light source increased the overall fluoride incorporation. Some significant side products can be seen in the ${ }^{19} \mathrm{~F}-\mathrm{NMR}$ as well. Interestingly, the vinyl protons seem to indicate complete consumption of the starting material even though less than a full equivalent of TBAF was provided to the reaction mixture. With these results in hand though we felt confident that our BODIPY scaffold was ready to be tested under $\left[{ }^{18} \mathrm{~F}\right]$ fluoride based radiolabeling conditions.

To further flush out the results, we developed a series of disubstituted BODIPYs all of which contain the phenyl moiety but varied the phenol type. We chose a $p$-methoxyphenol and $p$-fluorophenol as good substrates because of their differences in electron density (Figure 29). Furthermore, we began to investigate radiolabeling conditions which would be required for fluorine-18 incorporation. After bombardment of the target, a mixture of $\left[{ }^{18} \mathrm{O}\right] \mathrm{H}_{2} \mathrm{O}$ and $\left[{ }^{18} \mathrm{~F}\right]$ fluoride was loaded onto an anion exchange resin. It was then eluted with a mixture of water, $\mathrm{K}_{2} \mathrm{CO}_{3}$ and acetonitrile from the resin. Following three total azeotropic dry downs each being reconstituted with acetonitrile. After the third dry down, the disubstituted BODIPY was added to the reaction mixture and incubated with light $(470 \mathrm{~nm})$ for 20 minutes at $25^{\circ} \mathrm{C}$ (Figure 30). Using coinjection with the cold standard to prove the identity of the radiofluorinated 
product we did see that $\left[{ }^{18} \mathrm{~F}\right]$ fluoride incorporation into BODIPY scaffold was possible (Figure 31). Based on the initial results the C,O-BODIPY (Phenyl, Phenol) was able to be labeled in $20 \% \mathrm{RCY}$, and the C,O-BODIPY (Phenyl, paramethoxy phenol) was able to be in done $10 \%$ RCY. 

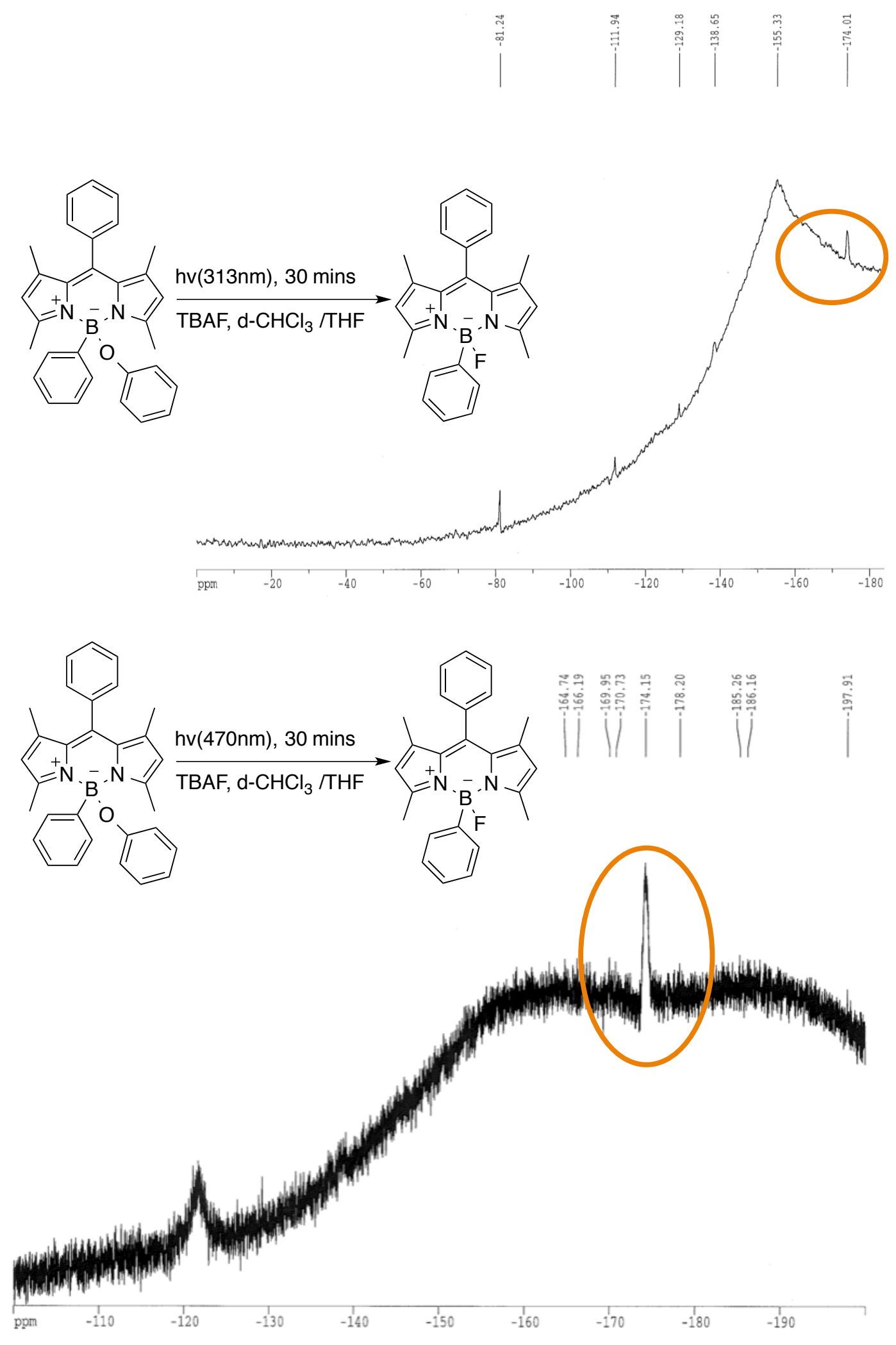

Figure 28: Fluorine-19 spectra from the irradiation of $C, O$-BODIPY(Phenyl, Phenol) with both $313 \mathrm{~nm}$ light and $470 \mathrm{~nm}$ light. 


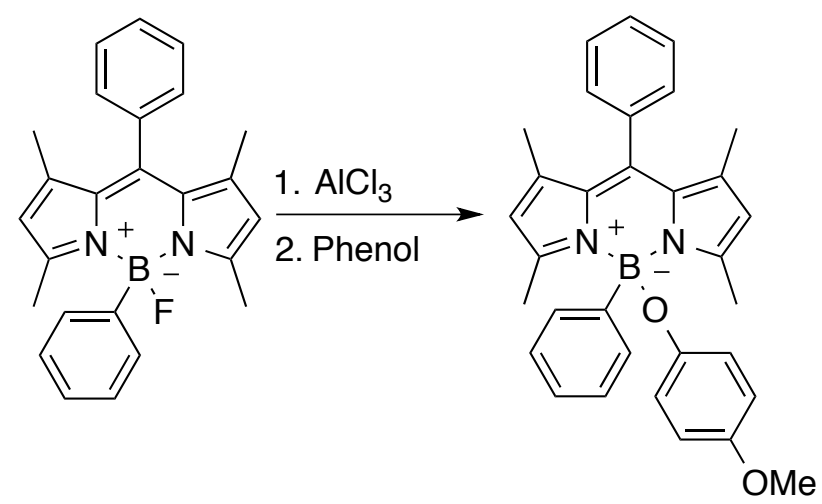

17

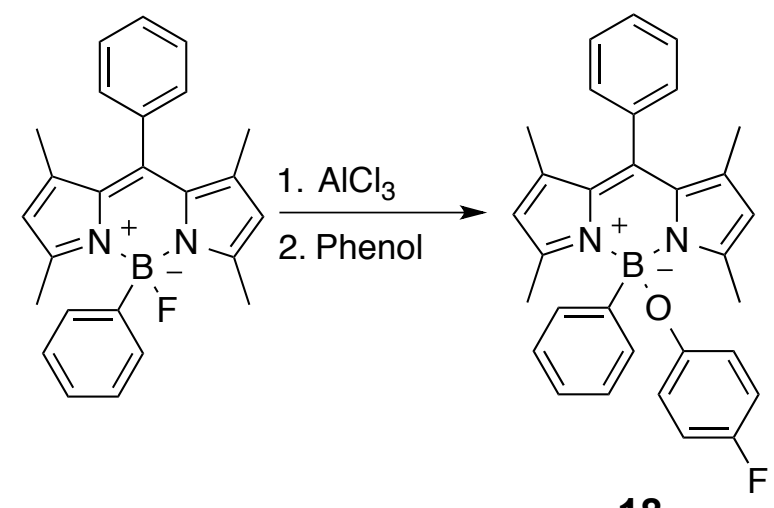

18

Figure 29: Synthesis of two different disbustituted $C, O$-BODIPYs

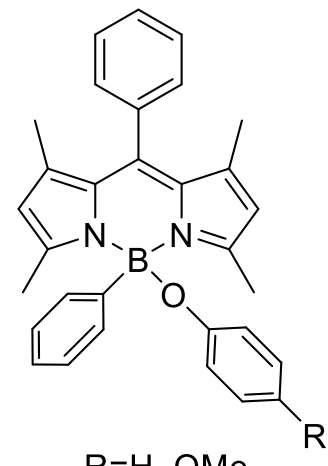

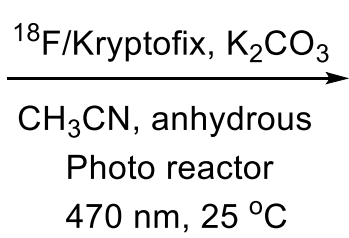

$\mathrm{R}=\mathrm{H}, \mathrm{OMe}$

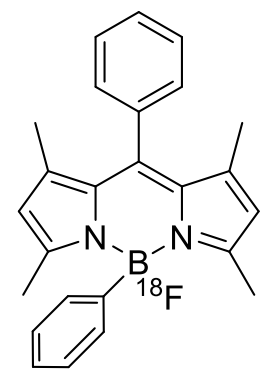

14-18F

16,17

Figure 30: Radiofluorination conditions used label the C,O-BODIPY derivate. 


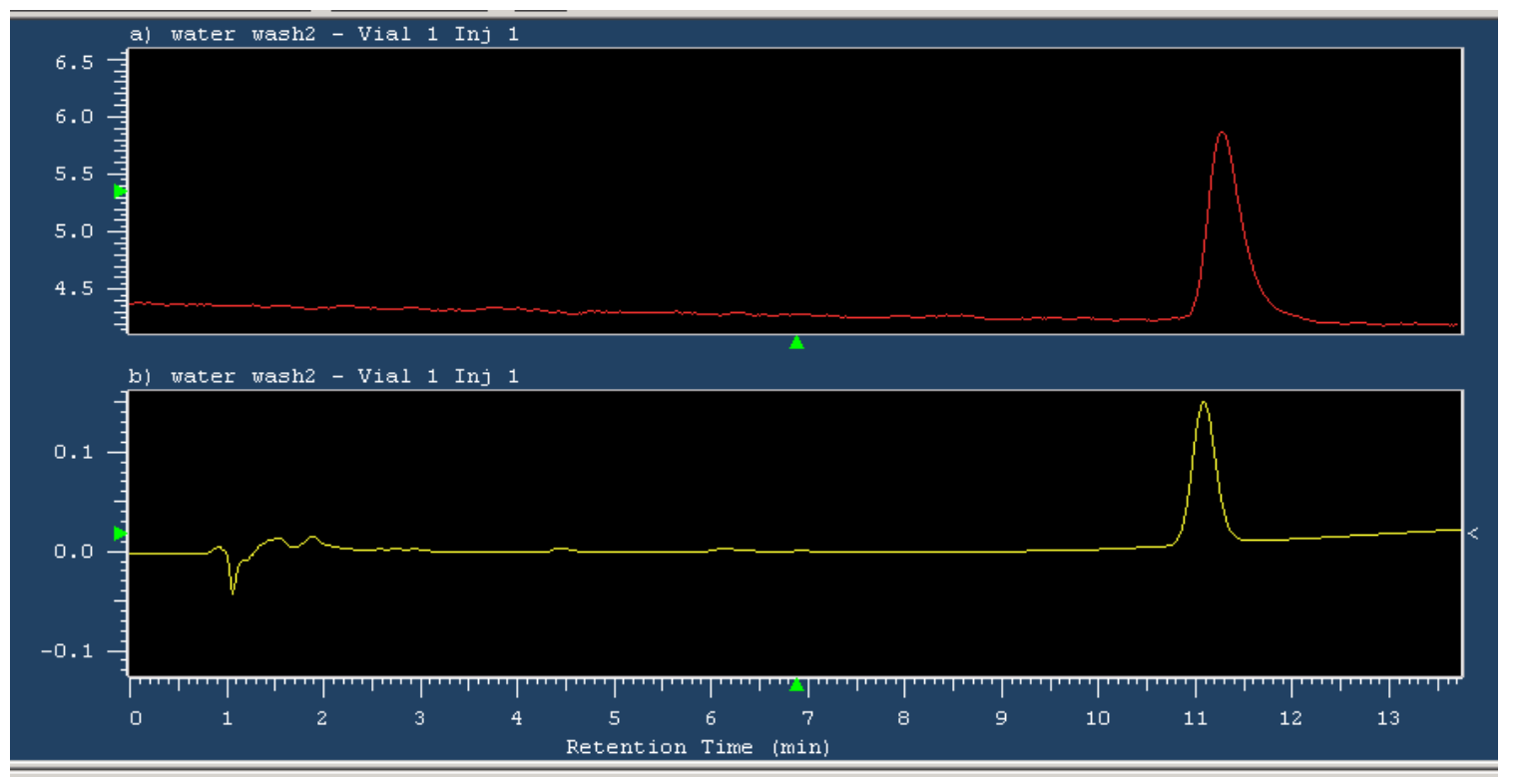

Figure 31: Semi-prep HPLC separated fraction co-injected with reference C,O-BODIPY (Phenyl, Phenol) compound. Radiometric Channel (Top) and UV Channel (Bottom)

\section{v. RESULTS AND CONCLUSTIONS}

Based on the current examples of dual modality (PET / fluorescence) probes found in the literature we can still find a need for a mild methods for fluorine-18 incorporation. Preferably, the incorporation of fluorine-18 would happed after probe has be conjugated to a peptide. Looking closely at the boronbased fluorine-18 incorporation published literature and the work done by the Glass group a few trends do emerge. Isotopic exchange based reaction have been developed by Conti and Perrin ${ }^{51,92}$. Furthermore, both groups have reported high specific activity, but the problem remains that isotopic exchange is still fundamentally a carrier added approach to fluorine-18 incorporation. Other 
approaches demonstrated by Conti, Weisselder, and the Glass group take advantage of an activated BODIPY core. The $\mathrm{N}$-BODIPY(F,DMAP) based method does allow for incorporation of fluorine-18 in a no carrier added method, but the DMAP substitution makes the BODIPY core unstable. This instability and current synthetic limitations means that the BODIPY can not be conjugated to a peptide prior to fluorine-18 incoporation ${ }^{88,89}$. To overcome this obstacle we began to develop the photolabile series of BODIPY dyes. To date, we have demonstrated that a photolabile BODIPY core bearing phenol derivatives can be used incorporate fluorine-18. 


\section{APPENDIX}

\section{Material and Methods}

All reagents, chemicals, and solvents were purchased from Sigma Aldrich (St. Louis, MO) or Acros Organics (Geel, Belgium). All solvents used were either distilled or used in an unchanged state. Radiochemical separations were carried out using a Waters ${ }^{\circledR}$ Silica SepPak or a Silica SepPak Plus (Milford, MA). All $\operatorname{NMR}(250,300$, and $500 \mathrm{MHz})$ Spectra $\left({ }^{1} \mathrm{H},{ }^{13} \mathrm{C},{ }^{19} \mathrm{~F}\right)$ where collected using a Bruker Spectrometer (Bruker Biospin Corp., Billerica, MA). Furthermore, ${ }^{1} \mathrm{H}-\mathrm{NMR}$ spectra taken in $\mathrm{CDCl}_{3}$ are reported relative to $7.26 \mathrm{ppm}$, and ${ }^{13} \mathrm{C}-\mathrm{NMR}$ spectra are reported relative to the peak at $77.0 \mathrm{ppm} .{ }^{1} \mathrm{H}-\mathrm{NMR}$ spectra taken in $\mathrm{CD}_{2} \mathrm{Cl}_{2}$ are reported relative to $5.32 \mathrm{ppm}$, and ${ }^{13} \mathrm{C}$ NMR spectra are reported relative to the peak at $54.0 \mathrm{ppm} .{ }^{19} \mathrm{~F}$ NMR spectra are referenced relative to an external standard $\mathrm{CFCl}_{3}$. Analytical HPLC for cold standards was carried out using an HPAgilent HPLC System. A Zorbax C8 (250 mm x 4.6 mm, 5 m) or Zorbax C8 (150 $\mathrm{mm} \times 4.6 \mathrm{~mm}, 5 \mu \mathrm{m}$ ) analytical column was used for all separations. RadioHPLC was done on an ISSCO HPLC system using a Bioscan ${ }^{\circledR}$ detector, in an Eckert \& Ziegler automated synthesis module (with a built in radiodetector), or a Waters ${ }^{\circledR}$ HPLC using a Bioscan ${ }^{\circledR}$ detector. RadioTLC was carried out with a Bioscan ${ }^{\circledR}$ AR2000 or via autoradiography using a $\mathrm{GE}^{\circledR}$ Typhoon. Several different HPLC methods where developed for this project; method A was $70 \%$ ACN with Water 
containing $0.1 \%$ TFA; Method B was $65 \%$ ACN in Water; Method C was $75 \%$ $\mathrm{ACN}$ in water.

\section{Light Source}

A series of different light sources were used for the photolysis experiments

- 254 nm Rayanette Light Source

- 310 nm LED Light Source

- 465 nm Blue LED Light Source (6000 Lumens)

- 465 nm Blue LED Light Source (42000 Lumens)

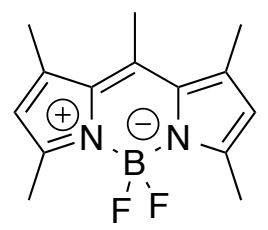

Pentamethyl BODIPY (F, F) 2,4 dimethyl pyrrole $(0.740 \mathrm{~g}, 7.78 \mathrm{mmol})$ was added to acetyl chloride $(0.306 \mathrm{~g}, 3.9 \mathrm{mmol})$ in anhydrous dichloromethane $(100 \mathrm{~mL})$. The reaction mixture was refluxed for 12 hours, and then triethylamine $(8.0 \mathrm{~mL}$, $57.30 \mathrm{~g} \mathrm{mmol})$ was added followed by $\mathrm{BF}_{3}$-etherate $(16.0 \mathrm{~mL}, 15.04 \mathrm{mmol})$. The reaction mixture was then stirred for 4 additional hours at room temperature. The solvent was then removed in vacuo, and the resulting residue was extracted two times with water and dichloromethane. The organic layer was dried over sodium sulfate. After evaporation, the crude mixture was purified by column chromatography on silica (2:1 Hexanes/Dichloromethane) to give a red powder 
(0.342 g, 33\%). M.P. $208^{\circ} \mathrm{C} ;{ }^{1} \mathrm{H}$ NMR $\left(\mathrm{CD}_{2} \mathrm{Cl}_{2}, 500 \mathrm{MHz}\right): \delta=6.09(\mathrm{~s}, 2 \mathrm{H}), 2.58$ (s, 3H), $2.47(\mathrm{~s}, 6 \mathrm{H}), 2.42(\mathrm{~s}, 6 \mathrm{H}) ;{ }^{13} \mathrm{C} \mathrm{NMR}\left(\mathrm{CD}_{2} \mathrm{Cl}_{2}, 125 \mathrm{Mhz}\right): \delta=153.78$, $142.33,141.78,132.36,121.50,121.47,17.42,16.71,15.77,14.50,14.48 ;{ }^{19} \mathrm{~F}$ $\operatorname{NMR}\left(\mathrm{CDCl}_{3}, 250 \mathrm{MHz}\right) \delta=-146.65,-146.79,-146.93,-147.05\left(\mathrm{q}, \mathrm{B}-\mathrm{F}_{2},{ }^{1} \mathrm{~J}=35\right.$ $\mathrm{hz})$

1H Proton | d-dichloromethane

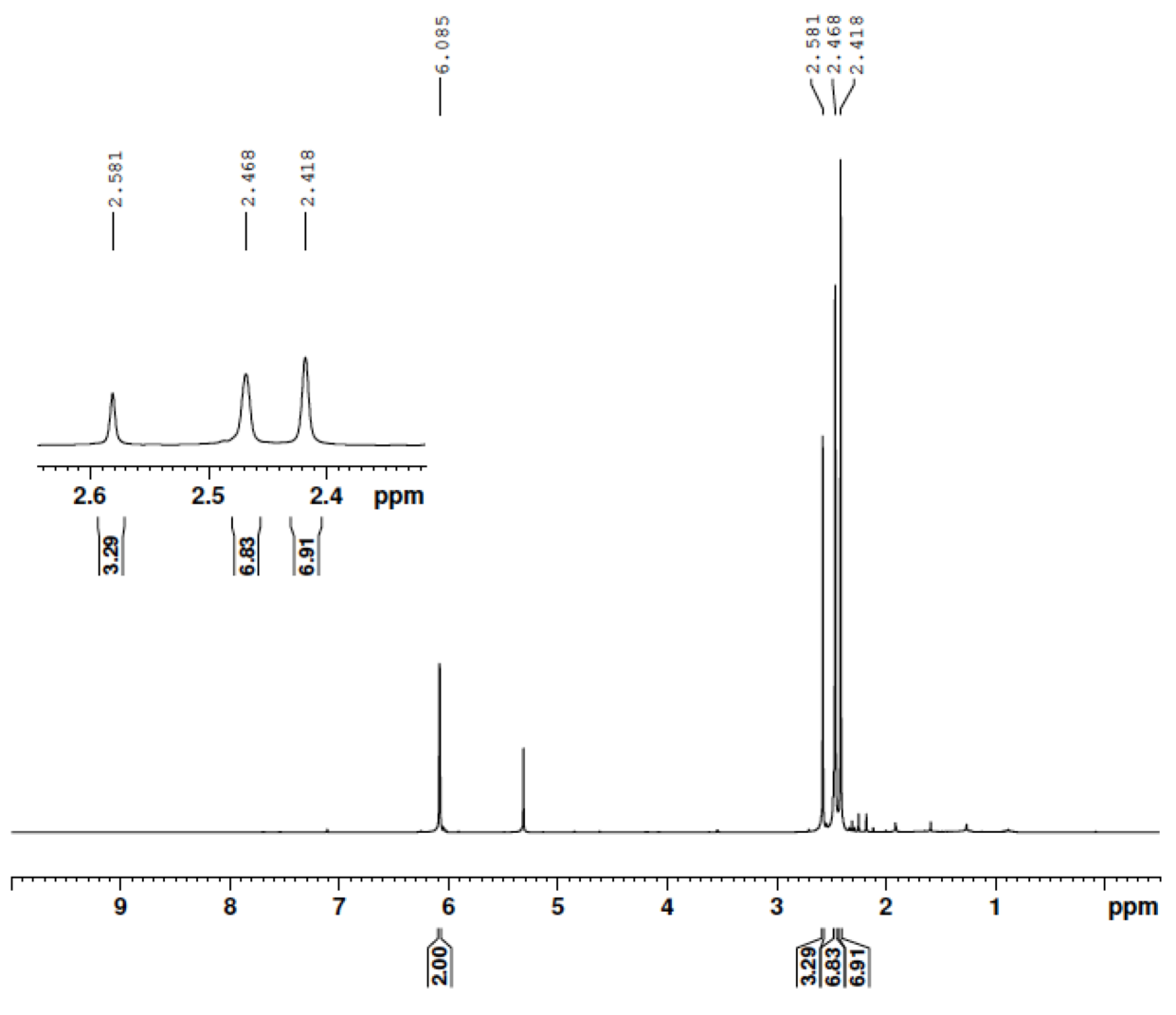




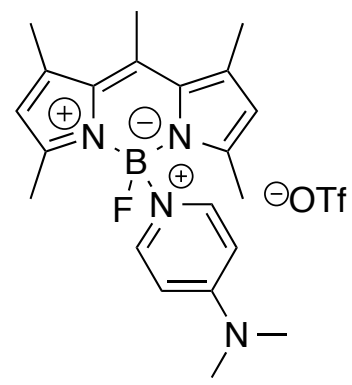

N-Pentamethyl BODIPY (F, DMAP) Pentamethyl BODIPY (0.0766 g, 0.292 mmol) was mixed with dichloromethane, and then TMS-OTf was added $(0.1 \mathrm{~mL}$, $0.584 \mathrm{mmol})$. The reaction mixture was stirred for 15 minutes, and then DMAP $(0.0902 \mathrm{~g}, 0.731 \mathrm{mmol})$ was added. The reaction was stirred for 10 additional minutes at which the point the solvent was removed. The crude material was extracted with water then dried over sodium sulfate, and after reducing the volume. The pure product was crashed out via precipitation with cold hexanes as a orange powder $(0.0960 \mathrm{~g}, 90 \%)$. M.P. $143{ }^{\circ} \mathrm{C}$ (decomposed); ${ }^{1} \mathrm{H} \mathrm{NMR}\left(\mathrm{CD}_{2} \mathrm{Cl}_{2}\right.$, $500 \mathrm{MHz}): \delta=7.89\left(\mathrm{~d},{ }^{3} \mathrm{~J}=6.9 \mathrm{~Hz}, 2 \mathrm{H}\right), 6.74\left(\mathrm{~d},{ }^{3} \mathrm{~J}=7.5 \mathrm{~Hz}, 2 \mathrm{H}\right), 6.15(\mathrm{~s}, 2 \mathrm{H})$, $3.18(\mathrm{~s}, 6 \mathrm{H}), 2.73(\mathrm{~s}, 3 \mathrm{H}), 2.50(\mathrm{~s}, 6 \mathrm{H}), 2.14(\mathrm{~s}, 6 \mathrm{H}) ;{ }^{13} \mathrm{C} \mathrm{NMR}\left(\mathrm{CD}_{2} \mathrm{Cl}_{2}, 125 \mathrm{Mhz}\right)$ : $\delta=156.95,154.43,144.53,143.87,142.04,142.00,132.86,123.32,107.60$ 40.28, 17.67, 17.12, 14.79, 14.76; ${ }^{19} \mathrm{~F} \mathrm{NMR}\left(\mathrm{CDCl}_{3}, 250 \mathrm{MHz}\right) \delta=-78.95$ (-OTf), $-167.53,-167.96,-167.86,-168.02(q, J=37 \mathrm{~Hz})$; IR (neat) $=3064.25 \mathrm{~cm}^{-1}$, 2958.00, 2921.23, 1535.38, 1495.12, 1298.98, 1192.74 ( MS, $\mathrm{m} / \mathrm{z}\left(\mathrm{M}^{+}\right): 365.0$ 


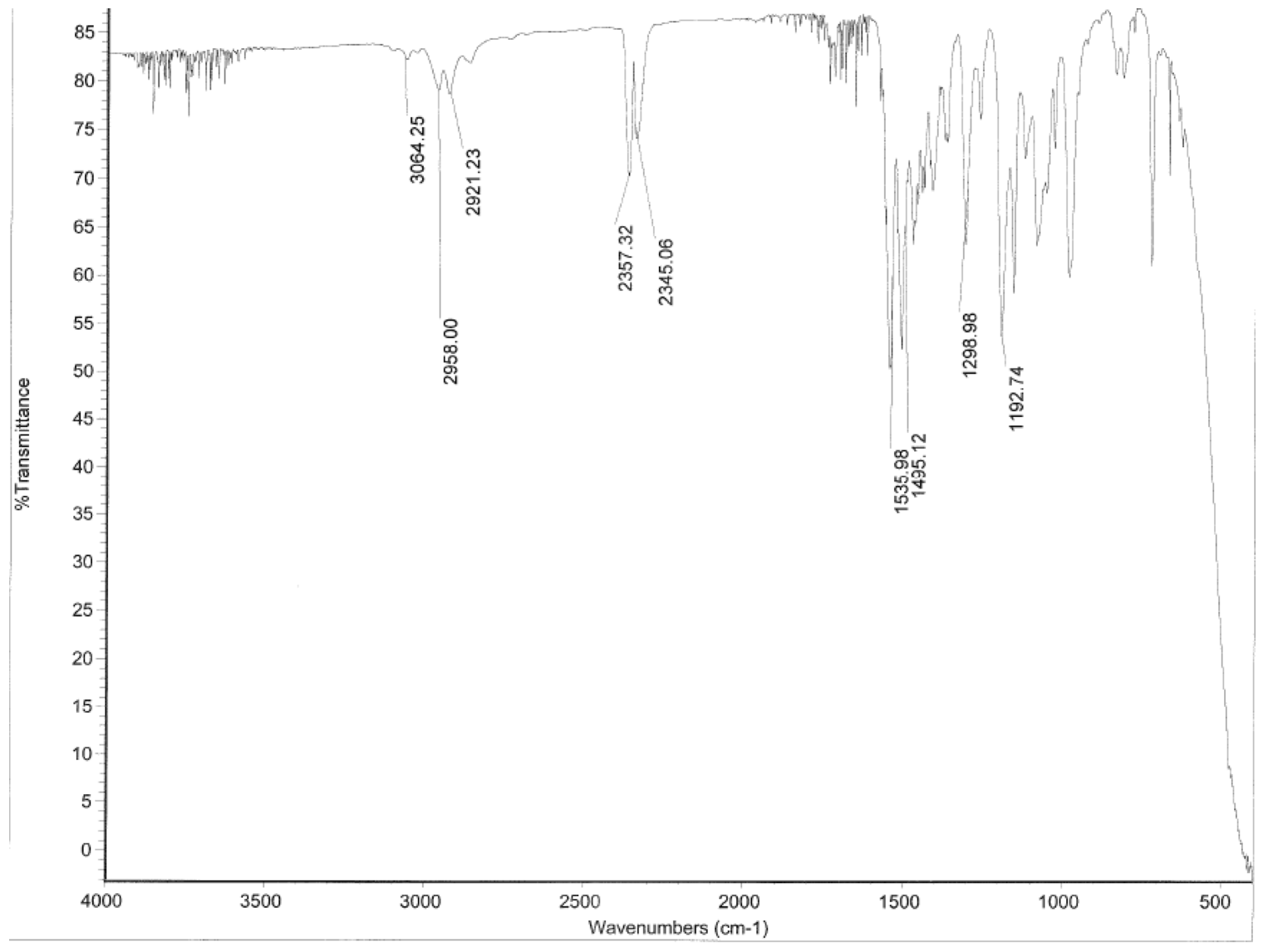



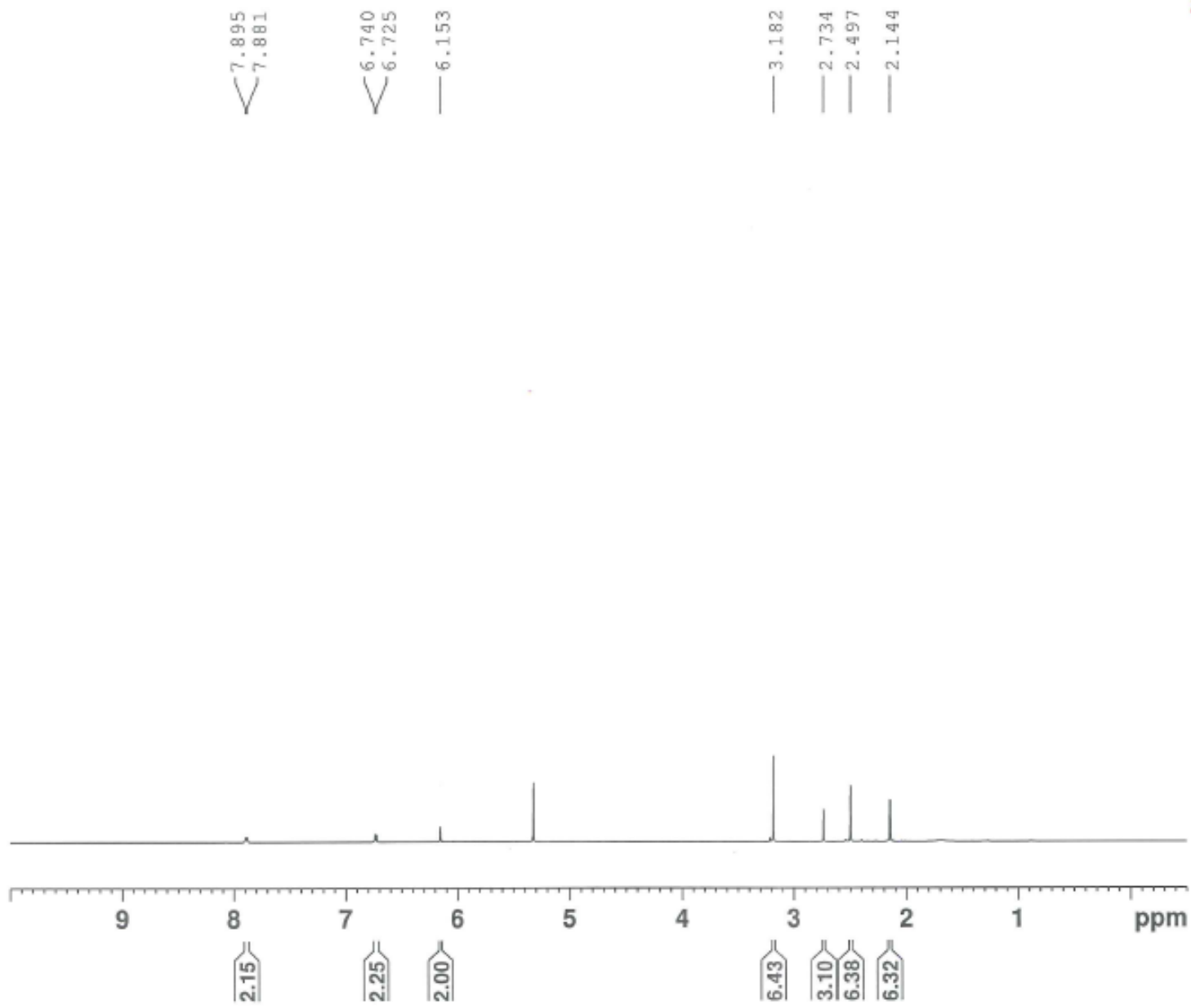


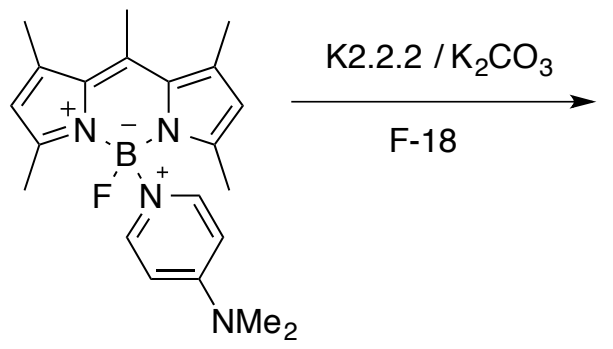

4

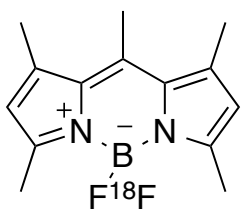

1-18F

Figure S-32: Reaction scheme showing the production 1-18F

Radiosynthesis of 4,4-difluoropentamethyl BODIPY $\left(\mathrm{F},{ }^{18} \mathrm{~F}\right): 1-{ }^{18} \mathrm{~F}$ $\left[{ }^{18} \mathrm{~F}\right]$ Fluoride $(110 \mathrm{mCi})$ with potassium carbonate, Kryptofix (K2.2.2), and water was dried at $110^{\circ} \mathrm{C}$ in a glass wheaton vial which was followed by three azeotropic dry downs in acetonitrile $\left(1.0 \mathrm{~mL}\right.$ each). The dried down ${ }^{18} \mathrm{~F}$ residue was then reconstituted in $300 \mu \mathrm{L}$ of acetonitrile. $100 \mu \mathrm{L} \mathrm{ACN}$ was then removed (34.7 mCi), and mixed with $4 \mathrm{~N}$-BODIPY $(F, D M A P)(1.0 \mathrm{mg} ; 0.0027 \mathrm{mmol})$ in $100 \mu \mathrm{L}$ acetonitrile. The mixture was then heated at $50{ }^{\circ} \mathrm{C}$ for 20 minutes, a small aliquot was removed and then injected onto an analytical radio-HPLC (Method B) (Figure S-35). Any residual amount of acetonitrile was removed, and then dissolved in a minimal amount of dichloromethane. The mixture was then injected on a preconditioned Waters Silica SepPak Column, and then eluted with a 2:1 mixture of dichloromethane and hexanes $(3.0 \mathrm{~mL})$. At which point it was spotted on a silica impregnated plastic backed TLC plate comparison of $R_{f}$ with chromatographic standard on TLC plates was used to confirm identity (TLC 2:1, dichloromethane and hexanes; $\left.R_{f}=0.64\right)$. This plate was this analyzed via radioTLC to provide a radiochemical yield (43.8\%) A summary of all reaction conditions used is provided in table S1. 


\begin{tabular}{|c|c|c|}
\hline Conc $(\mathrm{mM})$ & Heat $\left({ }^{\circ} \mathrm{C}\right) /$ Time (Mins) & $\underline{\mathrm{RCY}(\mathrm{RCP}(\%))}$ \\
\hline 29.0 & $\mathrm{RT} / 10$ & 24.85 \\
\hline 51.74 & $\mathrm{RT} / 10$ & $45.47(74.29)$ \\
\hline 76.66 & $\mathrm{RT} / 10$ & 18.54 \\
\hline 55.86 & $\mathrm{RT} / 10$ & 12.58 \\
\hline 58.59 & $\mathrm{RT} / 20$ & 48.08 \\
\hline 57.22 & $\mathrm{RT} / 30$ & 34.03 \\
\hline 82.68 & $50 / 20$ & $43.78(93)$ \\
\hline 41.62 & $50 / 20$ & 47.56 \\
\hline 27.75 & $50 / 20$ & 31.49 \\
\hline 55.86 & $50 / 20$ & 16.57 \\
\hline 58.59 & $50 / 30$ & 8.00 \\
\hline 57.22 & $50 / 40$ & 20.86 \\
\hline 84.33 & $80 / 20$ & $6.54(74.88)$ \\
\hline 42.16 & $80 / 20$ mins & 13.44 \\
\hline 28.11 & $80 / 20$ mins & \\
\hline & & \\
\hline
\end{tabular}

Table S-1: Summary of reaction conditions using the development of BODIPY 


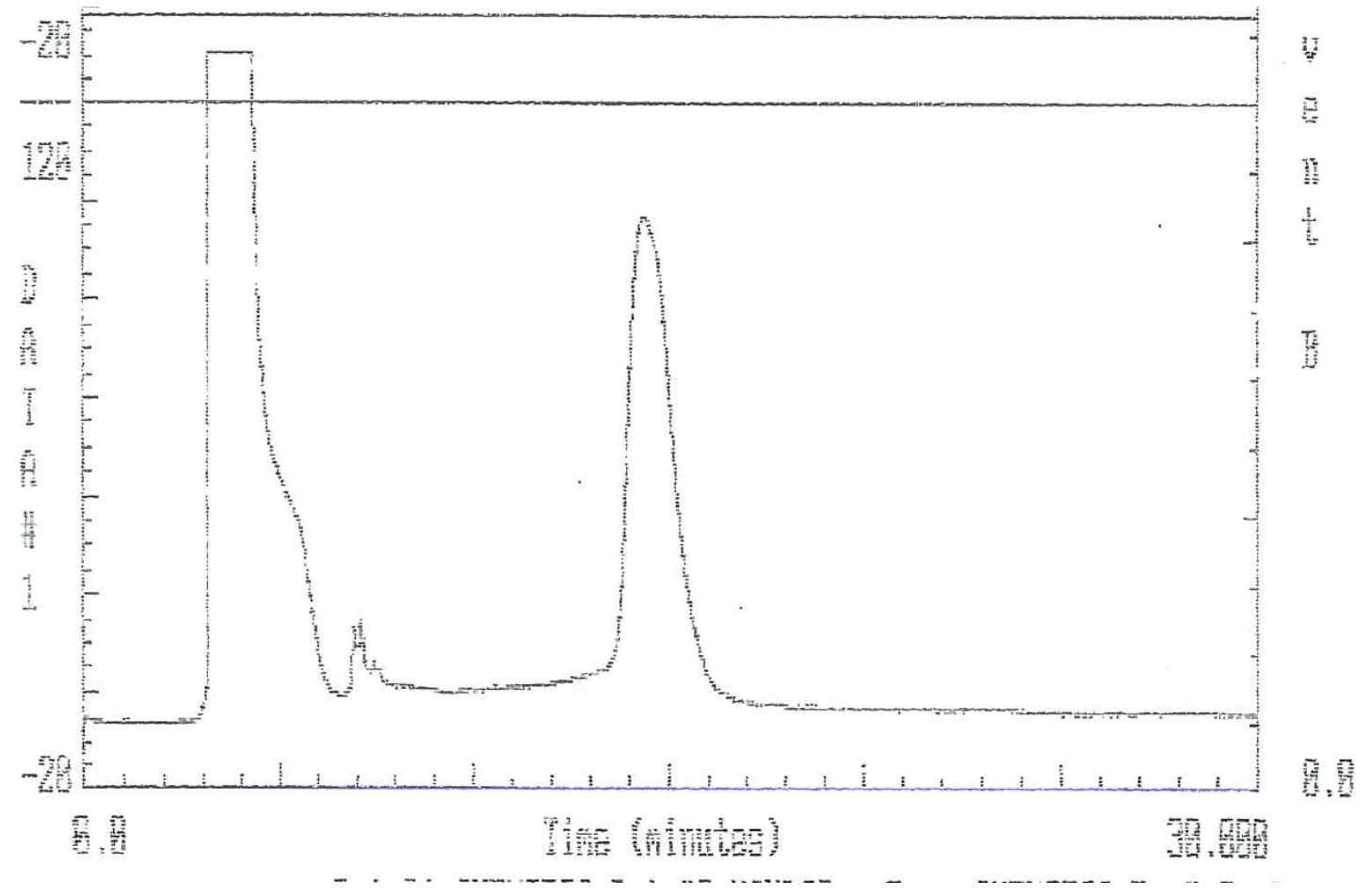

Figure S-32: A crude RadioHPLC trace of ${ }^{18}$ F-BODIPY (1) after labeling with fluorine-18 


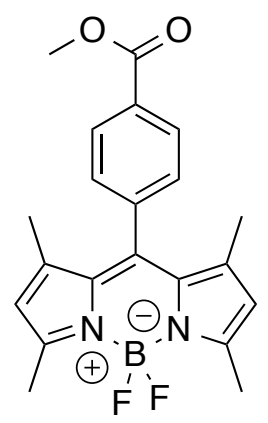

8-Phenyl Methyl Ester BODIPY (F,F) 2,4-dimethyl pyrrole $(0.5 \mathrm{~g}, 5.33 \mathrm{mmol})$ was mixed with 4-formyl benzoate $(0.348 \mathrm{~g}, 2.12 \mathrm{mmol})$ in anhydrous dichloromethane $(150 \mathrm{~mL})$. A drop of trifluoroacetic acid was added, and then the mixture was stirred for 2 hours at room temperature. 2,3-dichloro-5,6-dicyano1,4-benzoquinone $(0.481 \mathrm{~g}, 2.12 \mathrm{mmol})$ was added, and then stirred for an additional for 1 hour. Triethylamine $(5 \mathrm{~mL})$ and $\mathrm{BF}_{3}$-Etherate $(5 \mathrm{~mL})$ was added to the reaction mixture and stirred for 4 hours. The crude reaction mixture was then washed with $\mathrm{H}_{2} \mathrm{O}$. After drying with sodium sulfate, the solvent was evaporated. The residue was purified by column chromatography on silica (5:1(Dichloromethane/Hexanes). The pure product, a red powder, was obtained in $63 \%$ yield (338.6 mg, $0.888 \mathrm{mmol})$. M.P. $187-189{ }^{\circ} \mathrm{C}$ (decompoased); ${ }^{1} \mathrm{H}$ NMR $\operatorname{NMR}\left(\mathrm{CD}_{2} \mathrm{Cl}_{2}, 500 \mathrm{MHz}\right): \delta=8.18\left(\mathrm{~d},{ }^{3} \mathrm{~J}=5.9 \mathrm{~Hz}, 2 \mathrm{H}\right), 7.43\left(\mathrm{~d},{ }^{3} \mathrm{~J}=5.0 \mathrm{~Hz}, 2 \mathrm{H}\right)$, $6.03(\mathrm{~s}, 2 \mathrm{H}), 3.94(\mathrm{~s}, 3 \mathrm{H}), 2.52(\mathrm{~s}, 6 \mathrm{H}), 1.37(\mathrm{~s}, 6 \mathrm{H}) ;{ }^{13} \mathrm{C} \mathrm{NMR}\left(\mathrm{CD}_{2} \mathrm{Cl}_{2}, 125 \mathrm{Mhz}\right)$ : $\delta=166.67,156.21,143.53,140.91,139.94,131.33,131.28,130.66,128.81$, $121.74,121.72,52.56,14.63 ;{ }^{19} \mathrm{~F} \mathrm{NMR}\left(\mathrm{CDCl}_{3}, 250 \mathrm{MHz}\right) \delta=-146.20,-146.34$, $-146.48,-146.61(q, J=33.8 \mathrm{~Hz})$; IR (neat) = $2953.92 \mathrm{~cm}^{-1}, 2908.97,1726.37$, $1547.71,1510.01,1309.35,1275.35,1193.61,1156.28 \mathrm{MS}, \mathrm{m} / \mathrm{z}(\mathrm{M}+\mathrm{H})^{+}: 383.23$ 


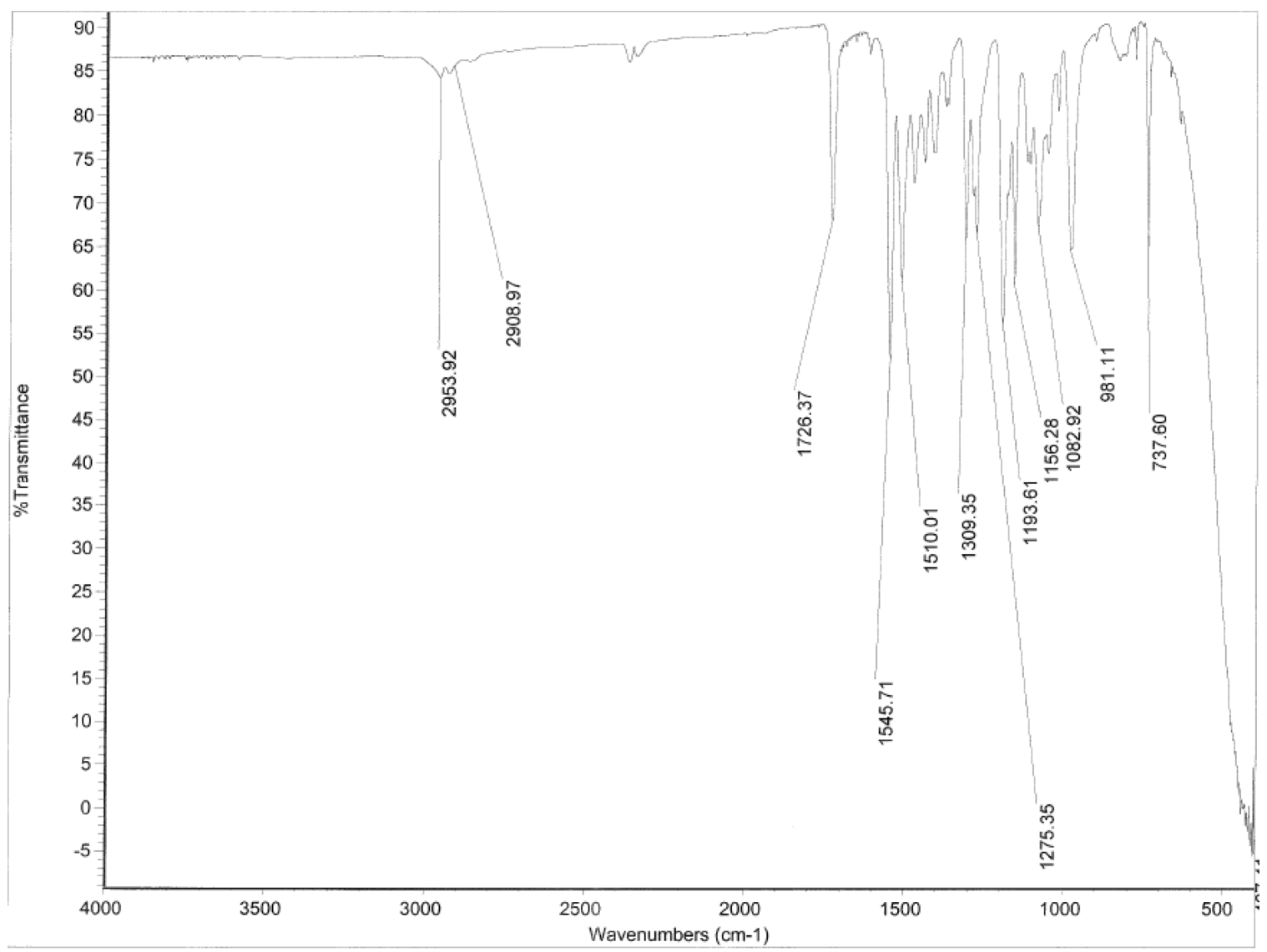




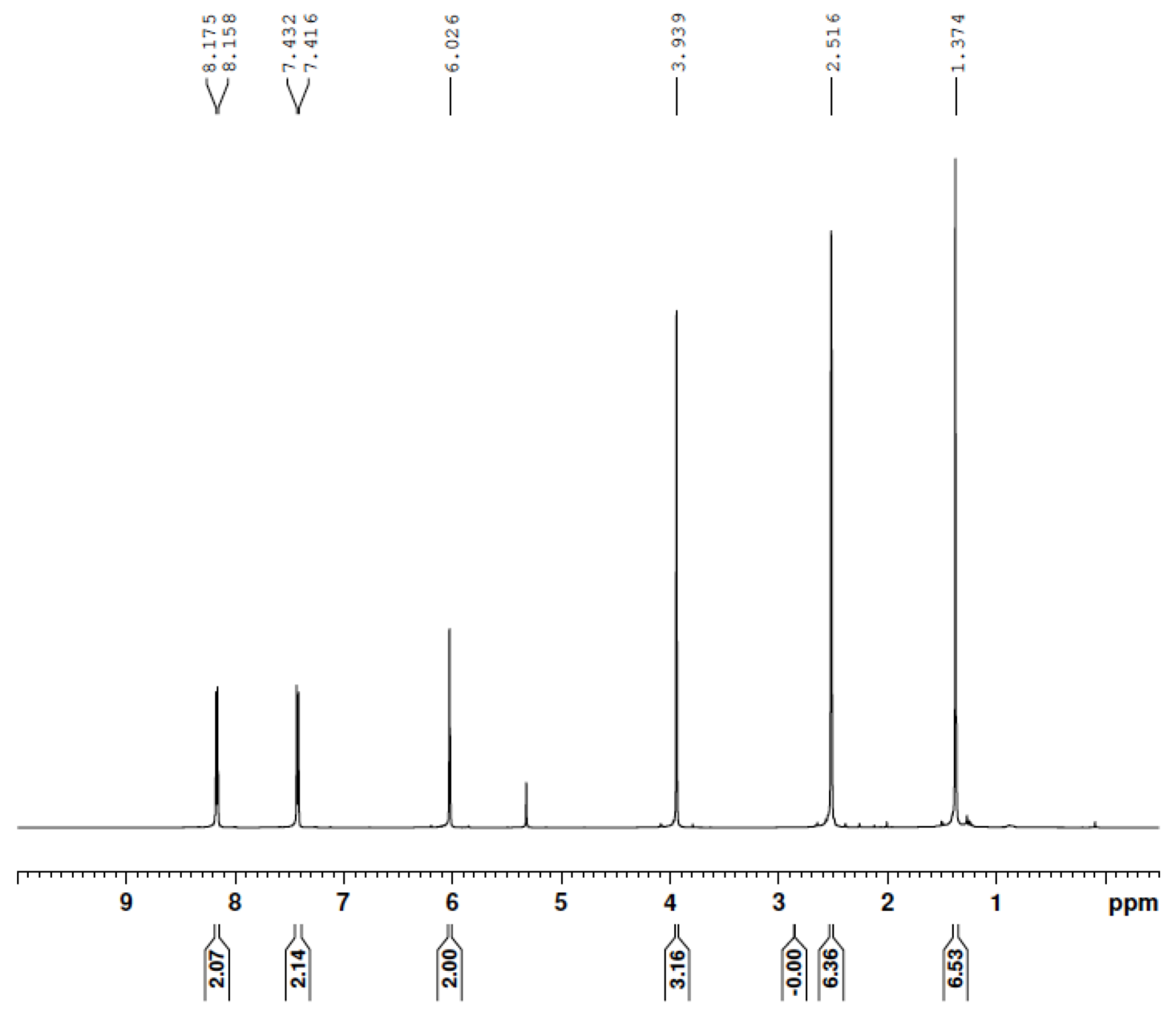




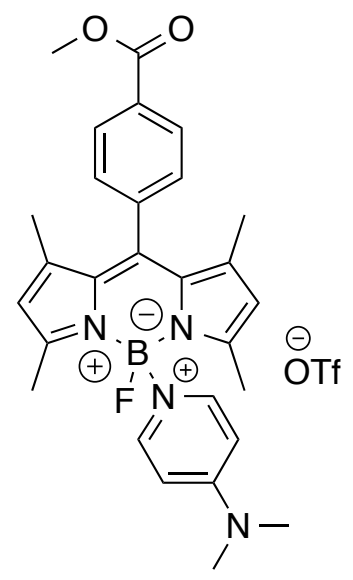

8-Phenyl Methyl Ester N-BODIPY (F,DMAP) 4-Dimethylaminopyridine (0.0709 g, $0.58 \mathrm{mmol}$ ) was mixed in anhydrous dichloromethane $(15 \mathrm{~mL})$ and chilled to $0^{\circ} \mathrm{C}$. TMS-OTf $(0.1 \mathrm{~mL}, 0.58 \mathrm{mmol})$ was a added, and the mixture was stirred for 20 minutes. The solvent was then removed in vacuo, and then reconstituted in dichloromethane. The [TMS-DMAP] ${ }^{+}$OTf solution was then added to a premixed solution of 8-Phenyl Methyl Ester BODIPY $(F, F)$ in anhydrous dichloromethane $(10 \mathrm{~mL})$. After 20 minutes, the reaction mixture was extracted with water and dried over sodium sulfate. Following a reduction in volume, the pure product was precipitated out by addition of cold hexanes (58.8\% yield, $14.7 \mathrm{mg}, 0.0302$ mmol). ${ }^{1} \mathrm{H}$ NMR NMR $\left(\mathrm{CD}_{2} \mathrm{Cl}_{2}, 500 \mathrm{MHz}\right): \delta=8.27\left(\mathrm{~d},{ }^{3} \mathrm{~J}=8 \mathrm{~Hz}, 1 \mathrm{H}\right), 8.23\left(\mathrm{~d},{ }^{3} \mathrm{~J}\right.$ $=1.5 \mathrm{~Hz}, 1 \mathrm{H}), 8.02(\mathrm{~m}, \mathrm{~J}=6.5 \mathrm{~Hz}, 2 \mathrm{H}), 7.65\left(\mathrm{~d},{ }^{3} \mathrm{~J}=1 \mathrm{~Hz}, 2 \mathrm{H}\right), 7.46\left(\mathrm{~d},{ }^{3} \mathrm{~J}=1\right.$ $\mathrm{Hz}, 1 \mathrm{H}), 6.85\left(\mathrm{~d},{ }^{3} \mathrm{~J}=7.5,2 \mathrm{H}\right), 3.96(\mathrm{~s}, 3 \mathrm{H}), 3.22(\mathrm{~s}, 6 \mathrm{H}), 2.18(\mathrm{~s}, 6 \mathrm{H}) ;{ }^{13} \mathrm{C}$ NMR $\left(\mathrm{CD}_{2} \mathrm{Cl}_{2}, 500 \mathrm{Mhz}\right): \delta=166.52,157.08,156.97,146.34,142.16,142.10,142.06$ $138.59,131.93,131.76,131.11,130.93,128.75,128.49,123.56,107.83,52.68$ 40.33, 14.90; ${ }^{19} \mathrm{~F} \mathrm{NMR}\left(\mathrm{CDCl}_{3}, 250 \mathrm{MHz}\right) \delta=-166.80,-166.96,-167.12,167.29$, 
$(q, J=41.25 \mathrm{~Hz}) ; \operatorname{IR}$ (neat) $=3101.02 \mathrm{~cm}^{-1}, 2925.31,1724.01,1641.69,1548.45$, 1505.78, 1472.64, 1274.67, 1100.60. MS, $\mathrm{m} / \mathrm{z}(\mathrm{M})^{+}: 485.03$

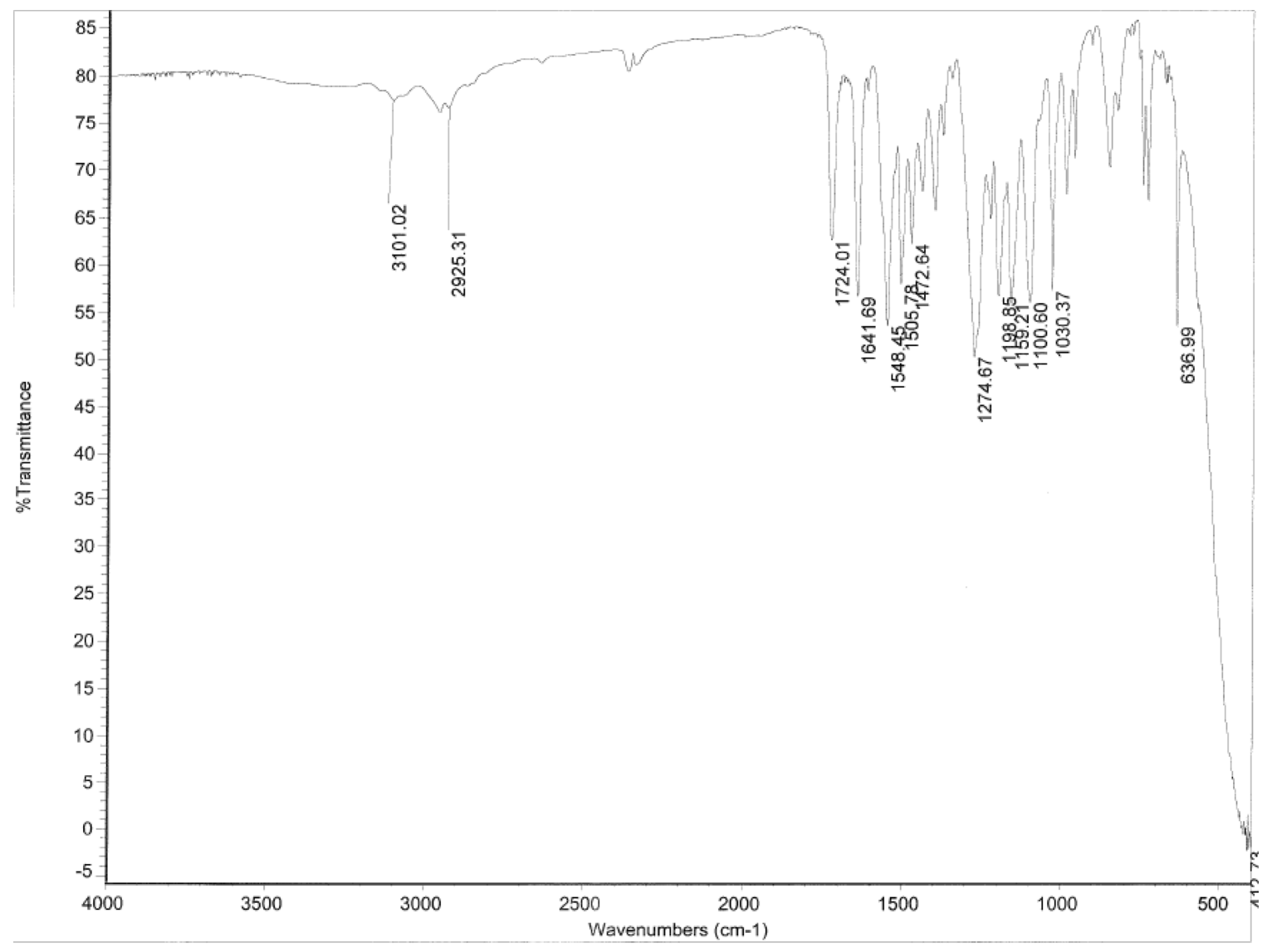




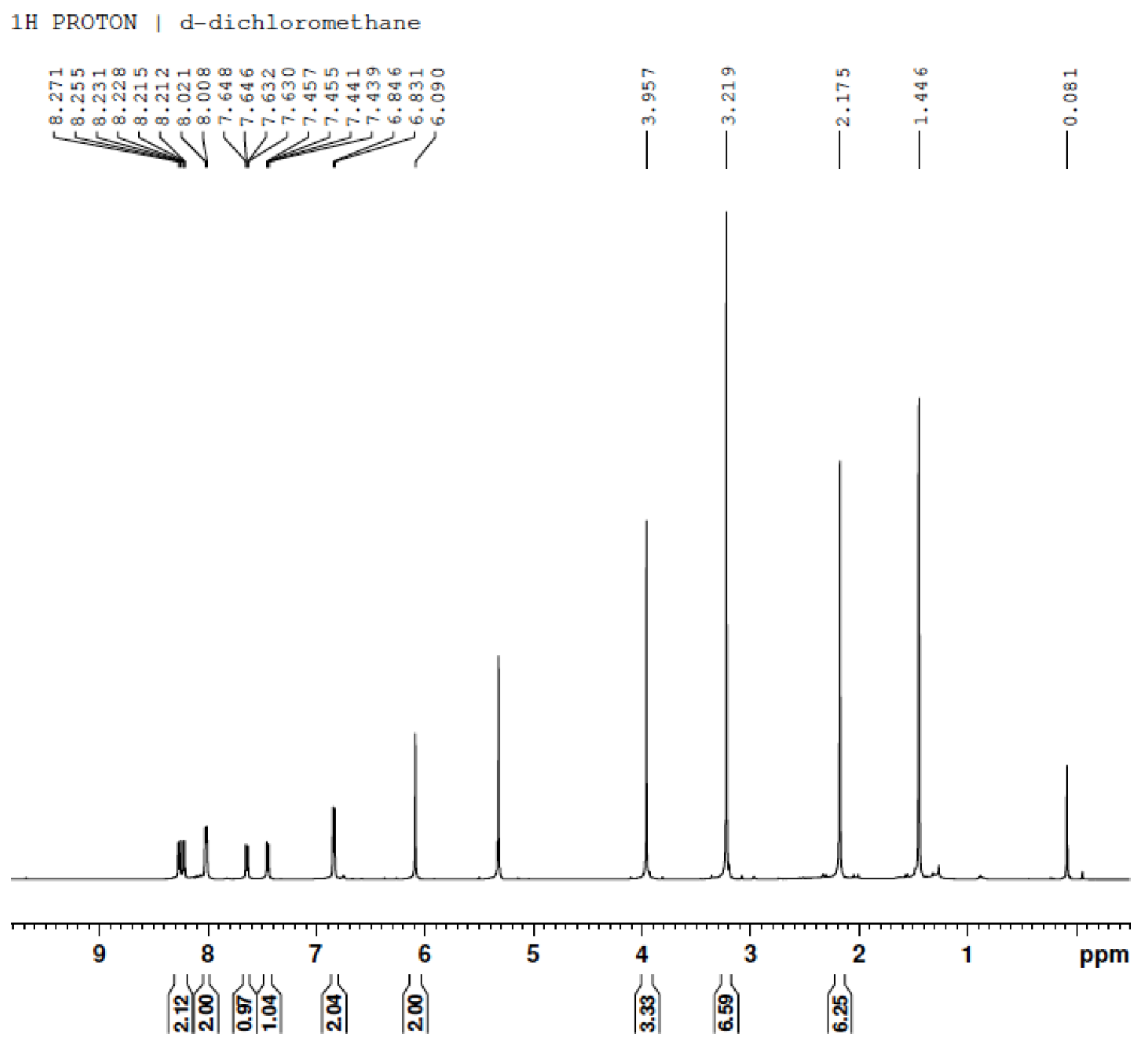




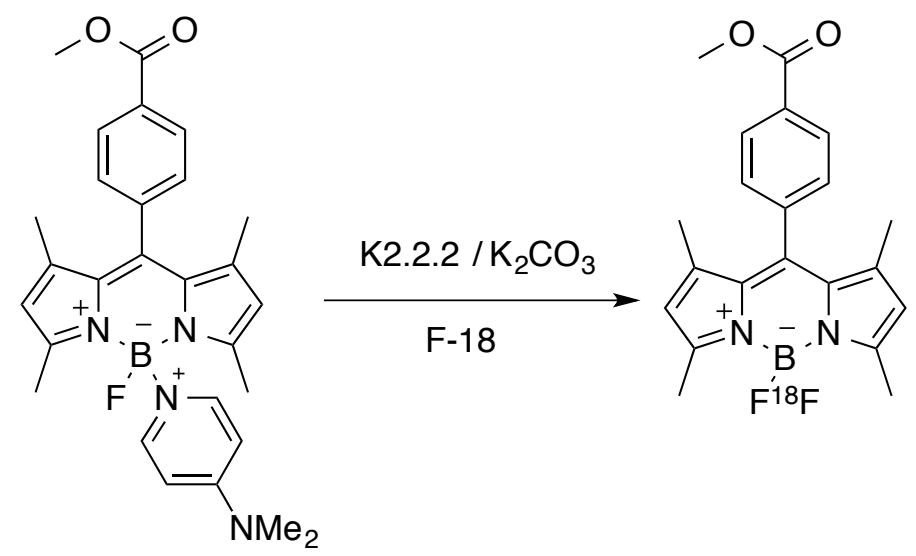

11

9-18F

Figure S-33: Reaction scheme showing the production 9-18F

Radiosynthesis of 8-methylbenzoiate-4,4-difluro-bodipy $\left(\mathrm{F},{ }^{18} \mathrm{~F}\right): 9-{ }^{18} \mathrm{~F}$

This synthesis was carried out and developed using an Eckert \& Ziegler automated synthesis module. $\left[{ }^{18} \mathrm{~F}\right] \mathrm{Fluoride}$ was received from the cyclotron in $\left[{ }^{18} \mathrm{O}_{\mathrm{H}} \mathrm{O}\right.$ and loaded onto a anion exchange resin (Waters QMA SepPak, 360 $\mathrm{mg})$. The $\left[{ }^{18} \mathrm{~F}\right]$ fluoride was eluted using $0.9 \mathrm{~mL} \mathrm{~K} \mathrm{CO}_{3}(1.0 \mathrm{mg} / \mathrm{ml})$ in $\mathrm{H}_{2} \mathrm{O}$ and 0.1 $\mathrm{mL}$ K2.2.2 (12.5 mg/ml) in ACN into reactor one (Figure S-37). Between 85-125 $\mathrm{mCi}$ would be recovered from the anion exchange cartridge. The mixture was then heated to dryness at $110^{\circ} \mathrm{C}$. The compound was then azotropically dried using $1.0 \mathrm{~mL}$ of $A C N$. The mixture was then reconstituted with $0.3 \mathrm{~mL}$ of $A C N$ and $0.2 \mathrm{~mL}$ of $11(1.0 \mathrm{mg})$ in ACN. The mixture was then heated at $35^{\circ} \mathrm{C}$ for 20 minutes. The crude reaction mixture was then loaded onto a preconditioned (10 $\mathrm{mL}$ DCM) Silica SepPak Plus (690 mg), and was subsequently eluted with $6 \mathrm{~mL}$ of $A C N$ into reactor two. After removal of the ACN/DCM mixture via pressure and heat, the dried mixture was reconstituted in $0.2 \mathrm{~mL}$ of $50 / 50\left(\mathrm{H}_{2} \mathrm{O}: \mathrm{ACN}\right)$ and injected onto the HPLC using method $C\left(t_{R}\left(\left[{ }^{18} \mathrm{~F}\right]-F^{-}\right)=4.0\right.$ minutes; $t_{R}\left(9-{ }^{18} F\right)=$ 8.2 minutes).

Prior to injection $\approx 0.1 \mu \mathrm{L}$ of crude mixture was taken for radioTLC. At which point it was spotted on a glass backed silica TLC plates for comparison to the cold standard 10 and to determine the radiochemical yield (RCY). Comparison of the 
$\mathrm{R}_{\mathrm{f}}$ with chromatographic standard 10 on TLC plates was used to confirm identity (TLC 1:1, dichloromethane and hexanes; $R_{f}=0.79$ ). This plate was this analyzed via radioTLC to provide a radiochemical yield. The RCY was $40.3 \%$ and the radiochemical purity $(\mathrm{RCP})$ was $93 \%$ determined via radioTLC of product peak. The Eckert and Ziegler Module Layout is provided in Figure S-37. 


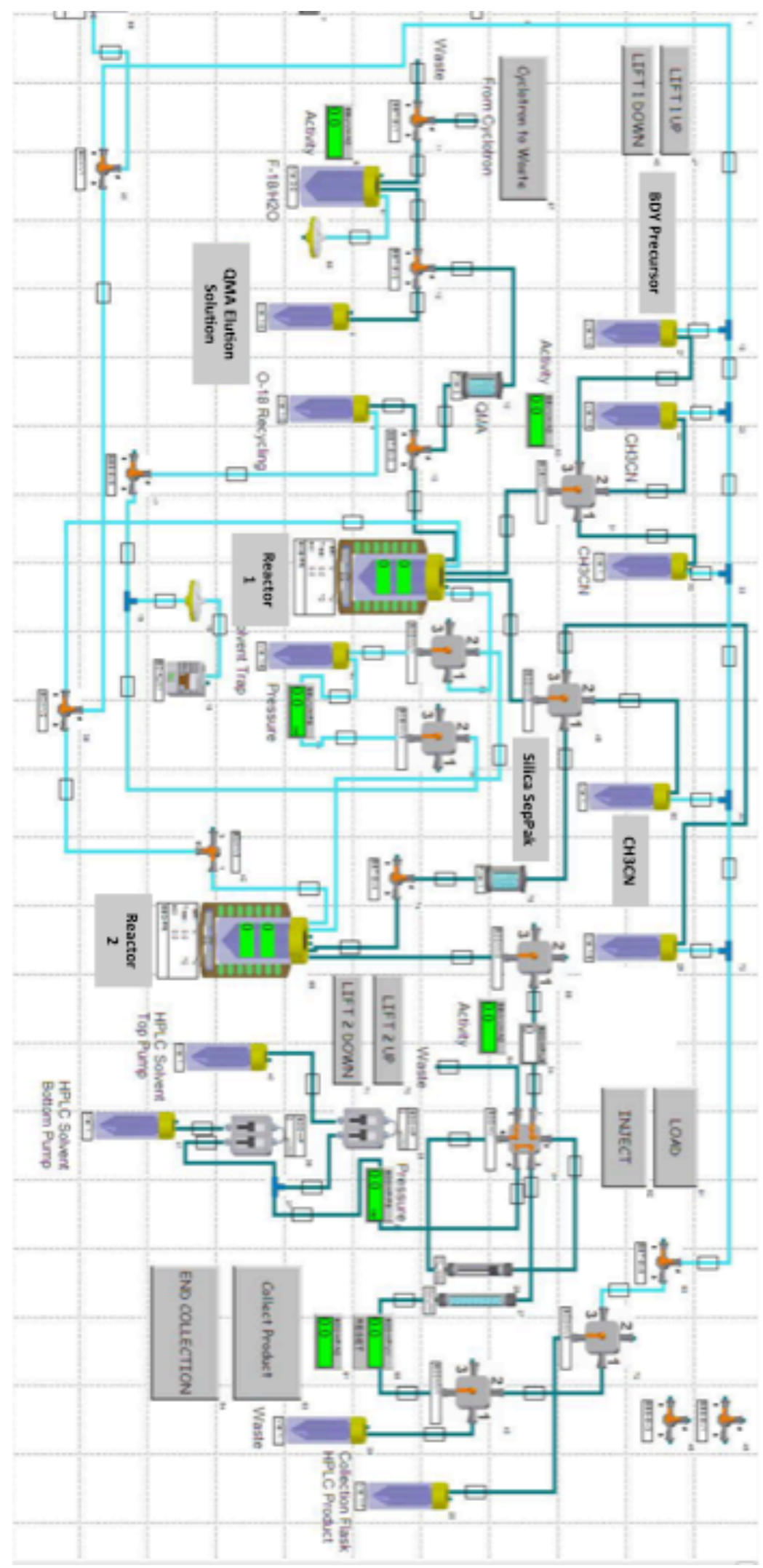

Figure S-34: Schematic of the Ekert \& Ziegler Automated Synthesis Module used for 


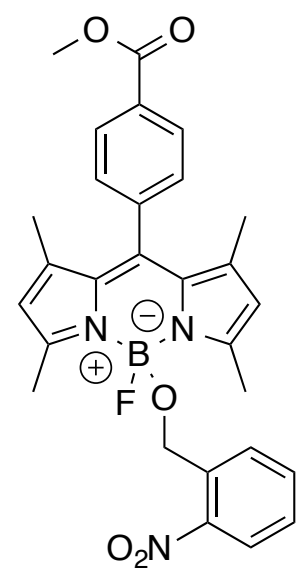

8-Phenyl Methyl Ester O-BODIPY (F, o-nitrobenzyl alcohol) 8-phenyl methyl ester BODIPY $(0.05 \mathrm{~g}, 0.131 \mathrm{mmol})$ was refluxed $\mathrm{AlCl}_{3}(0.0228 \mathrm{~g}, 0.144 \mathrm{mmol})$ in anhydrous dichloromethane for 5 minutes. A solution of $o$-nitrobeznyl alcohol $(0.0247 \mathrm{~g}, 0.157 \mathrm{mmol})$ alcohol was then added and the reaction was then refluxed for an additional 5 minutes. The $\mathrm{AlCl}_{3}$ was then filtered away, and pure product was obtained in $16 \%$ yield $(10.8 \mathrm{~g}, 0.0210 \mathrm{mmol}$ following column chromatography on silica (9:1 (Hexanes/Ethyl Acetate)). ${ }^{1} \mathrm{H}$ NMR NMR (d-DMSO, $250 \mathrm{MHz}): \delta=8.20-8.12(\mathrm{~m}, 2 \mathrm{H}), 7.99\left(\mathrm{~d},{ }^{3} \mathrm{~J}=10 \mathrm{~Hz}, 1 \mathrm{H}\right), 7.81-7.67(\mathrm{~m}, 2 \mathrm{H})$, 7.59-7.46 (m, 3H), $6.13(\mathrm{~s}, 2 \mathrm{H}), 4.35(\mathrm{~s}, 2 \mathrm{H}), 3.91(\mathrm{~s}, 3 \mathrm{H}), 2.40(\mathrm{~s}, 6 \mathrm{H}), 1.32(\mathrm{~s}$, $6 \mathrm{H}) ;{ }^{19} \mathrm{~F}$ NMR (d-DMSO, $\left.250 \mathrm{MHz}\right) \delta=-149.67$ 


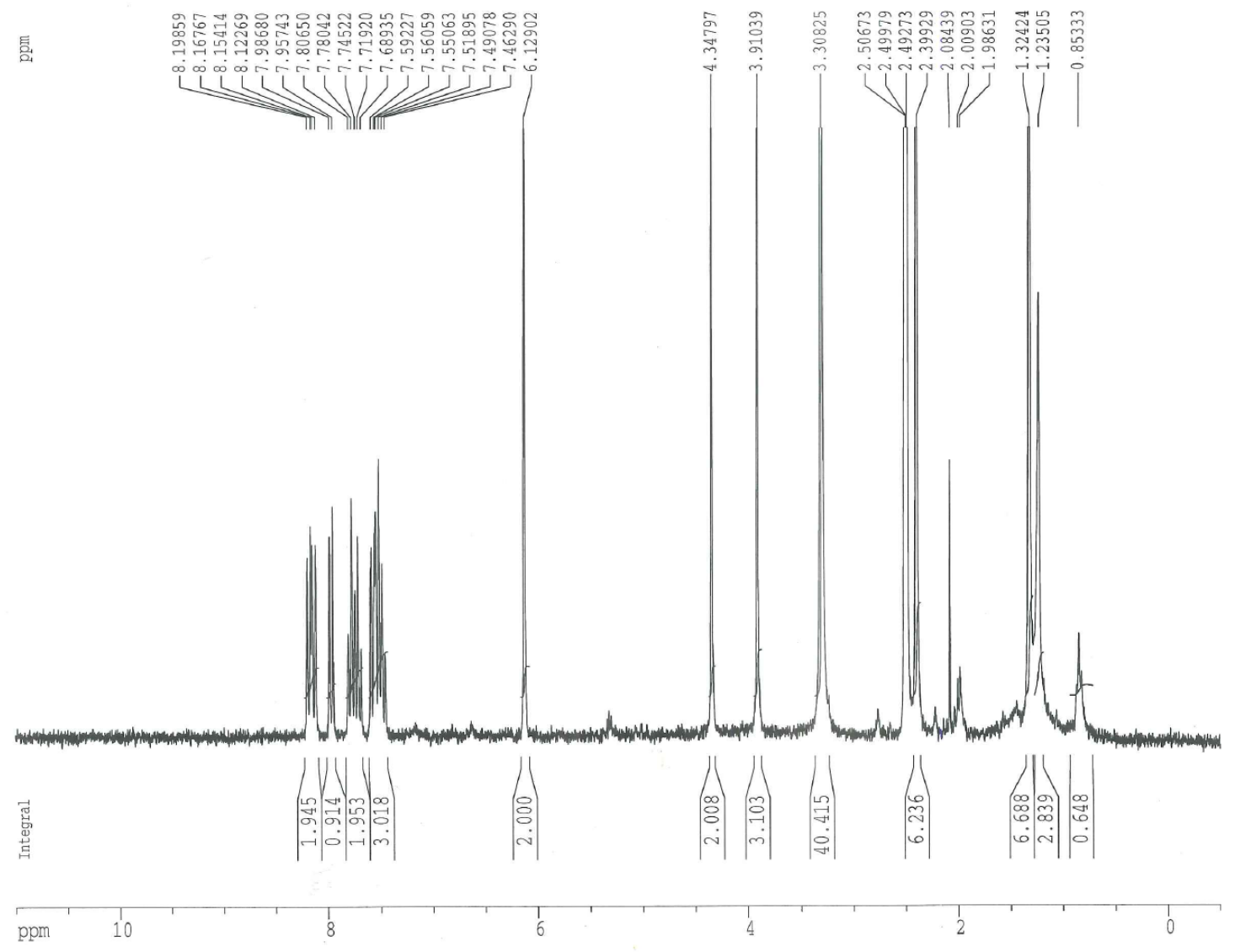




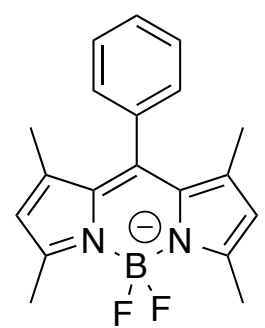

8-Phenyl BODIPY (F,F) Benzoyl chloride (1.2 mL, $11.0 \mathrm{mmol}$ ) and 2,4-dimethyl pyrrole $(2.0 \mathrm{~mL}, 20.0 \mathrm{mmol})$ was mixed in anhydrous dichloromethane with a drop of catalytic trifluoroacetic acid for twelve hours at room temperate. The mixture was then chilled to $0^{\circ} \mathrm{C}$, triethylamine $(10 \mathrm{~mL})$ followed by $\mathrm{BF}_{3}$-etherate $(10 \mathrm{~mL})$ was added. After reducing the volume, the reaction mixture was washed two times with water and dried with sodium sulfate. After evaporation, the crude compound was purified via two consecutive columns on silica (100\% DCM, 1:1 (Hexane/DCM)) as an orange crystalline solid (372.1 mg, $1.15 \mathrm{mmol})$ in $24.2 \%$. ${ }^{1} \mathrm{H}$ NMR NMR $\left(\mathrm{CD}_{2} \mathrm{Cl}_{2}, 500 \mathrm{MHz}\right): \delta=7.51-7.49(\mathrm{~m}, 3 \mathrm{H}), 7.31-7.29(\mathrm{~m}, 2 \mathrm{H}), 6.02$ (s, 2H), $2.51(\mathrm{~s}, 6 \mathrm{H}), 1.39(\mathrm{~s}, 6 \mathrm{H}) ;{ }^{13} \mathrm{C} \mathrm{NMR}\left(\mathrm{CD}_{2} \mathrm{Cl}_{2}, 125 \mathrm{Mhz}\right): \delta=143.76$, $142.39,135.23,131.75,129.3,129.6,128.35,121.48,14.45,14.65 ;{ }^{19} \mathrm{~F}$ NMR $\left(\mathrm{CDCl}_{3}, 250 \mathrm{MHz}\right) \delta=-146.20,-146.34,-146.48,-146.61(\mathrm{q}, \mathrm{J}=40 \mathrm{~Hz}) . \mathrm{IR}$ (neat) $=3064.25 \mathrm{~cm}^{-1}, 2958.00,2921.23,2357.32,2345.06,1535.98,1495.12$, 1298.98, 1192.74 MS, $m / z(M)^{+}: 325.19$ 


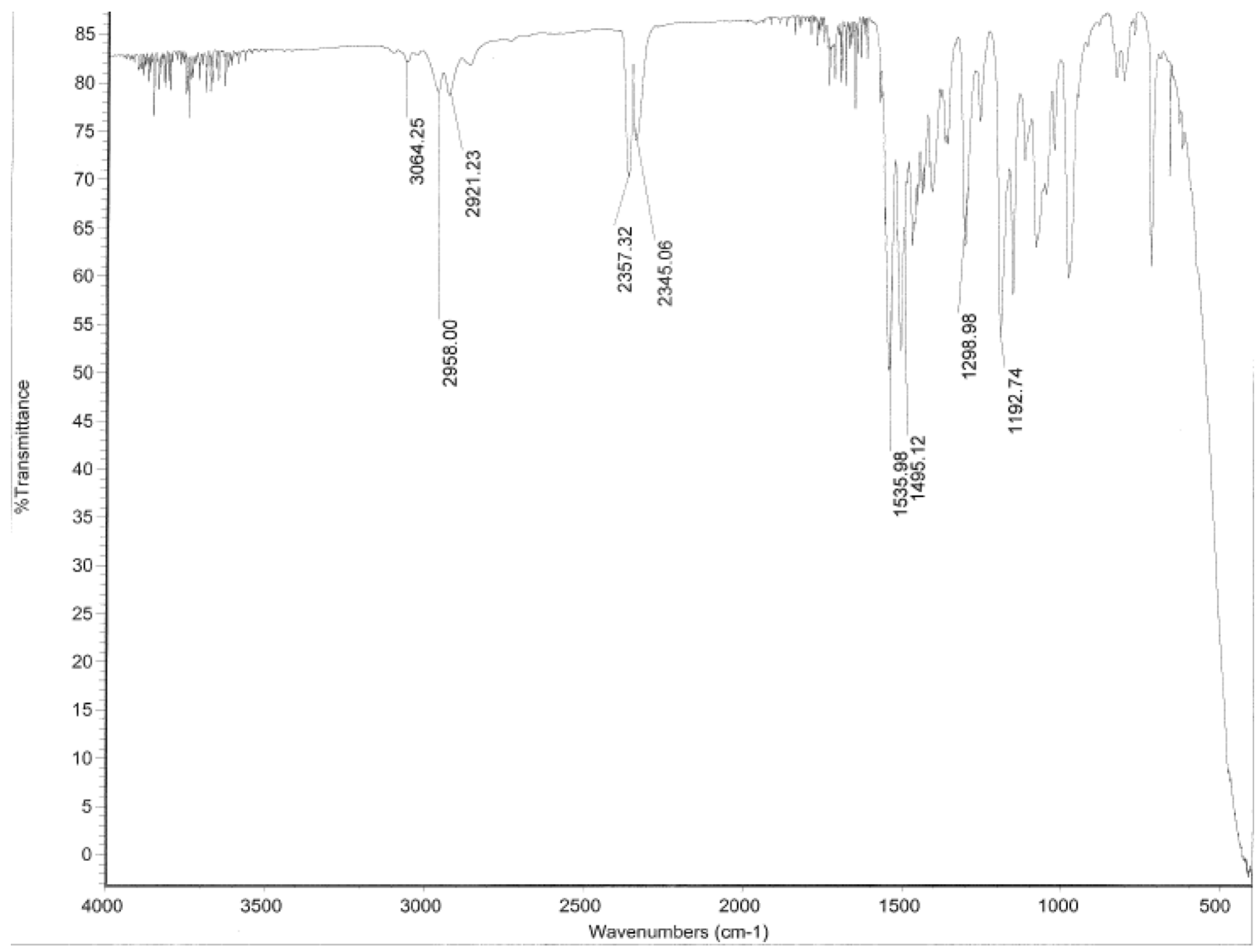


1H Proton | d-dichloromethane
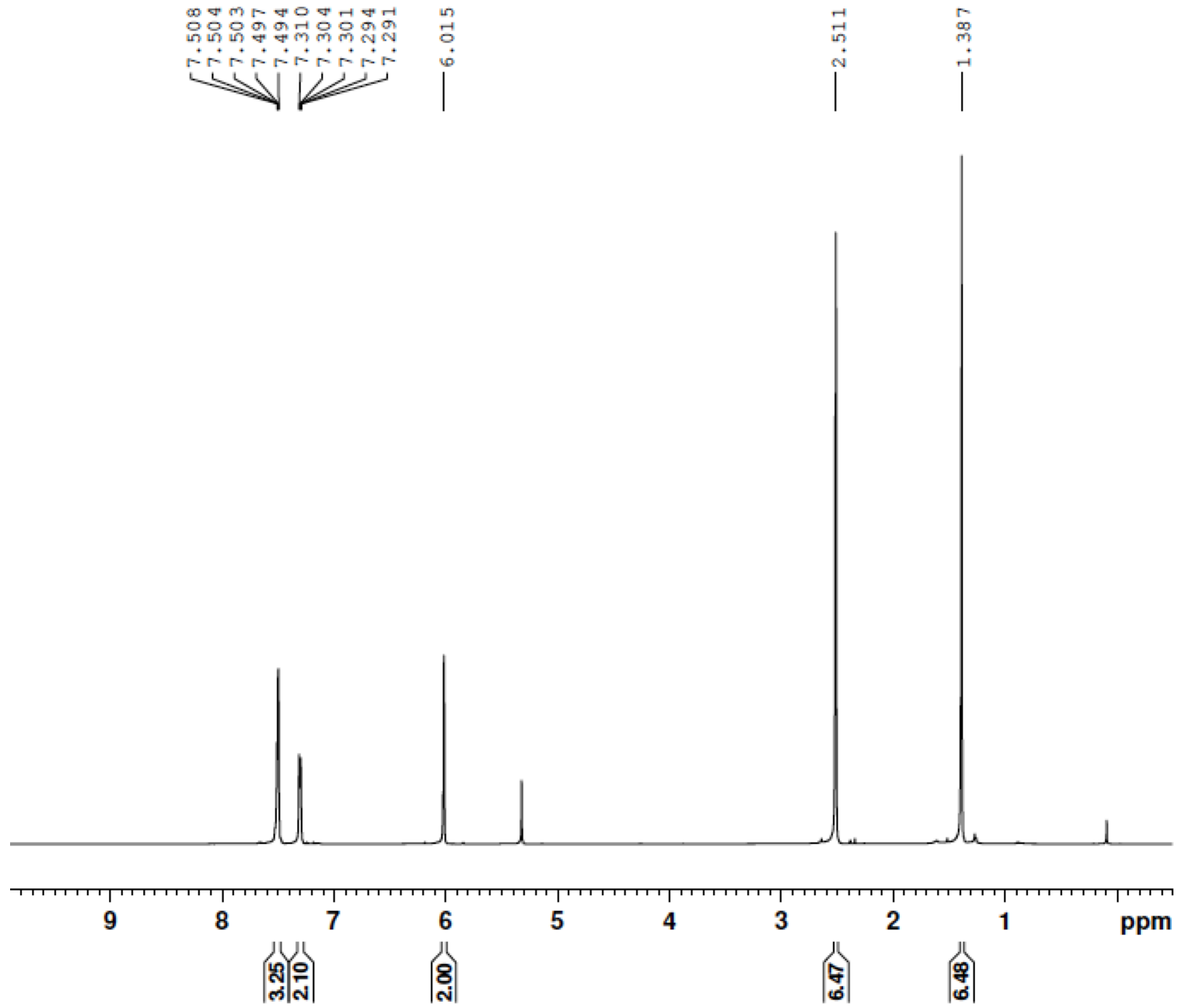


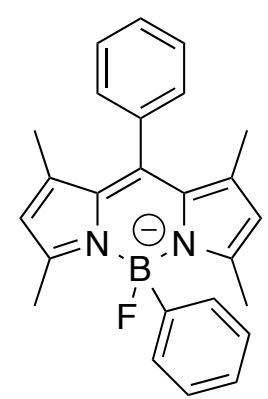

8-Phenyl C-BODIPY (Phenyl,F) 8-Phenyl BODIPY (F,F) (0.303 g, 0.925 mmol) was reacted with phenyl magnesium bromide $(0.336 \mathrm{~g}, 1.8 \mathrm{mmol})$ in absolute THF at room temperature for 20 minutes. The reaction was quenched with $\mathrm{H}_{2} \mathrm{O}$, and then extracted with dichloromethane. After drying with sodium sulfate and removal of the solvent, the pure product, as a red powder, was obtained following column chromatography on silica (3:1 (Hexanes/Dichloromethane)) in 18\% yield (0.032 g, 0.0833 mmol). ${ }^{1} \mathrm{H}$ NMR NMR $\left(\mathrm{CD}_{2} \mathrm{Cl}_{2}, 500 \mathrm{MHz}\right): \delta=7.56-7.52(\mathrm{~m}, 3 \mathrm{H})$, 7.45-7.42 (m, 3H), 7.38-7.36 (m, 1H), 7.24-7.21 (t, $\left.{ }^{3} \mathrm{~J}=7 \mathrm{~Hz}, 2 \mathrm{H}\right), 5.94(\mathrm{~s}, 2 \mathrm{H})$, $2.18(\mathrm{~s}, 6 \mathrm{H}), 1.43(\mathrm{~s}, 6 \mathrm{H}) ;{ }^{13} \mathrm{C}$ NMR $\left(\mathrm{CD}_{2} \mathrm{Cl}_{2}, 125 \mathrm{Mhz}\right): \delta=155.66,142.72$, $142.40,135.75,132.09,132.06,131.36,129.51,129.45,129.18,128.68,128.47$ 127.29, 126.56, 121.62, 15.37, 15.34; ${ }^{19} \mathrm{~F} \mathrm{NMR}\left(\mathrm{CD}_{2} \mathrm{Cl}_{2}, 250 \mathrm{MHz}\right) \delta=-174.53$ (bs). IR (neat) $=3019.30 \mathrm{~cm}^{-1}, 2921.23,2855.85,1547.68,1509.76,1469.85$, 1408.20, 1302.12, 1181.44, 1153.08 MS, $\mathrm{m} / \mathrm{z}(\mathrm{M}+\mathrm{H})^{+}: 383.21$ 


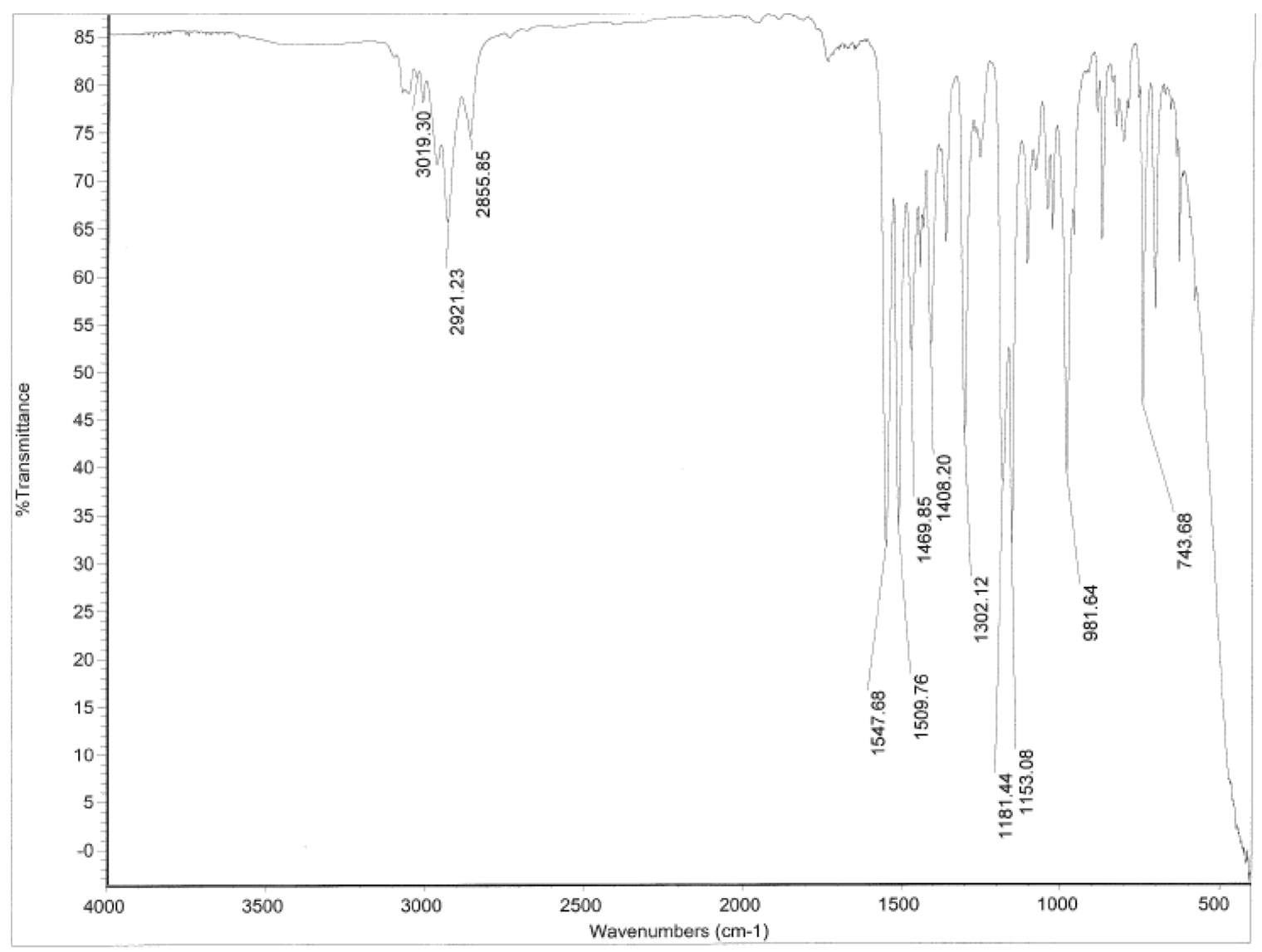




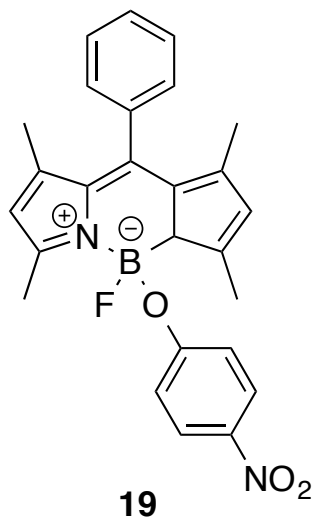

A solution of $13(52 \mathrm{mg}, 0.16 \mathrm{mmol})$ and $\mathrm{AlCl}_{3}(18 \mathrm{mg}, 0.14 \mathrm{mmol})$ in $4 \mathrm{~mL}$ of $\mathrm{CH}_{2} \mathrm{Cl}_{2}$ was refluxed for 10 minutes. To the solution 4-methoxyphenol (22 mg, $0.16 \mathrm{mmol}$ ) in $3 \mathrm{~mL} \mathrm{CH} \mathrm{Cl}_{2}$ was added and refluxed for 10 minutes. After removal of the solvent, two sequential columns (Al2O3, EtOAc) (Silica, $\mathrm{CH}_{2} \mathrm{Cl}_{2}: \mathrm{Hexane}$ $(1 / 1))$ to yield $19(11 \mathrm{mg}, 14 \%) .{ }^{1} \mathrm{H}$ NMR (d-ACN, $\left.600 \mathrm{Mhz}\right) \delta=8.04-8.02(\mathrm{~d}, 2 \mathrm{H}$, $\left.{ }^{3} \mathrm{~J}=12 \mathrm{hz}\right), 7.57-7.56(\mathrm{~m}, 3 \mathrm{H}), 7.45-7.44(\mathrm{~m}, 1 \mathrm{H}), 7.42-7.40(\mathrm{~m}, 1 \mathrm{H}), 6.65-6.63$ (d, 2H, $\left.{ }^{3} \mathrm{~J}=12 \mathrm{~Hz}\right), 6.07$ (s, 2H), $2.53(\mathrm{~s}, 6 \mathrm{H}), 1.40$ (s, 6H); ${ }^{13} \mathrm{C}$ NMR (d-ACN, 150 $\mathrm{MHz}) 163.73,163.67,156.91,145.36,143.81,141.70,135.40,132.59,130.42$, $130.32,130.30,129.23,129.01,126.85,122.91,118.83,15.0 q 14.71,14.63 ;{ }^{19} \mathrm{~F}$ NMR (d-chloroform, $564 \mathrm{MHz}$ ) -148.25, -148.29, -148.34, -148.38; IR (neat) = $2923.23 \mathrm{~cm}^{-1}, 1541.68,1496.41,1340.62,1291.72,1274.86,1187.11,1155.30$; M.P. $=212^{\circ} \mathrm{C}$ 


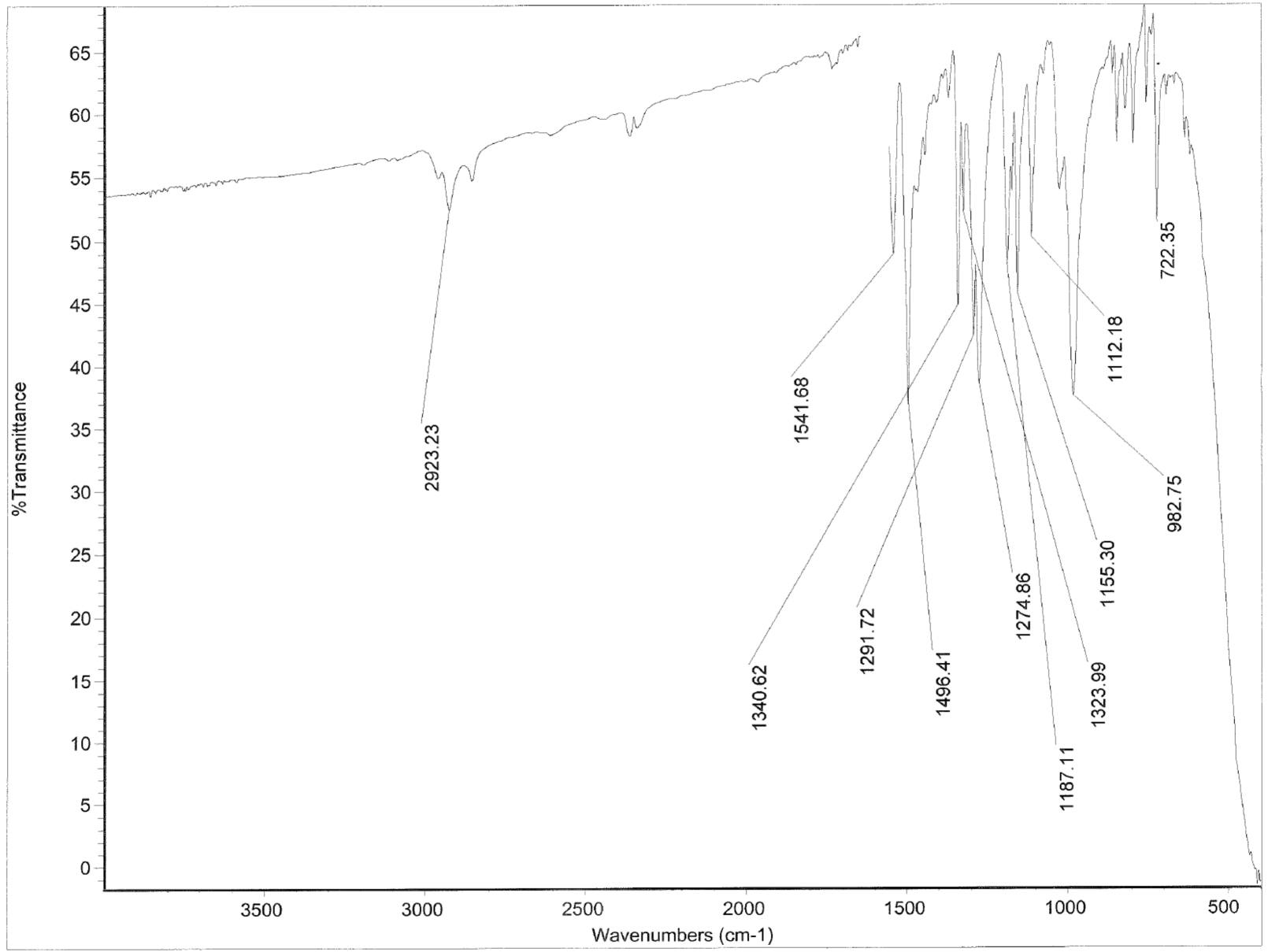




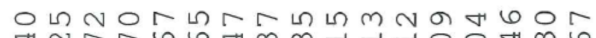

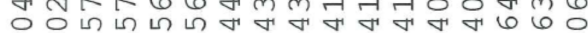

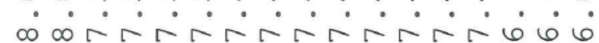
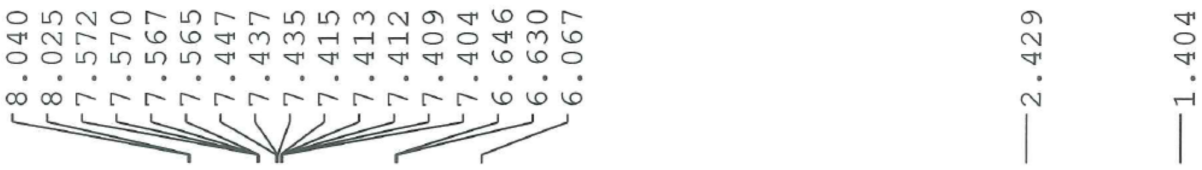

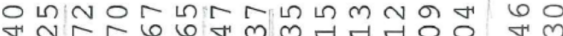

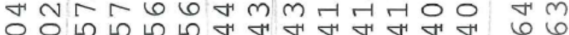
$0015 \sqrt{0}$

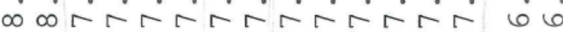
$3 \longrightarrow$

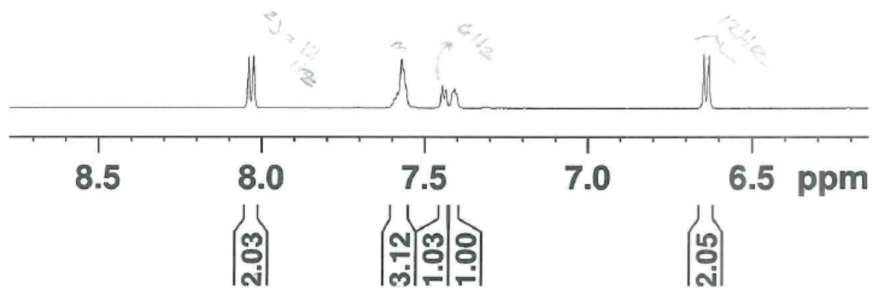

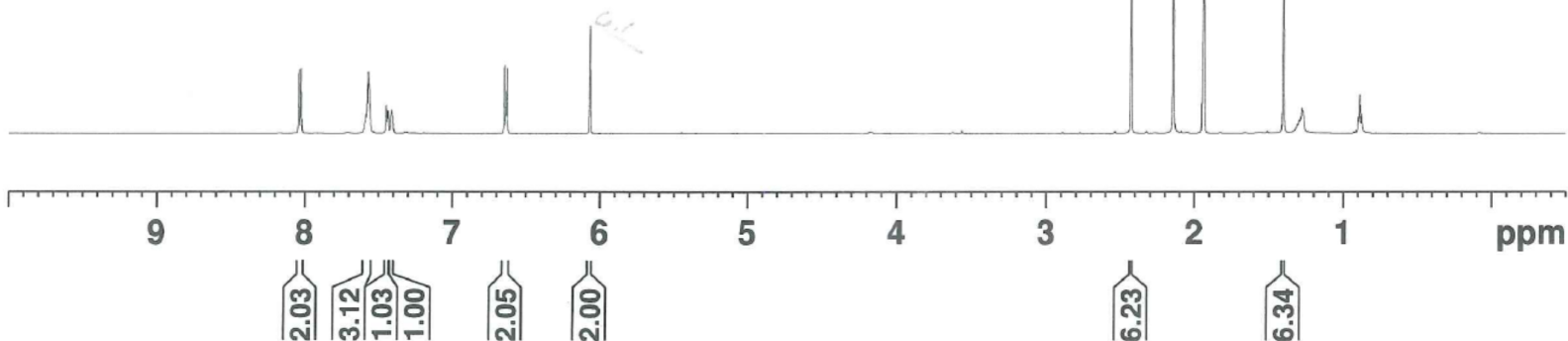




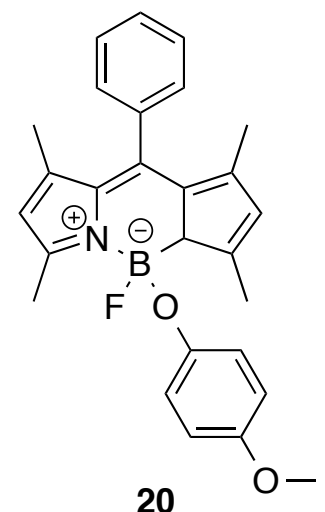

A solution of $13(51 \mathrm{mg}, 0.16 \mathrm{mmol})$ and $\mathrm{AlCl}_{3}(22 \mathrm{mg}, 0.14 \mathrm{mmol})$ in $3 \mathrm{~mL}$ of $\mathrm{CH}_{2} \mathrm{Cl}_{2}$ was refluxed for 10 minutes. To the solution 4-methoxyphenol (22 mg, $0.16 \mathrm{mmol}$ ) in $4 \mathrm{~mL} \mathrm{CH}_{2} \mathrm{Cl}_{2}$ was added and refluxed for 10 minutes. After removal of the solvent, two sequential columns (Al2O3, EtOAc) (Silica, EtOAc:Hexane $(1 / 5))$ to yield 20 (17 mg, 24\%). ${ }^{1} \mathrm{H}$ NMR (d-Chloroform, $\left.600 \mathrm{Mhz}\right) \delta=7.48-7.47$ (m, 3H), 7.316-7.312 (d, $\left.2 \mathrm{H}^{3} \mathrm{~J}=2.4 \mathrm{~Hz}\right), 7.198-7.196\left(\mathrm{~d}, 2 \mathrm{H},{ }^{3} \mathrm{~J}=1.2 \mathrm{~Hz}\right), 6.65-$ $6.63\left(\mathrm{~d}, 2 \mathrm{H},{ }^{3} \mathrm{~J}=9 \mathrm{~Hz}\right), 6.47-6.45\left(\mathrm{~d}, 2 \mathrm{H},{ }^{3} \mathrm{~J}=9 \mathrm{~Hz}\right), 5.93(\mathrm{~s}, 2 \mathrm{H}), 3.70(\mathrm{~s}, 3 \mathrm{H})$, $2.51(\mathrm{~s}, 6 \mathrm{H}), 1.37(\mathrm{~s}, 6 \mathrm{H}){ }^{13} \mathrm{C}$ NMR (d-chloroform, $\left.150 \mathrm{MHz}\right)$ 155.8, 152.9, 150.4, 150.3, 143.0, 141.7, 135.1, 131.7, 129.1, 128.9, 128.0, 128.9, 128.01, 127.96, $121.51,118.70,114.31,55.54,14.88,14.86 ;{ }^{19} \mathrm{~F}$ NMR (d-chloroform, $564 \mathrm{MHz}$ ) 149.01, -149.05, -149.1, -149.15; IR (neat) $=3421.30 \mathrm{~cm}^{-1}, 2953.92,2917.14$, $1652.86,1545.57,1507.06,1471.75,1303.78,1188.00,1155.74 ;$ M.P. $=212^{\circ} \mathrm{C}$ 
क

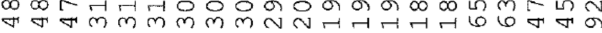

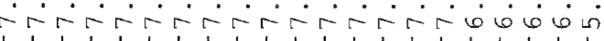

$\longrightarrow$

(1)
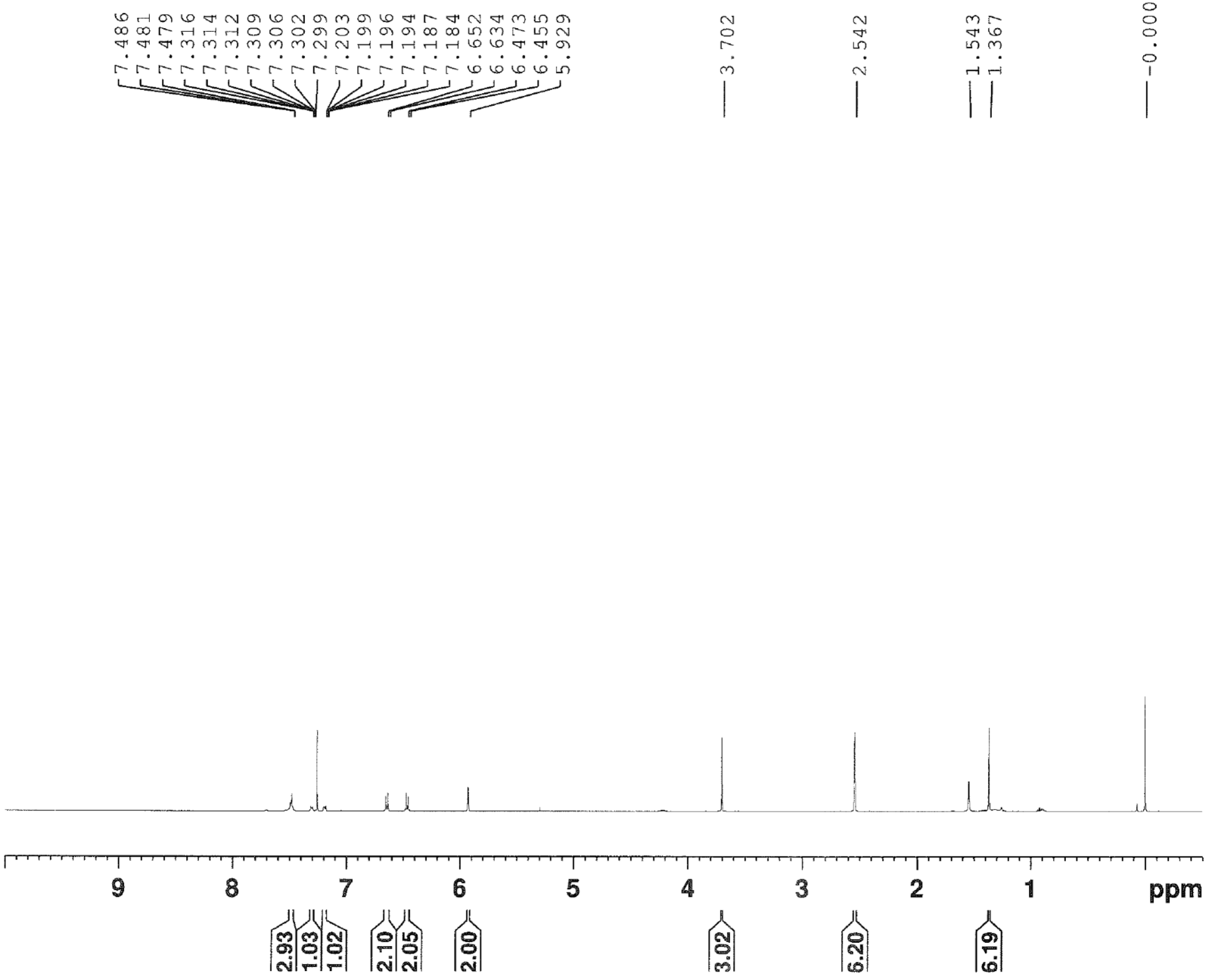


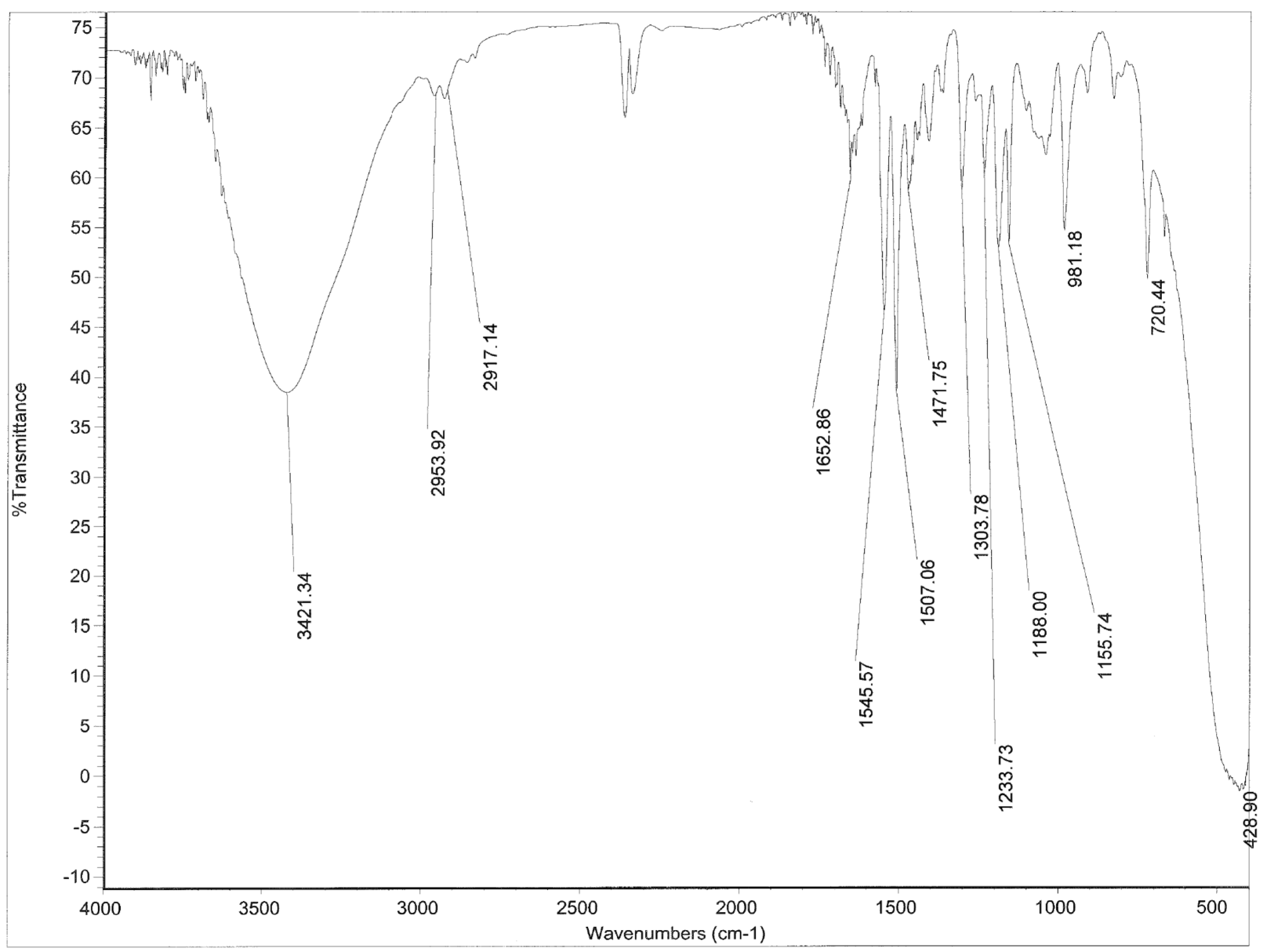




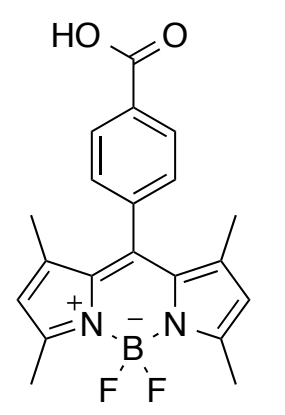

5
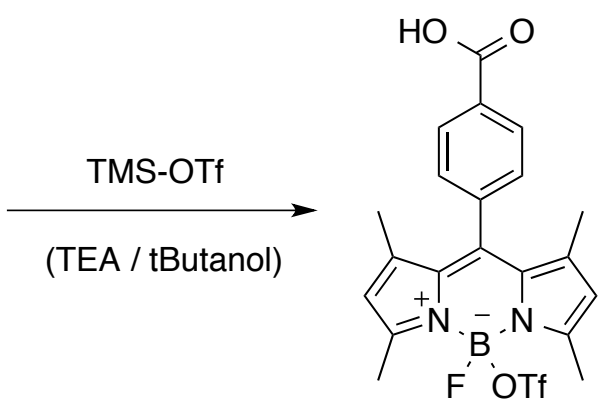

$5^{\prime}$
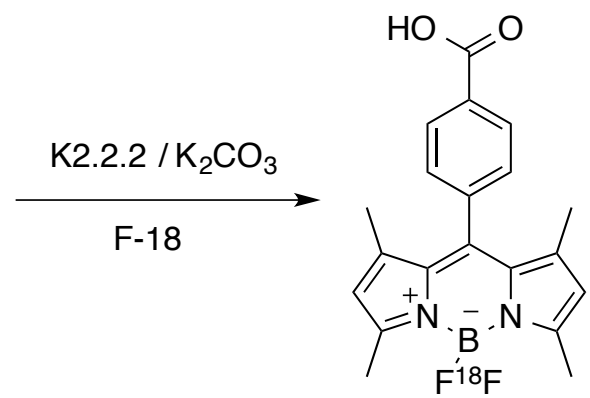

$5-18 F$

Figure S-35: Reaction scheme showing the production $5-18 \mathrm{~F}$

Radiosynthesis of 8-benzoate-4,4-difluro-BODIPY $\left(\mathrm{F},{ }^{18} \mathrm{~F}\right)$ : 5-18F

To a mixture of $\left[{ }^{18} \mathrm{~F}\right]$ Fluoride $(10 \mathrm{mCi})$ and potassium carbonate in water, Kryptofix $(1.0 \mathrm{mg})$ and $\mathrm{ACN}(0.5 \mathrm{~mL})$ was added; this mixture was then heated under pressure at $110^{\circ} \mathrm{C}$ until dryness. This process was then followed by three azeotropic dry downs using $1.0 \mathrm{~mL}$ of $\mathrm{ACN}$ each. Following the final dry down, it was reconstituted in $0.2 \mathrm{~mL}$ of ACN. During this process, $5(1.0 \mathrm{mg}, 0.0027$ $\mathrm{mmol}$ ) was incubated with TMS-OTf ( $3.02 \mathrm{mg}, 0.0136 \mathrm{mmol}$ ) for 30 minutes at room temperature in $1.0 \mathrm{~mL}$ of $\mathrm{ACN}$ at room temperature. This reaction was then quenched with tert-butanol $(5.0 \mathrm{mg}, 0.068 \mathrm{mmol})$ and TEA. $(6.8 \mathrm{mg}, 0.068$ $\mathrm{mmol})$. The dried $\left[{ }^{18} \mathrm{~F}\right]$ fluoride mixture in $\mathrm{ACN}$ was then mixed with the activated BODIPY 5' for 10 minutes at $50^{\circ} \mathrm{C}$ in a sealed vial. Following RadioHPLC using method $A$, a peak matching the cold standard was eluted $\left(R_{T}=5.2\right.$ mins) (Figure S1). The RCY was $6.3 \%$ for this reaction, based on a peak height calibration curve (data not shown). 


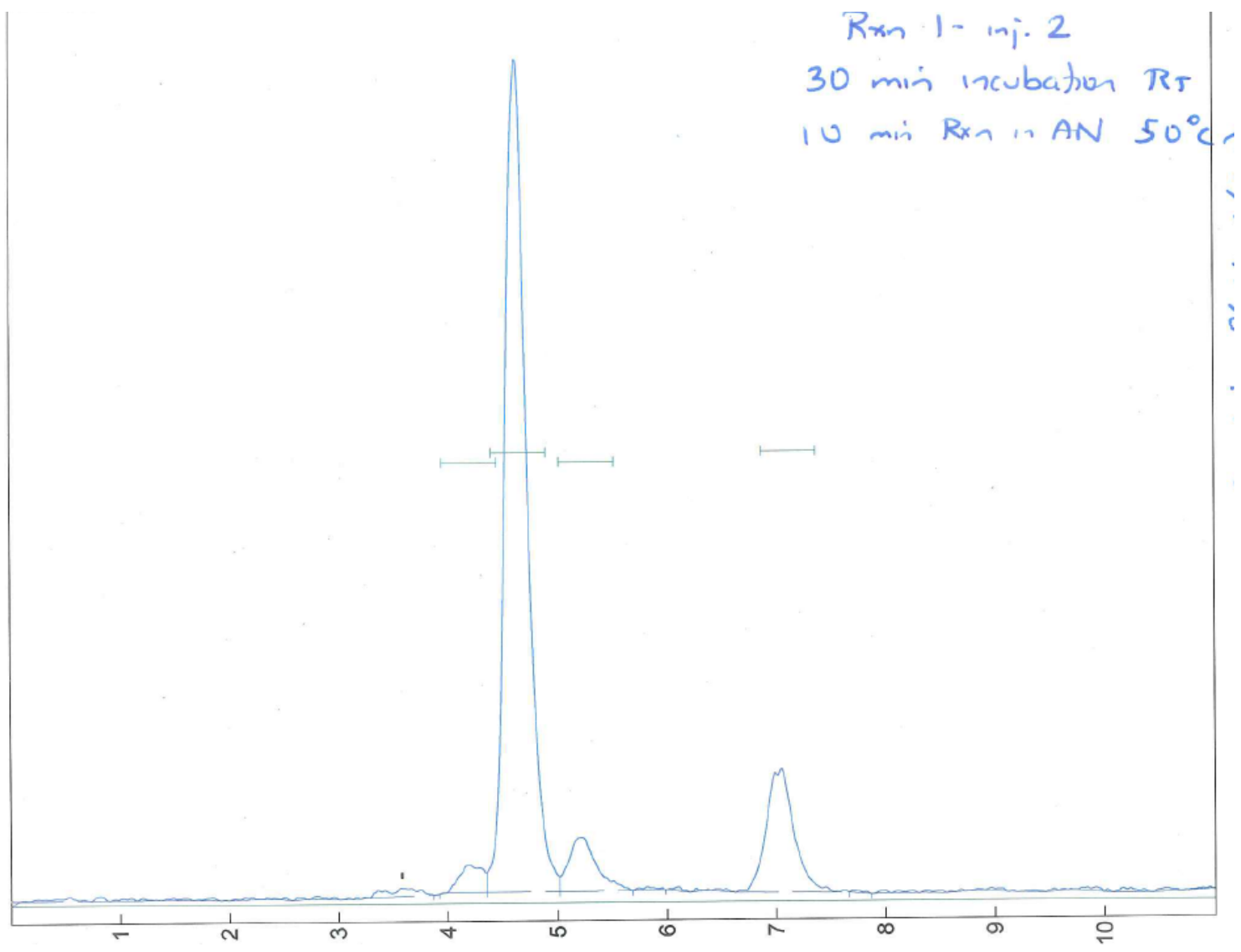

Figure S-36: RadioHPLC chromatogram of the crude reaction mixture after incubating with [ ${ }^{18}$ F]fluoride with $5^{\prime}$ for 10 minutes at room temperature. 


\section{BIBLIOGRAPHY}

(1) Lichtman, J. W.; Conchello, J.-A. Nat. Methods 2005, 2, 910-919.

(2) Lakowicz, J. R. Principles of fluorescence spectroscopy; 2006; pp. 1-954.

(3) Valeur, B. Molecular fluorescence: principles and applications; 2002; p. 402.

(4) Cutler, C. S.; Schwarz, S. W. Targeted Molecular Imaging; Welch, M.; Eckelman, W. C., Eds.; First.; CRC Press: New York, 2012; pp. 91-113.

(5) Lieser, K. H. Nuclear and Radiochemistry, Fundamentals and Applications; Second.; Wiley-VCH: New York, 2001; pp. 29-46.

(6) Aldoff, J.-P.; Guillaumont, R. Fundamentals of Radiochemistry; CRC Press: Ann Arbor, 1993; pp. 44-50.

(7) Anderson, C. J.; Ferdani, R. 2009, 24.

(8) Mastren, T.; Guthrie, J.; Eisenbeis, P.; Voller, T.; Mebrahtu, E.; Robertson, J. D.; Lapi, S. E. Appl. Radiat. Isot. 2014, 90, 117-121.

(9) Cherry, S. R.; Sorenson, J. A.; Phelps, M. E. Physics in Nuclear Medicine; Third.; Saunders: Philadelphia, 2003; pp. 1-88.

(10) Fowler, J. S.; Ido, T. Semin. Nucl. Med. 2002, 32, 6-12.

(11) Wang, C.; Willis, D. L.; Loveland, W. D. Radiotracer Methodology in the Biological, Environmental, and Physical Sciences; first.; Prentice Hall: New York City, 1975; pp. 326-362.

(12) Miller, P. W.; Long, N. J.; Vilar, R.; Gee, A. D. Angew. Chem. Int. Ed. Engl. 2008, 47, 8998-9033.

(13) Kealey, S.; Gee, A.; Miller, P. W. J. Labelled Comp. Radiopharm. 2014, 57, 195-201.

(14) Gaja, V.; Gómez-Vallejo, V.; Puigivila, M.; Pérez-Campaña, C.; Martin, A.; García-Osta, A.; Calvo-Fernández, T.; Cuadrado-Tejedor, M.; Franco, R.; Llop, J. Mol. Imaging Biol. 2014, 16, 538-549.

(15) Gómez-Vallejo, V.; Gaja, V.; Gona, K. B.; Llop, J. J. Labelled Comp. Radiopharm. 2014, 57, 244-254. 
(16) Berridge, M. S.; Adler, L. P.; Nelson, A. D.; Cassidy, E. H.; Muzic, R. F.; Bednarczyk, E. M.; Miraldi, F. J. Cereb. Blood Flow Metab. 1991, 11, 707715.

(17) Kabalka, G. W.; Lambrecht, R. M.; Sajjad, M.; Fowler, J. S.; Kunda, S. A.; McCollum, G. W.; MacGregor, R. Int. J. Appl. Radiat. Isot. 1985, 36, 853855.

(18) Treibs, A.; Kreuzer, F.-H. Justus Liebigs Ann. Chem. 1968, 718, 208-223.

(19) Ulrich, G.; Ziessel, R.; Harriman, A. The chemistry of fluorescent bodipy dyes: Versatility unsurpassed. Angewandte Chemie - International Edition, 2008, 47, 1184-1201.

(20) Loudet, A.; Burgess, K. Chem. Rev. 2007, 107, 4891-4932.

(21) Guo, B.; Peng, X.; Cui, A.; Wu, Y.; Tian, M.; Zhang, L.; Chen, X.; Gao, Y. Dye. Pigment. 2007, 73, 206-210.

(22) Wu, L.; Burgess, K. Chem. Commun. (Camb). 2008, 4933-4935.

(23) Leen, V.; Yuan, P.; Wang, L.; Boens, N.; Dehaen, W. Org. Lett. 2012, 14, 6150-6153.

(24) Jiao, L.; Yu, C.; Liu, M.; Wu, Y.; Cong, K.; Meng, T.; Wang, Y.; Hao, E. J. Org. Chem. 2010, 75, 6035-6038.

(25) Seiichiro, M.; Tsuyoshi, T.; Akira, K. PYRROMETHENEMETALCOMPLEXAND LIGHT EMITTING DEVICE COMPOSITION AND LIGHT EMITTING DEVICES USING THE SAME. 20030082406A1, 2002.

(26) Ziessel, R.; Goze, C.; Ulrich, G. Synthesis (Stuttg). 2007, 2007, 936-949.

(27) Goze, C.; Ulrich, G.; Ziessel, R. Org. Lett. 2006, 8, 4445-4448.

(28) Goze, C.; Ulrich, G.; Mallon, L. J.; Allen, B. D.; Harriman, A.; Ziessel, R. J. Am. Chem. Soc. 2006, 128, 10231-10239.

(29) Hudnall, T. W.; Lin, T.-P.; Gabbaï, F. P. J. Fluor. Chem. 2010, 131, 11821186.

(30) Kim, H.; Burghart, A.; Welch, M. B.; Reibenspies, J.; Burgess, K. Synthesis and spectroscopic properties of a new 4-bora-3a,4a-diaza-s-indacene (BODIPY®) dye. Chemical Communications, 1999, 1889-1890. 
(31) Tahtaoui, C.; Klotz, P.; Duportail, G.; Me, Y.; Bonnet, D.; Hibert, M.; Strasbourg, D. P. De; Rhin, R.; July, R. V. 2007, 269-272.

(32) Courtis, A. M.; Santos, S. a; Guan, Y.; Hendricks, J. A.; Ghosh, B.; SzantaiKis, D. M.; Reis, S. a; Shah, J. V; Mazitschek, R. Bioconjug. Chem. 2014, 25, 1043-1051.

(33) Hudnall, T. W.; Gabbaï, F. P. Chem. Commun. (Camb). 2008, 4596-4597.

(34) Fowler, J. S.; Volkow, N. D.; Kassed, C. A.; Chang, L. Sci. Pract. Perspect. 2007, 3, 4-16.

(35) Klunk, W. E.; Engler, H.; Nordberg, A.; Wang, Y.; Blomqvist, G.; Holt, D. P.; Bergström, M.; Savitcheva, I.; Huang, G. F.; Estrada, S.; Ausén, B.; Debnath, M. L.; Barletta, J.; Price, J. C.; Sandell, J.; Lopresti, B. J.; Wall, A.; Koivisto, P.; Antoni, G.; Mathis, C. A.; Långström, B. Ann. Neurol. 2004, 55, 306-319.

(36) Shokeen, M.; Anderson, C. J. Acc. Chem. Res. 2009, 42, 832-841.

(37) Carlin, S.; Zhang, H.; Reese, M.; Ramos, N. N.; Chen, Q.; Ricketts, S.-A. J. Nucl. Med. 2014, 55, 515-521.

(38) Di Carli, M. F.; Dorbala, S.; Meserve, J.; El Fakhri, G.; Sitek, A.; Moore, S. C. J. Nucl. Med. 2007, 48, 783-793.

(39) Hilderbrand, S. a; Weissleder, R. Curr. Opin. Chem. Biol. 2010, 14, 71-79.

(40) Culver, J.; Akers, W.; Achilefu, S. J. Nucl. Med. 2008, 49, 169-172.

(41) Townsend, D. W. J. Nucl. Med. 2008, 49, 938-955.

(42) Jennings, L. E.; Long, N. J. Chem. Commun. (Camb). 2009, 3511-3524.

(43) Darne, C.; Lu, Y.; Sevick-Muraca, E. M. Phys. Med. Biol. 2014, 59, R1R64.

(44) Helmchen, F.; Denk, W. Nat. Methods 2005, 2, 932-940.

(45) Willmann, J. K.; van Bruggen, N.; Dinkelborg, L. M.; Gambhir, S. S. Nat. Rev. Drug Discov. 2008, 7, 591-607.

(46) Pansare, V.; Hejazi, S.; Faenza, W.; Prud'homme, R. K. Chem. Mater. 2012, 24, 812-827. 
(47) Rao, J.; Dragulescu-Andrasi, A.; Yao, H. Curr. Opin. Biotechnol. 2007, 18, 17-25.

(48) Ozawa, T.; Yoshimura, H.; Kim, S. Anal. Chem. 2012, 85, 590-609.

(49) Culver, J.; Akers, W.; Achilefu, S. J. Nucl. Med. 2008, 49, 169-172.

(50) Xu, H.; Baidoo, K.; Y, A. J. G.; Boswell, C. A.; Milenic, D. E.; Y, P. L. C.; Brechbiel, M. W. J. Med. Chem. 2008, 50, 4759-4765.

(51) Xing, Y.; Zhao, J.; Conti, P. S.; Chen, K. Theranostics 2014, 4, 290-306.

(52) Edwards, W. B.; Xu, B.; Akers, W.; Cheney, P. P.; Liang, K.; Rogers, B. E.; Anderson, C. J.; Achilefu, S. 2008, 192-200.

(53) Backer, M. V; Levashova, Z.; Patel, V.; Jehning, B. T.; Claffey, K.; Blankenberg, F. G.; Backer, J. M. Nat. Med. 2007, 13, 504-509.

(54) Ogawa, M.; Regino, C. a S.; Seidel, J.; Green, M. V; Xi, W.; Williams, M.; Kosaka, N.; Choyke, P. L.; Kobayashi, H. Bioconjug. Chem. 2009, 20, 2177-2184.

(55) Vance, D. E.; Ehmann, W. D. Radiochemistry and Nuclear Methods of Analysis; First.; Wiley-Interscience: New York City, 1991; p. 560.

(56) Kleinberg, J. The radiochemistry of fluorine, chlorine, bromine and iodine,; Subcommittee on Radiochemistry National Academy of Sciences-National Research Council; available from the Office of Technical Services Dept. of Commerce: Washington, 1960.

(57) Kamlet, A. S.; Neumann, C. N.; Lee, E.; Carlin, S. M.; Moseley, C. K.; Stephenson, N.; Hooker, J. M.; Ritter, T. PLoS One 2013, 8, e59187.

(58) Cai, L.; Lu, S.; Pike, V. W. European J. Org. Chem. 2008, 2008, 28532873.

(59) Littich, R.; Scott, P. J. H. Angew. Chem. Int. Ed. Engl. 2012, 51, 11061109.

(60) Huang, X.; Liu, W.; Ren, H.; Neelamegam, R.; Hooker, J. M.; Groves, J. T. J. Am. Chem. Soc. 2014, 136, 6842-6845.

(61) Graham, T. J. a; Lambert, R. F.; Ploessl, K.; Kung, H. F.; Doyle, A. G. J. Am. Chem. Soc. 2014, 136, 5291-5294. 
(62) Teare, H.; Robins, E. G.; Kirjavainen, A.; Forsback, S.; Sandford, G.; Solin, O.; Luthra, S. K.; Gouverneur, V. Angew. Chemie 2010, 122, 6973-6976.

(63) Hollingworth, C.; Gouverneur, V. Chem. Commun. (Camb). 2012, 48, 2929-2942.

(64) Lee, E.; Kamlet, A. S.; Powers, D. C.; Neumann, C. N.; Boursalian, G. B.; Furuya, T.; Choi, D. C.; Hooker, J. M.; Ritter, T. Science 2011, 334, 639642.

(65) Li, X.-G.; Haaparanta, M.; Solin, O. J. Fluor. Chem. 2012, 143, 49-56.

(66) Poethko, T.; Schottelius, M.; Thumshirn, G.; Herz, M.; Haubner, R.; Henriksen, G.; Kessler, H.; Schwaiger, M.; Wester, H. J. Radiochim. Acta 2004, 92, 317-327.

(67) Poethko, T.; Schottelius, M.; Thumshirn, G.; Hersel, U.; Herz, M.; Henriksen, G.; Kessler, H.; Schwaiger, M.; Wester, H.-J. J. Nucl. Med. 2004, 45, 892-902.

(68) Tredwell, M.; Gouverneur, V. Angew. Chem. Int. Ed. Engl. 2012, 51, $11426-11437$.

(69) Hausner, S. H.; Carpenter, R. D.; Bauer, N.; Sutcliffe, J. L. Nucl. Med. Biol. 2013, 40, 233-239.

(70) Glaser, M.; Morrison, M.; Solbakken, M.; Arukwe, J.; Karlsen, H.; Wiggen, U.; Champion, S.; Kindberg, G. M.; Cuthbertson, A. 2008, 951-957.

(71) Liu, Z.; Pourghiasian, M.; Radtke, M. A.; Lau, J.; Pan, J.; Dias, G. M.; Yapp, D.; Lin, K.-S.; Bénard, F.; Perrin, D. M. Angew. Chem. Int. Ed. Engl. 2014, 53, 11876-11880.

(72) Gifford, A. N.; Bennett, C. V.; Fowler, J. S. J. Label. Compd. Radiopharm. 2012, 55, 441-446.

(73) Thompson, S.; Zhang, Q.; Onega, M.; McMahon, S.; Fleming, I.; Ashworth, S.; Naismith, J. H.; Passchier, J.; O'Hagan, D. Angew. Chem. Int. Ed. Engl. 2014, 53, 8913-8918.

(74) McBride, W. J.; Sharkey, R. M.; Goldenberg, D. M. EJNMMI Res. 2013, 3, 36.

(75) D’Souza, C. A.; McBride, W. J.; Sharkey, R. M.; Todaro, L. J.; Goldenberg, D. M. Bioconjug. Chem. 2011, 22, 1793-1803. 
(76) Schirrmacher, E.; Wängler, B.; Cypryk, M.; Bradtmöller, G.; Schäfer, M.; Eisenhut, M.; Jurkschat, K.; Schirrmacher, R. Bioconjug. Chem. 2007, 18, 2085-2089.

(77) Wängler, C.; Niedermoser, S.; Chin, J.; Orchowski, K.; Schirrmacher, E.; Jurkschat, K.; lovkova-Berends, L.; Kostikov, A. P.; Schirrmacher, R.; Wängler, B. Nat. Protoc. 2012, 7, 1946-1955.

(78) Kostikov, A. P.; lovkova, L.; Chin, J.; Schirrmacher, E.; Wängler, B.; Wängler, C.; Jurkschat, K.; Cosa, G.; Schirrmacher, R. J. Fluor. Chem. 2011, 132, 27-34.

(79) Mu, L.; Höhne, A.; Schubiger, P. A.; Ametamey, S. M.; Graham, K.; Cyr, J. E.; Dinkelborg, L.; Stellfeld, T.; Srinivasan, A.; Voigtmann, U.; Klar, U. Angew. Chem. Int. Ed. Engl. 2008, 47, 4922-4925.

(80) Höhne, A.; Mu, L.; Honer, M.; Schubiger, P. A.; Ametamey, S. M.; Graham, K.; Stellfeld, T.; Borkowski, S.; Berndorff, D.; Klar, U.; Voigtmann, U.; Cyr, J. E.; Friebe, M.; Dinkelborg, L.; Srinivasan, A. Bioconjug. Chem. 2008, 19, 1871-1879.

(81) Wade, C. R.; Broomsgrove, A. E. J.; Aldridge, S.; Gabbaï, F. P. Chem. Rev. 2010, 110, 3958-3984.

(82) Li, Y.; Asadi, A.; Perrin, D. M. J. Fluor. Chem. 2009, 130, 377-382.

(83) Ting, R.; Harwig, C.; auf dem Keller, U.; McCormick, S.; Austin, P.; Overall, C. M.; Adam, M. J.; Ruth, T. J.; Perrin, D. M. J. Am. Chem. Soc. 2008, 130, 12045-12055.

(84) Ting, R.; Harwig, C. W.; Lo, J.; Li, Y.; Adam, M. J.; Ruth, T. J.; Perrin, D. M. J. Org. Chem. 2008, 73, 4662-4670.

(85) Ting, R.; Lo, J.; Adam, M. J.; Ruth, T. J.; Perrin, D. M. J. Fluor. Chem. 2008, 129, 349-358.

(86) Liu, Z.; Pourghiasian, M.; Bénard, F.; Pan, J.; Lin, K.-S.; Perrin, D. M. J. Nucl. Med. 2014, 55, 1499-1505.

(87) Li, Z.; Lin, T.-P.; Liu, S.; Huang, C.-W.; Hudnall, T. W.; Gabbaï, F. P.; Conti, P. S. Chem. Commun. (Camb). 2011, 47, 9324-9326.

(88) Li, Z.; Lin, T.-P.; Liu, S.; Huang, C.-W.; Hudnall, T. W.; Gabbaï, F. P.; Conti, P. S. Chem. Commun. (Camb). 2011, 47, 9324-9326. 
(89) Hendricks, J. A.; Keliher, E. J.; Wan, D.; Hilderbrand, S. a.; Weissleder, R.; Mazitschek, R. Angew. Chemie 2012, 124, 4681-4684.

(90) Liu, S.; Lin, T.-P.; Li, D.; Leamer, L.; Shan, H.; Li, Z.; Gabbaï, F. P.; Conti, P. S. Theranostics 2013, 3, 181-189.

(91) Hendricks, J. A.; Keliher, E. J.; Wan, D.; Hilderbrand, S. a; Weissleder, R.; Mazitschek, R. Angew. Chem. Int. Ed. Engl. 2012, 51, 4603-4606.

(92) Liu, Z.; Radtke, M. A.; Wong, M. Q.; Lin, K.; Yapp, D. T.; Perrin, D. M. Bioconjug. Chem. 2014.

(93) Seo, Y. J.; Kang, Y.; Muench, L.; Reid, A.; Caesar, S.; Jean, L.; Wagner, F.; Holson, E.; Haggarty, S. J.; Weiss, P.; King, P.; Carter, P.; Volkow, N. D.; Fowler, J. S.; Hooker, J. M.; Kim, S. W. ACS Chem. Neurosci. 2014, 5, 588-596.

(94) Zeng, D.; Zeglis, B. M.; Lewis, J. S.; Anderson, C. J. J. Nucl. Med. 2013, 54, 829-832.

(95) Kimura, R. H.; Miao, Z.; Cheng, Z.; Gambhir, S. S.; Cochran, J. R. Bioconjug. Chem. 2010, 21, 436-444.

(96) Ulrich, G.; Goze, C.; Goeb, S.; Retailleau, P.; Ziessel, R. New J. Chem. 2006, 30, 982.

(97) Inoue, N.; Suzuki, Y.; Yokoyama, K.; Karube, I. Biosci. Biotechnol. Biochem. 2009, 73, 1215-1217.

(98) Klán, P.; Šolomek, T.; Bochet, C. G.; Blanc, A.; Givens, R.; Rubina, M.; Popik, V.; Kostikov, A.; Wirz, J. Chem. Rev. 2013, 113, 119-191.

(99) Shinmyozu, T.; Nogita, R.; Akita, M.; Lim, C. In CRC Handbook of Organic Photochemistry and Photobiology; Horspool, W. H.; Lenci, F., Eds.; CRC Press: Boca Rotan, Florida, 2004.

(100) Barltrop, J. A.; Schofield, P. Tetrahedron Lett. 1962, 3, 697-699.

(101) Barltrop, J. A.; Plant, P. J.; Schofield, P. Chem. Commun. 1966, 822.

(102) Engels, J.; Schlaeger, E. J. J. Med. Chem. 1977, 20, 907-911.

(103) Nagano, T.; Urano, Y.; Umeda, N. Caged Compound, 2008. 
(104) Yogo, T.; Urano, Y.; Ishitsuka, Y.; Maniwa, F.; Nagano, T. J. Am. Chem. Soc. 2005, 127, 12162-12163.

(105) Rurack, K.; Kollmannsberger, M.; Resch-Genger, U.; Daub, J. J. Am. Chem. Soc. 2000, 122, 968-969.

(106) Sunahara, H.; Urano, Y.; Kojima, H.; Nagano, T. J. Am. Chem. Soc. 2007, 129, 5597-5604. 


\section{VITA}

Patrick L. Cavins was born in Jerseyville, Illinois to some pretty amazing parents who have shepherded him through this amazing journal with their love and support. His career science began with employment at Monsanto in St. Louis, MO during the summers of 2005 and 2006. While at Monsanto, he was a member of the crop physiology team working on developing protocols to better understand diurnal variations in water content in maize, sorghum, and soybeans. Furthermore, he worked directly with a team of molecular biologists to help understand the effects different gene constructs have on various physiological plant traits.

During this time, he was also pursuing his B.A in Biochemistry (Honors in Chemistry) from Knox College in Galesburg, IL. While at Knox College he undertook various summer research projects and a year long. During the summer of the 2007 he received a Stephen Summer Research Fellowship at the University of Missouri-Columbia. During that fellowship he worked on developing 
metal based systems for the detection of nucleosides under the mentorship of Dr.

Timothy E. Glass. The following summer he again received the Stephens Fellowship. Under the direction of Dr. Glass, he worked on creating a new NIR based sensor for the detection of glucose in vivo. Following these two summer fellowship he was accepted into the College Honors Program at Knox College. In the honors program, he completed a year long research project resulting in a honors thesis. This project focused on using fluorescence anisotropy as means to determine the molecular volume of various proteins. This project was carried out under the direction of Dr. Andrew Mehl and Dr. Larry Welch.

Following successful completion of his B.A he accepted a position at the University of Missouri-Columbia as a student in the PhD program in Chemistry. While working towards his PhD he worked the direction of Dr. Glass (PI), Dr. Jurisson, Dr. Fowler, and Dr. Feirreri. His research focused on the development of BODIPY based platforms to capture fluorine-18. He successfully defended his thesis in February of 2015 and graduated from the University of MissouriColumbia in May of 2015 with his PhD. 
